
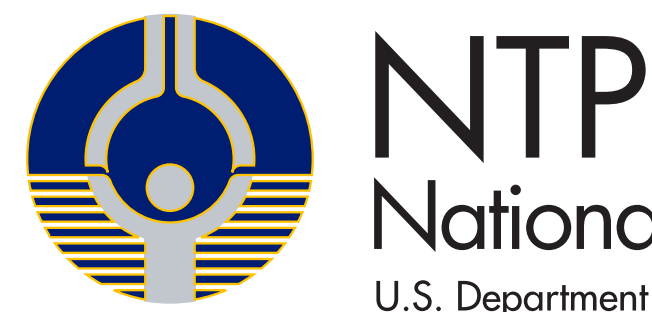

National Toxicology Program

U.S. Department of Health and Human Services

NTP IMMUNOTOXICITY

TECHNICAL REPORT ON THE

DERMAL HYPERSENSITIVITY AND

IRRITANCY STUDIES OF

4-METHYLCYCLOHEXANEMETHANOL

(CASRN 34885-03-5)

AND CRUDE

4-METHYLCYCLOHEXANEMETHANOL

ADMINISTERED TOPICALLY TO

FEMALE BALB/C MICE

NTP IMM 01

JULY 2020 


\title{
NTP Immunotoxicity Technical Report on the Dermal Hypersensitivity and Irritancy Studies of 4-Methylcyclohexanemethanol (CASRN 34885-03-5) and Crude 4-Methylcyclohexanemethanol Administered Topically to Female BALB/c Mice
}

Immunotoxicity Report 01

July 2020

\author{
National Toxicology Program \\ Public Health Service \\ U.S. Department of Health and Human Services
}

ISSN: 2690-2060

Research Triangle Park, North Carolina, USA 


\section{Foreword}

The National Toxicology Program (NTP), established in 1978, is an interagency program within the Public Health Service of the U.S. Department of Health and Human Services. Its activities are executed through a partnership of the National Institute for Occupational Safety and Health (part of the Centers for Disease Control and Prevention), the Food and Drug Administration (primarily at the National Center for Toxicological Research), and the National Institute of Environmental Health Sciences (part of the National Institutes of Health), where the program is administratively located. NTP offers a unique venue for the testing, research, and analysis of agents of concern to identify toxic and biological effects, provide information that strengthens the science base, and inform decisions by health regulatory and research agencies to safeguard public health. NTP also works to develop and apply new and improved methods and approaches that advance toxicology and better assess health effects from environmental exposures.

The Immunotoxicity Report series began in 2017. The studies described in the Immunotoxicity Report series are designed and conducted to characterize and evaluate the potential of selected substances to affect the immune system in laboratory animals. Substances selected for NTP immunotoxicity studies are chosen primarily on the basis of human exposure, level of production, and chemical structure. The interpretive conclusions presented in the Immunotoxicity Reports are derived solely from the results of these NTP studies and extrapolation of these results to other species, including characterization of hazards and risks to humans, requires analyses beyond the intent of these reports. Selection for study per se is not an indicator of a substance's immunotoxicologic potential.

NTP conducts its studies in compliance with its laboratory health and safety guidelines and Food and Drug Administration Good Laboratory Practice Regulations and meets or exceeds all applicable federal, state, and local health and safety regulations. Animal care and use are in accordance with the Public Health Service Policy on Humane Care and Use of Laboratory Animals. Studies are subjected to retrospective quality assurance audits before they are presented for public review. Draft reports undergo external peer review before they are finalized and published.

The NTP Immunotoxicity Study Reports are available free of charge on the NTP website and cataloged in PubMed, a free resource developed and maintained by the National Library of Medicine (part of the National Institutes of Health). Data for these studies are included in NTP's Chemical Effects in Biological Systems database.

For questions about the reports and studies, please email NTP or call 984-287-3211. 


\section{Table of Contents}

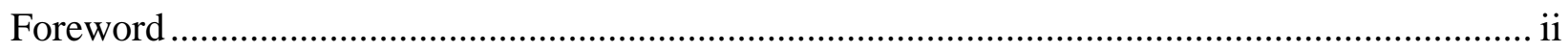

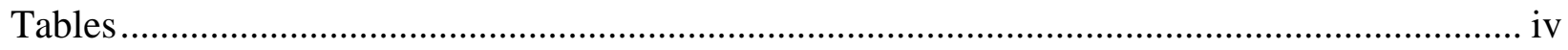

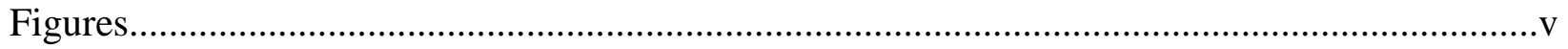

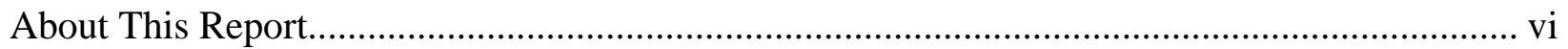

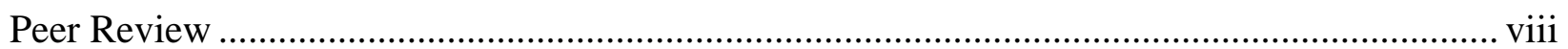

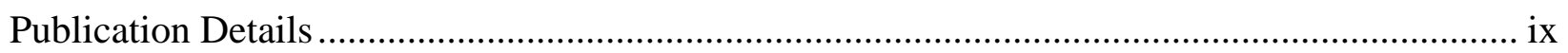

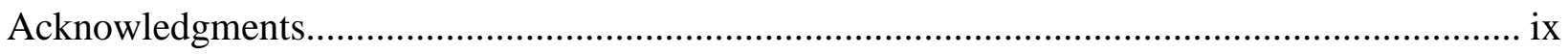

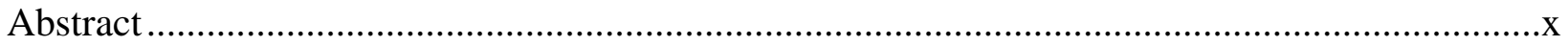

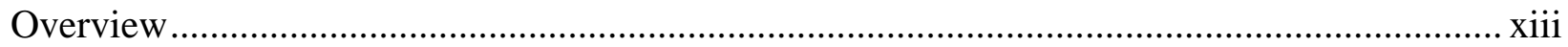

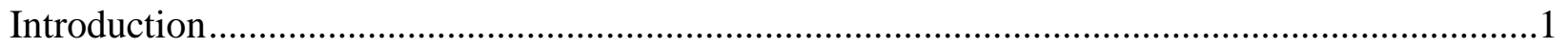

Chemical and Physical Properties................................................................................ 1

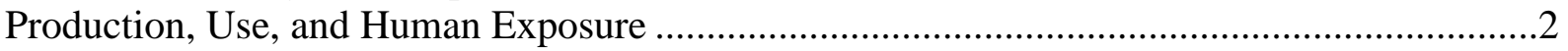

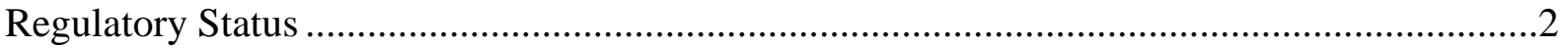

Absorption, Distribution, Metabolism, and Excretion ......................................................

Experimental Animals ........................................................................................

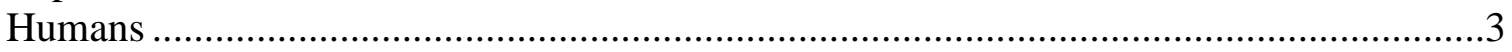

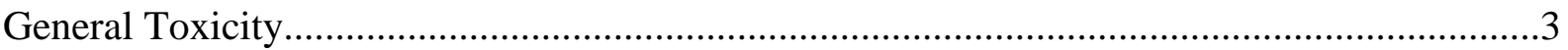

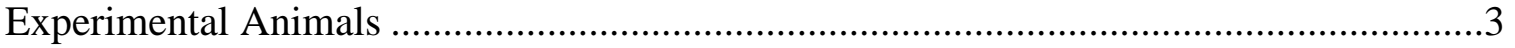

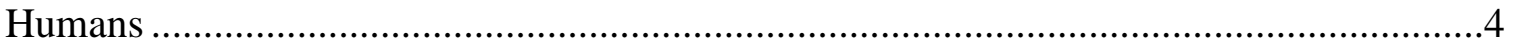

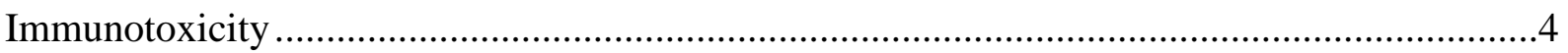

Experimental Animals .....................................................................................

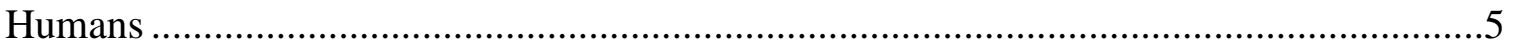

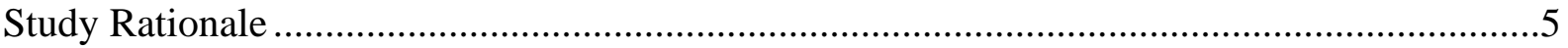

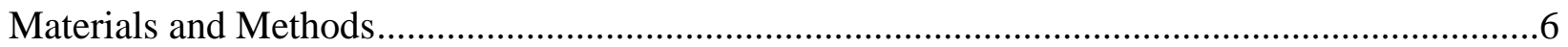

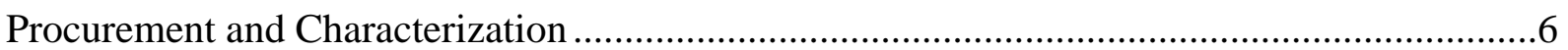

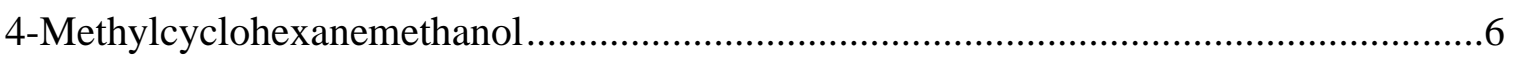

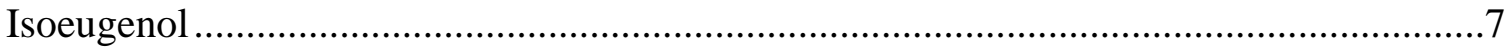

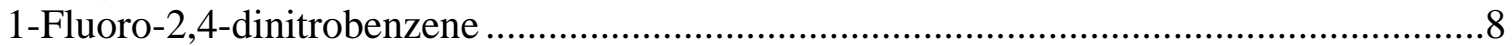

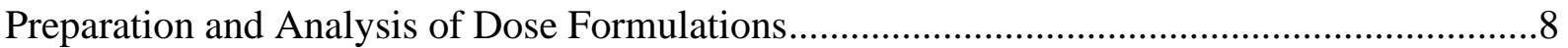

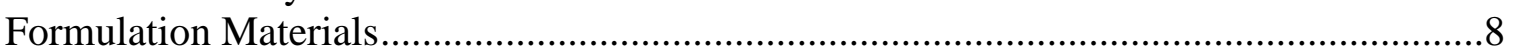

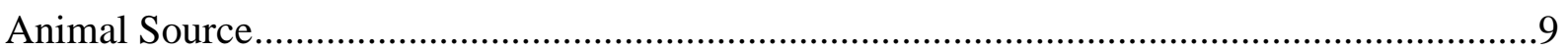

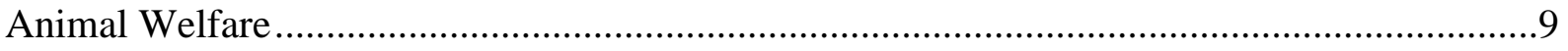

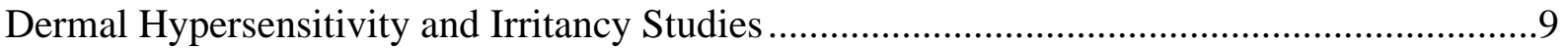

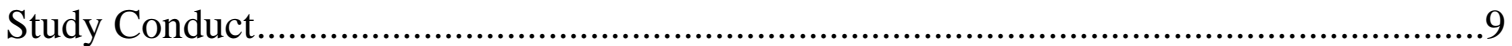

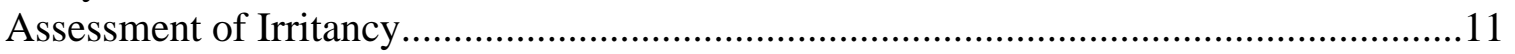

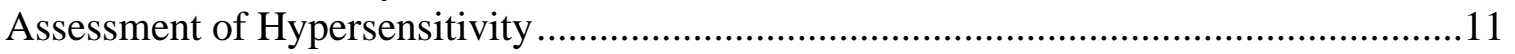

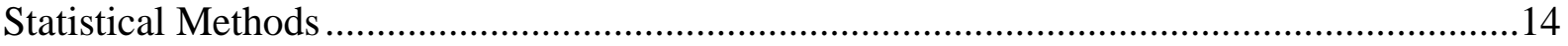

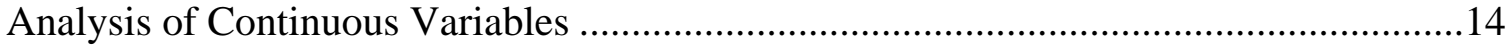

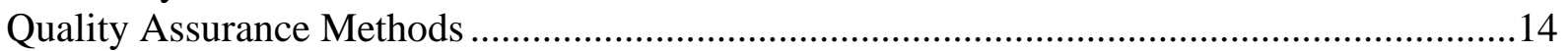




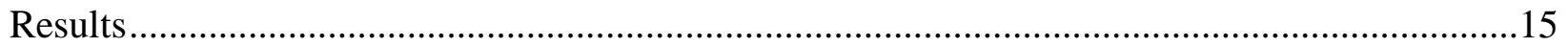

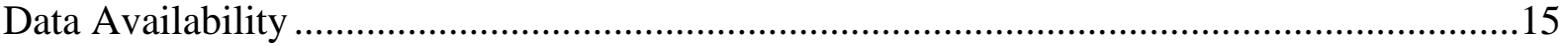

4-Methylcyclohexanemethanol .............................................................................................15

Crude 4-Methylcyclohexanemethanol ...................................................................................18

Crude 4-Methylcyclohexanemethanol (Repeat Study) ..............................................................21

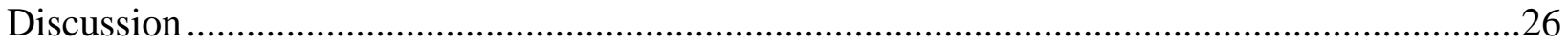

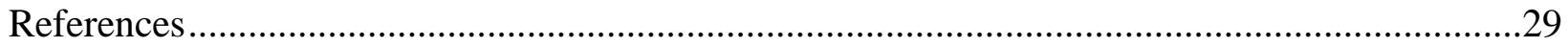

Appendix A. Chemical Characterization and Dose Formulation Studies.................................... A-1

Appendix B. Ingredients, Nutrient Composition, and Contaminant Levels in NTP-2000 Rat and Mouse Ration .....................................................................................

Appendix C. Sentinel Animal Program …………......................................................................

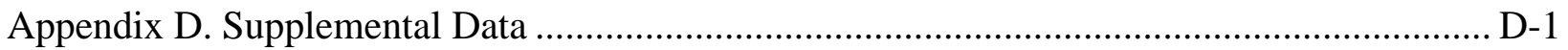

\section{Tables}

Summary of Findings Considered Immunotoxicologically Relevant in Female BALB/c Mice Topically Administered 4-Methylcyclohexanemethanol and Crude 4-Methylcyclohexanemethanol ..................................................................................... xii

Table 1. Constituents of Crude 4-Methylcyclohexanemethanol......................................................

Table 2. Study Design for the Repeat Study of Crude 4-Methylcyclohexanemethanol.................11

Table 3. Experimental Design and Materials and Methods in the Dermal Hypersensitivity and Irritancy Studies of 4-Methylcyclohexanemethanol and Crude 4-Methylcyclohexanemethanol ........................................................................................12

Table 4. Disposition of Female Mice in the Dermal Hypersensitivity and Irritancy Study of 4-Methylcyclohexanemethanol ...............................................................................15

Table 5. Survival and Mean Body Weights of Female Mice in the Dermal Hypersensitivity and Irritancy Study of 4-Methylcyclohexanemethanol........................15

Table 6. Clinical Observations for Female Mice in the Dermal Hypersensitivity and Irritancy Study of 4-Methylcyclohexanemethanol .........................................................16

Table 7. Summary of Ear Thickness Measurement Data for Female Mice in the Dermal Hypersensitivity and Irritancy Study of 4-Methylcyclohexanemethanol.........................16

Table 8. Summary of ${ }^{125}$ I-UdR Incorporation and Stimulation Index Data for Female Mice in the Dermal Hypersensitivity and Irritancy Study of 4-Methylcyclohexanemethanol

Table 9. Disposition of Female Mice in the Dermal Hypersensitivity and Irritancy Study of Crude 4-Methylcyclohexanemethanol .....

Table 10. Survival and Mean Body Weights of Female Mice in the Dermal Hypersensitivity and Irritancy Study of Crude 4-Methylcyclohexanemethanol...........18

Table 11. Clinical Observations for Female Mice in the Dermal Hypersensitivity and Irritancy Study of Crude 4-Methylcyclohexanemethanol

Table 12. Summary of Ear Thickness Measurement Data for Female Mice in the Dermal Hypersensitivity and Irritancy Study of Crude 4-Methylcyclohexanemethanol 
Table 13. Summary of ${ }^{125} \mathrm{I}$-UdR Incorporation and Stimulation Index for Female Mice in the Dermal Hypersensitivity and Irritancy Study of Crude 4-Methylcyclohexanemethanol

Table 14. Disposition of Female Mice in the Dermal Hypersensitivity and Irritancy Study of Crude 4-Methylcyclohexanemethanol (Repeat Study)

Table 15. Survival and Mean Body Weights of Female Mice in the Dermal Hypersensitivity and Irritancy Study of Crude 4-Methylcyclohexanemethanol (Repeat Study)

Table 16. Clinical Observations for Female Mice in the Dermal Hypersensitivity and Irritancy Study of Crude 4-Methylcyclohexanemethanol (Repeat Study)

Table 17. Summary of Ear Thickness Measurement Data for Female Mice in the Dermal Hypersensitivity and Irritancy Study of Crude 4-Methylcyclohexanemethanol (Repeat Study)

Table 18. Summary of ${ }^{125} \mathrm{I}$-Udr Incorporation and Stimulation Index Data for Female Mice in the Dermal Hypersensitivity and Irritancy Study of Crude 4-Methylcyclohexanemethanol (Repeat Study)

\section{Figures}

Figure 1. MCHM (CASRN 34885-03-5; Chemical Formula: $\mathrm{C}_{8} \mathrm{H}_{16} \mathrm{O}$; Molecular Weight: 128.21) and Crude MCHM (CASRN N/A)

Figure 2. ${ }^{125} \mathrm{I}-\mathrm{UdR}$ Incorporation and Stimulation Index Data in the Dermal Hypersensitivity and Irritancy Study of 4-Methylcyclohexanemethanol

Figure 3. ${ }^{125}$ I-UdR Incorporation and Stimulation Index Data in the Dermal Hypersensitivity and Irritancy Study of Crude 4-Methylcyclohexanemethanol

Figure 4. ${ }^{125} \mathrm{I}$-UdR Incorporation and Stimulation Index Data in the Dermal Hypersensitivity and Irritancy Study of Crude 4-Methylcyclohexanemethanol (Repeat Study) 


\section{About This Report}

National Toxicology Program ${ }^{1}$

${ }^{1}$ Division of the National Toxicology Program, National Institute of Environmental Health

Sciences, Research Triangle Park, North Carolina, USA

\section{Collaborators}

K.A. Shipkowski, V.J. Johnson, S.S. Auerbach, C.R. Blystone, F.G. Burleson, G.R. Burleson, B.J. Collins, J.M. Fostel, P.M. Foster, D.R. Germolec, M.J. Hooth, A.P. King-Herbert, G.E. Kissling, S.A. Masten, K.R. Shockley, M.D. Stout, S. Waidyanatha, N.J. Walker

Division of the National Toxicology Program, National Institute of Environmental Health Sciences, Research Triangle Park, North Carolina, USA

Evaluated and interpreted results and reported findings

K.A. Shipkowski, Ph.D., Study Scientist

S.S. Auerbach, Ph.D.

C.R. Blystone, Ph.D.

B.J. Collins, M.S.P.H.

J.M. Fostel, Ph.D.

P.M. Foster, Ph.D.

D.R. Germolec, Ph.D.

M.J. Hooth, Ph.D.

A.P. King-Herbert, D.V.M.

G.E. Kissling, Ph.D.

S.A. Masten, Ph.D.

K.R. Shockley, Ph.D.

M.D. Stout, Ph.D.

S. Waidyanatha, Ph.D.

N.J. Walker, Ph.D.

Burleson Research Technologies, Inc., Cary, North Carolina, USA

Conducted studies and evaluated findings

V.J. Johnson, Ph.D., Principal Investigator

F.G. Burleson, Ph.D.

G.R. Burleson, Ph.D.

\section{Contributors}

Division of the National Toxicology Program, National Institute of Environmental Health Sciences, Research Triangle Park, North Carolina, USA

Oversight of peer review

E.A. Maull, Ph.D.

M.S. Wolfe, Ph.D.

CSS Corporation, Research Triangle Park, North Carolina, USA

Prepared quality assessment audits 
S. Brecher, Ph.D., Principal Investigator

S. Iyer, B.S.

V.S. Tharakan, D.V.M.

Social \& Scientific Systems, Inc., Research Triangle Park, North Carolina, USA

Provided statistical analyses

M.V. Smith, Ph.D., Principal Investigator

L.J. Betz, M.S.

S.F. Harris, B.S.

ASRC, Research Triangle Park, North Carolina, USA

Prepared data for report

P. Brown, B.S.

H. Gong, M.S.

C. Martini, B.S.

C. Meyers, M.S.

N. Sayers, B.S.

M. Shaw, B.S.

R. Whittlesey, M.S.

Biotechnical Services, Inc., Little Rock, Arkansas, USA

Prepared report

S.R. Gunnels, M.A., Principal Investigator

B.F. Hall, M.S.

L.M. Harper, B.S.

J.I. Powers, M.A.P.

D.C. Serbus, Ph.D.

ICF, Durham, North Carolina, USA

Provided contract oversight

D. Burch, M.E.M., Principal Investigator

Conducted external peer review

S.E. Blaine, B.A.

L.M. Green, M.P.H.

S.A. Hearn, B.S.

Prepared report

K.A. Clark, B.A.

T.W. Cromer, M.P.S.

J.S. Frye, M.S.L.S.

T. Hamilton, M.S.

K.R. Helmick, M.P.H. 


\section{Peer Review}

The draft NTP Immunotoxicity Technical Report on the Dermal Hypersensitivity and Irritancy Studies of 4-Methylcyclohexanemethanol (CASRN 34885-03-5) and Crude 4-Methylcyclohexanemethanol Administered Topically to Female BALB/c Mice was evaluated by the reviewers listed below. These reviewers served as independent scientists, not as representatives of any institution, company, or governmental agency. In this capacity, reviewers determined if the design and conditions of these NTP studies were appropriate and ensured that this Immunotoxicity Report presents the experimental results and conclusions fully and clearly.

\section{Peer Reviewers}

\section{Anne Marie Api, Ph.D.}

Vice President, Human Health Sciences, Research Institute for Fragrance Materials, Inc. (RIFM) Woodcliff Lake, New Jersey, USA

Joan Chapdelaine Ph.D.

Principal Owner/Consultant, Chapdelaine Consulting, LLC

Tunkhannock, Pennsylvania, USA 


\section{Publication Details}

Publisher: National Toxicology Program

Publishing Location: Research Triangle Park, NC

ISSN: 2690-2060

DOI: https://doi.org/10.22427/NTP-IMM-01

Report Series: NTP Immunotoxicity Report Series

Report Series Number: 01

Official citation: National Toxicology Program (NTP). 2020. NTP immunotoxicity technical report on the dermal hypersensitivity and irritancy studies of 4-methylcyclohexanemethanol (CASRN 34885-03-5) and crude 4-methylcyclohexanemethanol administered topically to female BALB/c mice. Research Triangle Park, NC: National Toxicology Program. Immunotoxicity Report 01.

\section{Acknowledgments}

This work was supported by the Intramural Research Program (ES103316, ES103318, and ES103319) at the National Institute of Environmental Health Sciences, National Institutes of Health and performed for the National Toxicology Program, Public Health Service, U.S. Department of Health and Human Services under contracts HHSN273201800006C, GS00Q14OADU417; HHSN273201600015U, HHSN273201600011C, HHSN273201600020C, HHSN273201500006C, HHSN273201400020C, HHSN273201400022C, HHSN273201400017C, HHSN273201300004C, HHSN316201200054W, HHSN316201200054W, and HHS273200900002C. 


\section{Abstract}

4-Methylcyclohexanemethanol (MCHM) and crude MCHM were nominated to the National Toxicology Program (NTP) for toxicity evaluation by the Centers for Disease Control and Prevention and the Agency for Toxic Substances and Disease Registry following the Elk River, West Virginia, chemical spill. The 10,000-gallon spill was a mixture of chemicals that contained approximately 75\% MCHM. Due to reports of reddened skin and erythema following dermal exposure to contaminated water from the spill, NTP conducted studies in female BALB/c mice to assess the potential dermal hypersensitivity and irritancy of MCHM and crude MCHM.

MCHM is a clear, colorless oil with low estimated water solubility and a reported alcohol or licorice-like odor. MCHM is commonly sold as a crude mixture, which can contain $68 \%$ to $89 \%$ MCHM with additional components. It is used as a flotation reagent in fine coal beneficiation. Human exposure can occur during handling or use of the chemical.

In the initial study evaluating whether MCHM and crude MCHM have similar immunotoxicologic profiles, groups of five mice were administered a vehicle control (acetone/olive oil, 4:1 v/v [AOO]); one of two positive controls (1 fluoro-2,4-dinitrobenzene [0.15\% in AOO] or isoeugenol [5\% in AOO]); $2 \%, 20 \%$, or $100 / 50 \%$ formulations of MCHM in AOO; or $1 \%, 2 \%, 5 \%, 20 \%, 40 \%$, or $100 / 80 \%$ formulations of crude MCHM in AOO. The $100 / 50 \%$ group was administered $100 \%$ on day 1 and $50 \%$ on days 2 and 3; the 100/80\% group was administered $100 \%$ on day 1 and $80 \%$ on days 2 and 3 . The $100 \%$ dose was lowered to $50 \%$ (MCHM) and 80\% (crude MCHM) on days 2 and 3 due to signs of morbidity. A repeat study of crude MCHM was undertaken to more clearly establish levels at which the test article induced sensitization in the absence of clinical toxicity. In the repeat study of crude MCHM, groups of female mice were administered the AOO vehicle control; a positive control (1 fluoro-2,4dinitrobenzene [0.15\% in AOO]); or crude MCHM at concentrations of $1 \%, 5 \%, 25 \%$, $50 \%$, or $75 \%$ in AOO. The mice were treated for three consecutive days by direct epicutaneous application of $25 \mu \mathrm{L}$ of the test or vehicle control article to the dorsum of each ear.

In the MCHM study, all mice administered $2 \%$ or $20 \%$ survived to study termination with no clinical observations of toxicity. Mice in the 100/50\% group demonstrated signs of morbidity on exposure day 1 , resulting in two mice being euthanized moribund. Clinical observations noted in surviving 100/50\% mice included eye squinting and hypoactivity. Concentration-dependent increases in mean ear thickness were observed in the 20\% and 100/50\% groups on day 3 and day 6 , relative to the vehicle control group. Treatment with MCHM did not significantly modulate mean group disintegrations per minute (DPM), compared to that of the vehicle control group or the stimulation index (SI) (ratio of treated group mean DPM/vehicle control group mean DPM) values in the local lymph node assay.

In the initial study of crude MCHM, all mice survived to study termination. Clinical signs of toxicity were only observed in the $100 / 80 \%$ group and included eye squinting, hypoactivity, and isolation from cage mates. Mean ear thickness was significantly increased on day 6 in the 20\% group relative to the vehicle control group. It was also increased in the 100/80\% group on day 3 , though not significantly, and there was a significant concentration-related trend on day 3 . In the local lymph node assay, mice treated with 5\% crude MCHM or greater had significantly increased DPM values relative to vehicle controls, and this proliferative response followed a significant concentration-related trend. Groups of mice treated with 5\% crude MCHM or greater 
had significantly increased mean SI values, with SI values of more than 3.0 occurring at $40 \%$ and $100 / 80 \%$. The concentration that would result in a SI of 3.0 (EC3) was calculated to be $34.6 \%$.

In the repeat study of crude MCHM, all mice survived to study termination. Clinical signs of toxicity were limited to the $50 \%$ and $75 \%$ groups and included eye squinting and isolation from cage mates. Ear thickness in the $75 \%$ group was significantly increased relative to that of the vehicle control group on days 3 and 6 . No changes in ear thickness were observed in the remaining dosed groups. Significant increases in lymph node cell proliferation as measured by DPM and SI values were observed at 50\% and 75\% crude MCHM. The concentration that would result in a SI of 3.0 (EC3) was calculated to be $60 \%$.

Under the conditions of these dermal hypersensitivity and irritancy studies, MCHM induced dermal irritation in female mice, as indicated by increases in ear swelling at concentrations of $20 \%$ and 100/50\%. Crude MCHM was identified as a skin sensitizer, with an EC3 value in the concentration range of $35 \%$ to $60 \%$. Dermal exposure to crude MCHM produced minimal irritant effects, indicated by increases in ear swelling at concentrations of $20 \%$ and $75 \%$, which were inconsistent across repeat studies.

Synonyms: Cyclohexanemethanol, 4-methyl-; 4-methyl-1-cyclohexanemethanol; (4methylcyclohexyl)methanol 
Summary of Findings Considered Immunotoxicologically Relevant in Female BALB/c Mice Topically Administered 4-Methylcyclohexanemethanol and Crude 4-Methylcyclohexanemethanol

\begin{tabular}{|c|c|c|c|}
\hline & $\begin{array}{c}\text { Pure } \\
\text { 4-Methylcyclohexanemethanol }\end{array}$ & $\begin{array}{c}\text { Crude } \\
\text { 4-Methylcyclohexanemethanol }\end{array}$ & $\begin{array}{c}\text { Crude } \\
\text { 4-Methylcyclohexanemethanol } \\
\text { (Repeat Study) }^{\mathrm{a}, \mathrm{b}}\end{array}$ \\
\hline $\begin{array}{l}\text { Concentrations } \\
\text { by Topical } \\
\text { Application }\end{array}$ & $0 \%, 2 \%, 20 \%$, or $100 / 50 \%$ & $\begin{array}{l}0 \%, 1 \%, 2 \%, 5 \%, 20 \%, 40 \% \text {, or } \\
100 / 80 \%\end{array}$ & $\begin{array}{l}0 \%, 1 \%, 5 \%, 25 \%, 50 \% \text {, } \\
\text { or } 75 \%\end{array}$ \\
\hline Survival Rates & $5 / 5,5 / 5,5 / 5,3 / 5$ & $5 / 5,5 / 5,5 / 5,5 / 5,5 / 5,5 / 5,5 / 5$ & $\begin{array}{l}\text { 13/13, 13/13, 13/13, 13/13, } \\
13 / 13,13 / 13\end{array}$ \\
\hline Body Weights & $\begin{array}{l}\text { Treated groups similar to the } \\
\text { vehicle control group }\end{array}$ & $\begin{array}{l}\text { Treated groups similar to the } \\
\text { vehicle control group }\end{array}$ & $\begin{array}{l}\text { Treated groups similar to the } \\
\text { vehicle control group }\end{array}$ \\
\hline $\begin{array}{l}\text { Clinical } \\
\text { Observations }\end{array}$ & $\begin{array}{l}\text { Isolation; eye shut, bilateral; } \\
\text { hunched posture; and } \\
\text { hypoactivity in 100/50\% group }\end{array}$ & $\begin{array}{l}\text { Isolation; eye shut, bilateral; } \\
\text { and hypoactivity in 100/80\% } \\
\text { group }\end{array}$ & $\begin{array}{l}\text { Isolation in } 50 \% \text { and } 75 \% \\
\text { groups and eye shut, bilateral in } \\
75 \% \text { group }\end{array}$ \\
\hline Irritancy & $\begin{array}{l}\uparrow \text { Mean ear thickness in the } 20 \% \\
\text { and } 100 / 50 \% \text { groups }\end{array}$ & $\begin{array}{l}\uparrow \text { Mean ear thickness in the } 20 \% \\
\text { group }\end{array}$ & $\begin{array}{l}\uparrow \text { Mean ear thickness in the } \\
75 \% \text { group }\end{array}$ \\
\hline \multirow[t]{2}{*}{ Hypersensitivity } & None & $\begin{array}{l}\uparrow \mathrm{DPM} \text { values in the } 5 \%, 20 \% \text {, } \\
40 \% \text {, and } 100 / 80 \% \text { groups } \\
\uparrow \text { SI values in the } 5 \%, 20 \% \text {, } \\
40 \% \text {, and } 100 / 80 \% \text { groups }\end{array}$ & $\begin{array}{l}\uparrow \mathrm{DPM} \text { values in the } 50 \% \text { and } \\
75 \% \text { groups } \\
\uparrow \text { SI values in the } 75 \% \text { group }\end{array}$ \\
\hline & Calculated EC3 = N/A & Calculated EC3 = 34.6\% & Calculated EC3 = 60.0\% \\
\hline $\mathrm{SI}>3$ & No & Yes (40\% and $100 / 80 \%$ groups) & Yes (75\% group) \\
\hline
\end{tabular}

$\mathrm{DPM}=$ disintegrations per minute (as measured by ${ }^{125} \mathrm{I}-\mathrm{UdR}$ incorporation); SI = stimulation index; N/A = not applicable because SI did not reach 3.

arritancy studies were conducted using groups 1 through 7 (as described in the Materials and Methods section).

${ }^{b}$ Hypersensitivity studies were conducted using groups 8 through 14 (as described in the Materials and Methods section). 


\section{Overview}

The Centers for Disease Control and Prevention and the Agency for Toxic Substances and Disease Registry nominated chemicals associated with the Elk River spill in West Virginia to the National Toxicology Program (NTP) for toxicology studies. In response, NTP performed research to evaluate the toxicity of 4-methylcyclohexanemethanol (MCHM) and the additional chemical components of crude MCHM through various short-term studies. The goals of this research program were to: (1) evaluate the teratogenic, immunotoxic, and genotoxic potential of MCHM; (2) identify sensitive biological effects of the spill chemicals and provide additional information about the levels at which there are no adverse effects; and (3) use efficient, medium-, and high-throughput methods to predict qualitative and quantitative toxicological properties of all chemicals spilled into the Elk River.

These goals were addressed utilizing prenatal developmental toxicity studies in rats, dermal hypersensitivity and irritancy studies in mice, short-term toxicogenomic studies in rats, mediumthroughput screening assessments in lower animal models, and high-throughput screening assays. The information and results presented in this Immunotoxicity Report are specific to the dermal hypersensitivity and irritancy studies on MCHM and crude MCHM, however, further information about the NTP research program related to the Elk River spill in West Virginia is available at: http://ntp.niehs.nih.gov/results/areas/wvspill/index.html.

This report is a comprehensive presentation of all data and information related to the studies of the dermal hypersensitivity and irritancy work on MCHM. 


\section{Introduction}

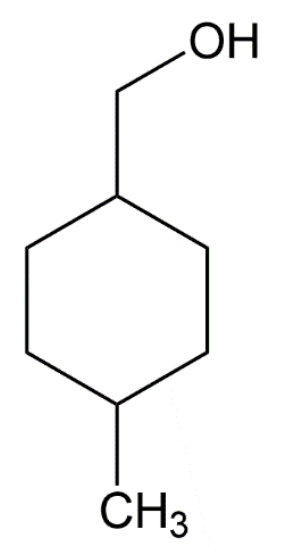

Figure 1. MCHM (CASRN 34885-03-5; Chemical Formula: $\mathrm{C}_{8} \mathrm{H}_{16} \mathrm{O}$; Molecular Weight: 128.21) and Crude MCHM (CASRN N/A)

Synonyms: Cyclohexanemethanol, 4-methyl-; 4-methyl-1-cyclohexanemethanol; (4-methylcyclohexyl)methanol.

\section{Chemical and Physical Properties}

4-Methylcyclohexanemethanol (MCHM) is an organic compound with a molecular weight of $128.21 \mathrm{~g} / \mathrm{mol}$ and a density of $0.9074 \mathrm{~g} / \mathrm{cm}^{3}$. MCHM has estimated boiling and melting points of $203.7^{\circ} \mathrm{C}$ and $-12.0^{\circ} \mathrm{C}$, respectively, and a vapor pressure of $0.0588 \mathrm{~mm} \mathrm{Hg}$ at $25^{\circ} \mathrm{C}$. It has an estimated water solubility of $2.024 \times 10^{3} \mathrm{mg} / \mathrm{L}$ (at $25^{\circ} \mathrm{C}$ ) and an estimated log Kow of 2.55 . MCHM is a clear, colorless oil and has been reported to have an alcohol or licorice-like odor. ${ }^{1-3}$ MCHM exists as two distinct isomers, cis-MCHM and trans-MCHM; the trans-isomer, believed to be the source of the licorice odor, has an air odor threshold concentration of $0.060 \mathrm{ppb} / \mathrm{v}^{4 ;} 5$

MCHM is commonly sold as a crude mixture, which can contain 68\% to 89\% MCHM with additional components including 4-(methoxymethyl)cyclohexanemethanol (CASRN 98955-272; $4 \%$ to $22 \%$ ), water (4\% to $10 \%$ ), methyl 4-methylcyclohexanecarboxylate (CASRN 51181-409; 5\%), dimethyl 1,4-cyclohexanedicarboxylate (CASRN 94-60-0; 1\%),

1,4-cyclohexanedimethanol (CASRN 105-08-8; $1 \%$ to 2\%), and methanol (1\%). ${ }^{1}$ Crude MCHM has a boiling point of $180^{\circ} \mathrm{C}$, a freezing point of $0^{\circ} \mathrm{C}$, and a vapor pressure of $18.0 \mathrm{~mm} \mathrm{Hg}$ at $20^{\circ} \mathrm{C}^{1}$

4-(Methoxymethyl)cyclohexanemethanol has a molecular weight of $158.24 \mathrm{~g} / \mathrm{mol}$, and methyl 4-methylcyclohexanecarboxylate has a molecular weight of $156.22 \mathrm{~g} / \mathrm{mol}$. ${ }^{6 ;}$ No information is available on additional chemical or physical properties of 4-(methoxymethyl)cyclohexanemethanol or methyl 4-methylcyclohexanecarboxylate.

Dimethyl 1,4-cyclohexanedicarboxylate is a partially crystalized liquid with a molecular weight of $200.23 \mathrm{~g} / \mathrm{mol}$, a boiling point of $259^{\circ} \mathrm{C}$ (at $760 \mathrm{~mm} \mathrm{Hg}$ ), and a melting point of either $14^{\circ} \mathrm{C}$ (cis-isomer) or $71^{\circ} \mathrm{C}$ (trans-isomer). The vapor pressure of dimethyl 1,4-cyclohexanedicarboxylate is $1 \mathrm{~mm} \mathrm{Hg}$ at $85.1^{\circ} \mathrm{C} .^{8}$ 
1,4-Cyclohexanedimethanol is a white, waxy solid with a molecular weight of $144.21 \mathrm{~g} / \mathrm{mol}$ and a density of $1,023 \mathrm{~g} / \mathrm{L}$ (at $50^{\circ} \mathrm{C}$ ). It has a melting point range of $41^{\circ} \mathrm{C}$ to $61^{\circ} \mathrm{C}$, a boiling point range of $284^{\circ} \mathrm{C}$ to $285^{\circ} \mathrm{C}$, and a freezing point of $24^{\circ} \mathrm{C}$. ${ }^{9}$

\section{Production, Use, and Human Exposure}

Information regarding the production volume of MCHM is currently unavailable. MCHM is used as a flotation reagent in fine coal beneficiation. Human exposure can occur during handling or use of the chemical.

On January 9, 2014, approximately 10,000 gallons of a mixture of chemicals containing predominantly MCHM was leaked into the Elk River upstream of the intake for West Virginia American Water Company's Elk River plant, a municipal water source serving approximately 300,000 people in Charleston, West Virginia. ${ }^{10}$ A number of chemicals were identified in the spill, including crude MCHM (estimated at 88.5\%), propylene glycol ether, and dipropylene glycol phenyl ether. ${ }^{11}$ Of the crude MCHM in the mixture, MCHM alone was estimated to be $75 \%$ of the entire 10,000 -gallon spill. ${ }^{12}$ This spill temporarily contaminated $15 \%$ of the state's tap water, and prior to flushing water lines, concentrations of MCHM in tap water ranged from less than $10 \mathrm{ppb}$ up to $420 \mathrm{ppb}$; levels of the other components of crude MCHM were not measured. ${ }^{13}$ Concentrations of MCHM were also measured at the intake (up to $3.35 \mathrm{ppm}$ ) and posttreatment (up to $2.4 \mathrm{ppm}$ ). ${ }^{10}$ Exposure to $2.4 \mathrm{ppm}$ is approximately equivalent to $0.07 \mathrm{mg} / \mathrm{kg}$ body weight per day for an adult (70 kg) consuming $2 \mathrm{~L}$ of water a day and $0.24 \mathrm{mg} / \mathrm{kg}$ per day for a child (10 kg) consuming $1 \mathrm{~L}$ of water a day. Levels of the other components of crude MCHM were not measured.

\section{Regulatory Status}

Workplace exposure limits for MCHM are currently unavailable. Immediately following the Elk River spill, the Center for Disease Control and Prevention (CDC) and the Agency for Toxic Substances and Disease Registry (ATSDR) established a short-term drinking water limit of $1 \mathrm{ppm}$ based on the approximate weight $(10 \mathrm{~kg})$ and drinking water intake $(1 \mathrm{~L})$ of a child. ${ }^{12}$ Evaluation of the same data using differing adjustment factors resulted in a calculated health advisory level of 120 ppb. ${ }^{14}$

\section{Absorption, Distribution, Metabolism, and Excretion}

\section{Experimental Animals}

There are no studies in the literature on the absorption, distribution, metabolism, or excretion of MCHM in experimental animals.

Radiolabeled $\left[{ }^{14} \mathrm{C}\right]$ 1,4-cyclohexanedimethanol (70\% trans, 30\% cis-isomers), a component of crude MCHM, was rapidly absorbed from the gastrointestinal tract in male and female Charles River Sprague Dawley rats. ${ }^{15}$ Of the administered dose (40 or $400 \mathrm{mg} / \mathrm{kg}$ ), 95\% was eliminated in the urine and $2.5 \%$ in the feces 48 hours postexposure. The half-life of 1,4-

cyclohexanedimethanol in plasma following a dose of $400 \mathrm{mg} / \mathrm{kg}$ was approximately 13 minutes. The metabolites of 1,4-cyclohexanedimethanol were evaluated in the urine of exposed rats and determined to be cyclohexanedicarboxylic acid (68\%) and 4-hydroxymethylcyclohexanecarboxylic 
acid (31\%). The ratio of trans- to cis-metabolites in the urine remained the same as that of the initial dose.

\section{Humans}

There are no studies in the literature on the absorption, distribution, metabolism, or excretion of MCHM in humans.

\section{General Toxicity}

\section{Experimental Animals}

4-Methylcyclohexanemethanol: The acute dermal toxicity of MCHM was evaluated in male and female rats [Crl:CD(SD)BR] administered a single topical dose $(0,2,6$, or $20 \mathrm{~mL} / \mathrm{kg}) \cdot{ }^{16} \mathrm{~A}$ dermal LD 50 value of $3.6 \mathrm{~mL} / \mathrm{kg}$ was determined for both males and females.

Oral LD50 values for MCHM were determined from an acute oral toxicity study in rats [Crl:CD(SD)BR] administered a single dose $(0,625,1,250$, or $2,500 \mathrm{mg} / \mathrm{kg})$ by oral gavage. ${ }^{16}$ LD 50 values of 1,768 and $884 \mathrm{mg} / \mathrm{kg}$ were calculated for male and female rats, respectively.

Male and female rats exposed to $\operatorname{MCHM}(0,25,100$, or $400 \mathrm{mg} / \mathrm{kg}$ per day) by oral gavage 5 days per week for 4 weeks exhibited increased liver weights, liver inflammation, and kidney tubular degeneration at $400 \mathrm{mg} / \mathrm{kg}$ per day. ${ }^{17}$ A no-observed-effect level was set at $100 \mathrm{mg} / \mathrm{kg}$ per day. The results of this study were used to establish the short-term drinking water limit of 1 ppm for MCHM.

The acute dermal toxicity of crude MCHM was evaluated in male and female rats administered a single dose of 2,000 mg/kg. ${ }^{18}$ Mortality occurred in two female rats, and clinical signs of toxicity in females included weakness, prostration, stumbling, red urine, and a lack of feces. Dermal effects observed in both male and female rats included erythema and desquamation. Dermal induration was observed only in female rats.

Crude 4-methylcyclohexanemethanol: Oral LD50 values for crude MCHM were established for both male (933 mg/kg) and female (707 mg/kg) Sprague Dawley rats (SAS:VAF[SD]) exposed to a single dose $(0,500,1,000$, or $2,000 \mathrm{mg} / \mathrm{kg})$ by oral gavage and observed for 14 days following exposure. ${ }^{19}$ Mortality occurred within 24 hours in all animals treated with 2,000 mg/kg and three males and four females treated with $1,000 \mathrm{mg} / \mathrm{kg}$. Additional clinical signs of toxicity were noted during the 14-day observation period and included weakness, prostration, stumbling, dehydration, and red urine.

Female Sprague Dawley rats [Crl:CD(SD)IGS BR] were administered a single dose (500 mg/kg) of crude MCHM via oral gavage to assess its potential to induce hematuria in this rat strain. ${ }^{20}$ Neither hematuria nor any additional clinical signs of toxicity were observed during a 14-day observation period.

Dimethyl 1,4-cyclohexanedicarboxylate ( $0 \%, 0.1 \%, 0.3 \%$, or $1.0 \%$ in feed), a component of crude MCHM, did not induce any clinical signs of toxicity in male or female Sprague Dawley rats exposed for 4 weeks. A no-observed-adverse-effect level (NOAEL) was established at 1.0\% (871 mg/kg in males, $894 \mathrm{mg} / \mathrm{kg}$ in females). ${ }^{21}$ An oral LD50 value for this chemical was reported to be greater than $5,000 \mathrm{mg} / \mathrm{kg}$ in rats. ${ }^{22}$ 
Acute exposure to 1,4-cyclohexanedimethanol (400 to $6,400 \mathrm{mg} / \mathrm{kg}$ ), a component of crude MCHM, for 14 days by oral gavage induced weakness, prostration, and vasodilation in rats. ${ }^{23}$ Male and female Sprague Dawley rats administered 1,4-cyclohexanedimethanol in drinking water $(0,4,8$, or $12.5 \mathrm{mg} / \mathrm{L})$ for 13 weeks demonstrated reduced survival rates, red urine, decreased food consumption, and losses in both body weight and body weight gain at $12.5 \mathrm{mg} / \mathrm{L}$. NOAELs were established at $479 \mathrm{mg} / \mathrm{kg}$ per day for male rats and at $754 \mathrm{mg} / \mathrm{kg}$ per day for female rats. An oral $\mathrm{LD}_{50}$ value for 1,4-cyclohexanedimethanol was calculated at 3,200 to $6,400 \mathrm{mg} / \mathrm{kg}$.

\section{Humans}

No studies were identified on the general toxicity of MCHM in humans in the scientific literature. Immediately following the Elk River spill, residents of Charleston, West Virginia, reported symptoms of chemical exposures including reddened skin and erythema from dermal exposure and gastrointestinal distress (nausea, vomiting, and/or diarrhea) from ingestion of

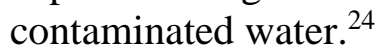

\section{Immunotoxicity}

\section{Experimental Animals}

4-Methylcyclohexanemethanol: Dermal irritation was observed in male guinea pigs [Crl:(HA)BR Hartley] 24 hours after topical administration of a single dose of $0.5 \mathrm{~mL} \mathrm{MCHM} .{ }^{16}$ Repeated dermal administration (9 applications over 11 days) of $0.5 \mathrm{~mL}$ MCHM in the same guinea pig model resulted in an aggravated response, as indicated by moderate erythema, moderate edema, moderate necrosis, and moderate to strong eschars. ${ }^{16}$

MCHM was determined to be a moderate eye irritant in New Zealand white rabbits administered a single dose $(0.1 \mathrm{~mL})$ to the eyes. ${ }^{16}$ Signs of irritation were observed 1 hour postexposure and included moderate erythema and edema of the eyelids, conjunctivae, and nictitating membranes, as well as moderate discharges.

Crude 4-methylcyclohexanemethanol: Acute dermal exposure (4 hours) to a mixture containing predominantly crude MCHM caused skin irritation, including erythema and edema, in albino rabbits [Hra:(NZW)SPF] ${ }^{25}$ Very slight to well-defined erythema and very slight to moderate edema were observed as early as 1 hour postexposure, and the degree of irritation increased in severity up to 72 hours postexposure.

Dermal irritation was observed at all dose levels in male and female rats exposed dermally to crude MCHM $\left(0,100,500\right.$, or 2,000 mg/kg per day) for 13 days. ${ }^{26}$ A NOAEL for systemic toxicity was established at $2,000 \mathrm{mg} / \mathrm{kg}$ crude MCHM. Dermal exposure to a single dose of $2,000 \mathrm{mg} / \mathrm{kg}$ crude MCHM induced dermal irritation in male and female rats during the 14-day postexposure observation period. ${ }^{18}$ Dermal irritation was indicated by the presence of focal necrosis and eschar formation on the skin of both males and females.

Crude MCHM did not induce skin hypersensitivity (i.e., allergic contact dermatitis) when evaluated in male guinea pigs [Crl:(HA)BR VAF/Plus ${ }^{\circledR}$ ] using the footpad method. ${ }^{27}$ 
Structure-activity relationship analysis predicted that MCHM would be positive in models for skin and eye irritation and corrosion. ${ }^{28}$

\section{Humans}

No studies were available on the immunotoxicity of MCHM in humans in the scientific literature. Immediately following the Elk River chemical spill, residents of Charleston reported symptoms of chemical exposures including mild rashes and reddened skin from dermal exposure. $^{11}$

\section{Study Rationale}

MCHM and crude MCHM were nominated to the National Toxicology Program (NTP) for toxicity evaluation by the CDC and ATSDR following the Elk River, West Virginia, chemical spill. Due to structural alerts from in silico models of potential sensitizers and reports of reddened skin and erythema following dermal exposure to contaminated water from the spill, NTP conducted studies in mice to assess the potential immunotoxicity, specifically dermal irritancy and hypersensitivity of MCHM and crude MCHM. 


\section{Materials and Methods}

\section{Procurement and Characterization}

\section{4-Methylcyclohexanemethanol}

4-Methylcyclohexanemethanol (MCHM) was obtained from TCI America (Portland, OR) in one lot (KDY3F). Crude MCHM was obtained from Eastman Chemical Company (Kingsport, TN) in one lot (TP14044373). Identity, purity, and stability analyses were conducted by the analytical chemistry laboratory at MRIGlobal (Kansas City, MO) (Appendix A). Reports on analyses performed in support of the MCHM studies are on file at the National Institute of Environmental Health Sciences (NIEHS).

Lot KDY3F of the pure chemical, a clear, colorless liquid, was identified as MCHM using Fourier transform infrared (FTIR) spectroscopy, Fourier transform proton and carbon-13 nuclear magnetic resonance (NMR) spectroscopy, and gas chromatography (GC) with mass spectrometry (MS) detection. In addition, boiling point, density, and octanol:water partition coefficient were determined. Karl Fischer titration was used to determine the water content of lot KDY3F. Purity of the test article was determined by elemental analyses for carbon, hydrogen, and nitrogen, and by determining the purity profile using GC with flame ionization detection (FID) and two columns with differing polarities.

For lot KDY3F, Karl Fischer titration indicated 0.21\% water. Elemental analyses for carbon, hydrogen, and nitrogen were consistent with the theoretical values for MCHM. GC/FID analysis detected two major peaks with a combined area of $99.97 \%$ of the total peak area and no impurities with areas greater than or equal to $0.05 \%$ of the total peak area. The relative areas of the two major peaks indicated that MCHM consisted of $67.99 \%$ cis- and $31.98 \%$ trans-isomers. GC/FID by a second system detected two major peaks with a combined relative area of $99.83 \%$ (with relative areas of $67.80 \%$ [cis] and 32.03\% [trans] isomers), and two minor impurities totaling $0.13 \%$ of the total peak area. The overall purity of lot KDY3F was determined to be greater than or equal to $99.8 \%$.

A chemical identity and purity screen of lot TP14044373 of the crude test chemical, a clear liquid, was performed using GC/MS. The test article was found to be a $90.35 \%$ mix of the cis(33.45\%) and trans- (56.90\%) isomers of MCHM on the basis of the relative areas of the two major peaks (Table 1). Six impurity components with a relative percent total area greater than or equal to $0.05 \%$ were observed, with a combined area of $9.66 \%$. Three of these impurity components (each with an individual relative percent area greater than 1\%) were tentatively identified as cyclohexanemethanol (1.82\%), and a mix of the cis- and trans-isomers of 1,4-cyclohexanedimethanol (7.15\%). The purity of lot TP14044373, relative to MCHM isomers, was estimated to be greater than $90 \%$. 
Table 1. Constituents of Crude 4-Methylcyclohexanemethanol

\begin{tabular}{lcc}
\hline \multicolumn{1}{c}{ Chemical Name } & CASRN & Concentration (\%) \\
\hline 4-Methylcyclohexanemethanol & $34885-03-5$ & 90.35 \\
Trans-isomer & - & 56.90 \\
Cis-isomer & - & 33.45 \\
Other Components Tentatively Identified & - & 10.0 (approximately) \\
1,4-Cyclohexanedimethanol (cis- and trans- isomers) & $105-08-8$ & 7.15 \\
Cyclohexanemethanol & $100-49-2$ & 1.82 \\
Methyl 4-methylcyclohexanecarboxylate & $51181-40-9$ & 0.50 \\
Cis-octahydroisobenzofuran & $13149-01-4$ & 0.13 \\
2-Ethyl-1-hexanol & $104-76-7$ & 0.06 \\
\hline
\end{tabular}

Stability studies of lot KDY3F were conducted using GC/FID. These studies indicated that MCHM was stable as a bulk chemical for at least 14 days when stored in amber glass vials under an inert headspace at temperatures up to $60^{\circ} \mathrm{C}$. To ensure stability, both bulk chemicals were stored at room temperature in amber glass bottles, and MCHM was stored under an inert headspace.

\section{Isoeugenol}

Isoeugenol was obtained from Sigma-Aldrich, Inc. (St. Louis, MO) in one lot (05622BEV) that was used as a positive control in the initial dermal hypersensitivity and irritancy study. Identity, purity, and stability analyses were conducted by the analytical chemistry laboratory at Research Triangle Institute (RTI) (Research Triangle Park, NC).

The identity of lot 05622BEV, received as a clear liquid, was determined using FTIR and proton and carbon-13 NMR spectroscopy, GC/MS spectrometry, and ultra-high-performance liquid chromatography (UHPLC)/time-of-flight (TOF) MS. Karl Fischer titration was used to determine the water content of lot 05622BEV. Purity of the test article was determined by elemental analyses for carbon, hydrogen, and oxygen, and by determining the purity profile using GC/FID and UHPLC with photodiode array (PDA) detection.

For lot 05622BEV, Karl Fischer titration indicated 0.23\% water. Elemental analyses for carbon, hydrogen, and oxygen were in agreement with the theoretical values for isoeugenol. GC/FID analysis indicated two major isomer peaks (totaling 98.7\% of the total peak area) and two impurities ( $0.7 \%$ and $0.4 \%$ of the total peak area). UHPLC/PDA analysis indicated two major isomer peaks (totaling $99.1 \%$ of the total peak area) and two impurities $(0.6 \%$ and $0.1 \%$ of the total peak area). The overall purity of lot $05622 \mathrm{BEV}$ was determined to be greater than or equal to $98.7 \%$.

Stability studies of lot 05622BEV conducted using GC/FID indicated that isoeugenol was stable as a bulk chemical for at least 14 days when stored in amber glass vials sealed with Teflon ${ }^{\circledR}$ lined caps at temperatures up to $60^{\circ} \mathrm{C}$. To ensure stability, the bulk chemical was stored at room temperature under nitrogen. 


\section{1-Fluoro-2,4-dinitrobenzene}

1-Fluoro-2,4-dinitrobenzene was obtained from Sigma-Aldrich, Inc. in one lot (BCBN2339V) that was used as a positive control in the initial and repeat dermal hypersensitivity and irritancy studies. Identity, purity, and stability analyses were conducted by the analytical chemistry laboratory at RTI.

The identity of lot BCBN2339V, a clear liquid, was determined using FTIR and proton, carbon13, and fluorine-19 NMR spectroscopy, GC/MS spectrometry, and UHPLC/TOF MS. The water content of lot BCBN2339V was determined using Karl Fischer titration. Purity of the test article was determined by elemental analyses for carbon, hydrogen, nitrogen, oxygen, and fluorine, and by determining the purity profile using GC/FID and UHPLC with PDA detection.

For lot BCBN2339V, the water content was less than the limit of quantitation of $0.1 \%$. Elemental analyses for carbon, hydrogen, nitrogen, and oxygen were in agreement with the theoretical values for 1-fluoro-2,4-dinitrobenzene; fluorine was not accurately quantitated due to interference with oxygen. GC/FID indicated one major peak (99.6\% of the total peak area), and two impurity peaks ( $0.2 \%$ each of the total peak area). UHPLC/PDA analysis indicated one major peak ( $99.4 \%$ of the total peak area) and three impurity peaks $(0.1 \%, 0.2 \%$, and $0.3 \%$ of the total peak area). The overall purity of lot BCBN2339V was determined to be greater than or equal to $99.4 \%$.

Stability studies of lot BCBN2339V conducted using GC/FID indicated that 1-fluoro-2,4dinitrobenzene was stable as a bulk chemical for at least 14 days when stored in amber glass vials sealed with Teflon-lined caps at temperatures up to $60^{\circ} \mathrm{C}$. To ensure stability, the bulk chemical was stored at room temperature under nitrogen.

\section{Preparation and Analysis of Dose Formulations}

\section{Formulation Materials}

For the initial study, all dose formulations were prepared by the study laboratory, Burleson Research Technologies, Inc. (Morrisville, NC), and analyzed by the analytical chemistry laboratory at RTI. For the repeat study, formulations were both prepared and analyzed by RTI.

Acetone and olive oil were obtained from multiple suppliers in multiple lots and these materials were combined with a 4:1 ratio to prepare the vehicle for the initial and repeat studies. For the repeat study, J.T. Baker Acetone (lot K30J01; Thermofisher Scientific, Waltham, MA) was analyzed using GC/FID indicating a purity of 99.9\%, acceptable for use in the study. Olive oil (lot 0240-0545; Welch, Holme, and Clark Co., Newark, NJ) was analyzed to determine peroxide levels using potentiometric titration. Peroxide levels were within the acceptable limit of $5 \mathrm{mEq} / \mathrm{kg}$.

Dose formulations of the test articles and positive controls for the initial study were prepared daily by mixing the appropriate amounts of each chemical with acetone:olive oil (4:1) to achieve the required concentrations. In the repeat study the dose formulations were stored in amber glass vials sealed with Teflon-lined caps at room temperature or refrigerated temperatures for up to 14 days. 
Stability studies of the $1 \%(\mathrm{v} / \mathrm{v})$ dose formulation of crude MCHM and the $0.15 \%(\mathrm{v} / \mathrm{v})$ dose formulation of 1-fluoro-2,4-dinitrobenzene were performed by RTI using two different GC/FID systems. Stability was confirmed for at least 14 days for these dose formulations stored in amber glass vials with minimal headspace sealed with Teflon-lined lids at room temperature and for 3 hours under simulated animal room conditions.

Analyses of the dose formulations for the initial and repeat studies were conducted by RTI using GC/FID by one system for MCHM and crude MCHM and by a second system for the positive controls isoeugenol and 1-fluoro-2,4-dinitrobenzene. During the initial dermal hypersensitivity and irritancy study, the dose formulations were analyzed once; two of three MCHM dose formulations were within 15\% of the target concentrations and five of six crude MCHM dose formulations were within $15 \%$ of the target concentrations (Table A-3). Single dose formulations of the positive controls isoeugenol and 1-fluoro-2,4-dinitrobenzene were each found to be within $15 \%$ of the target concentrations. During the repeat dermal hypersensitivity and irritancy study, the dose formulations were analyzed once, and animal room samples of these dose formulations were also analyzed (Table A-4). All five crude MCHM dose formulations were within 15\% of the target concentrations; all five animal room samples were also within $15 \%$ of the target concentrations. A single dose formulation of 1-fluoro-2,4-dinitrobenzene and its associated animal room sample were both found to be within 15\% of the target concentrations.

\section{Animal Source}

Female BALB/c mice were obtained from Taconic Biosciences, Inc. (Germantown, NY). The National Toxicology Program (NTP) notes that the CBA mouse is the strain of choice for the local lymph node assay (LLNA). NTP began using BALB/c mice for hypersensitivity testing prior to the development of the OECD 429 Guidance. To maintain consistency with a large body of historical data, NTP continues to use the BALB/c mouse. NTP and others have conducted studies to examine the sensitivity of this mouse strain as compared with the CBA and multiple groups have concluded that the performance of LLNA with BALB/c mice is comparable with that of the CBA mouse. ${ }^{29-31}$

\section{Animal Welfare}

Animal care and use are in accordance with the Public Health Service Policy on Humane Care and Use of Animals. All animal studies were conducted in an animal facility accredited by the Association for the Assessment and Accreditation of Laboratory Animal Care International. Studies were approved by the Burleson Research Technologies, Inc., Animal Care and Use Committee and conducted in accordance with all relevant NIH and NTP animal care and use policies and applicable federal, state, and local regulations and guidelines.

\section{Dermal Hypersensitivity and Irritancy Studies}

\section{Study Conduct}

Female mice were 5 to 7 weeks old upon receipt. Animals were quarantined for 8 (initial MCHM and crude MCHM study) or 17 (crude MCHM repeat study) days and were 8 weeks old on the first day of dosing. Before the studies began, five mice were randomly selected for parasite evaluation and gross observation for evidence of disease. The health of the animals was 
monitored during the studies according to the protocols of the NTP Sentinel Animal Program (Appendix C). All test results were negative.

In the initial study evaluating whether MCHM and crude MCHM have similar immunotoxicologic profiles, groups of five mice were administered a vehicle control (acetone/olive oil, 4:1 v/v [AOO]); one of two positive controls (1-fluoro-2,4-dinitrobenzene [0.15\% in AOO] or isoeugenol [5\% in AOO]); $2 \%, 20 \%$, or $100 / 50 \%$ formulations of MCHM in AOO; or $1 \%, 2 \%, 5 \%, 20 \%, 40 \%$, or $100 / 80 \%$ formulations of crude MCHM in AOO. The $100 / 50 \%$ group was administered $100 \%$ on day 1 and $50 \%$ on days 2 and 3; the $100 / 80 \%$ group was administered $100 \%$ on day 1 and $80 \%$ on days 2 and 3. Doses of MCHM and crude MCHM were selected on the basis of dermal immunotoxicity studies previously performed by the sponsor, Eastman Kodak Company. ${ }^{25 ;}$ 18; 26 To determine if the crude mixture of MCHM was responsible for any potential dermal immunotoxicity, three concentrations (2\%, 20\%, and 100\%) were chosen for comparison between MCHM and crude MCHM.

A repeat study of crude MCHM was undertaken to more clearly establish levels in which the test article induced sensitization in the absence of clinical toxicity. In the repeat study of crude MCHM, groups of eight (groups 1 through 7) or five (groups 8 through 14) female mice were administered the AOO vehicle control; a positive control (1-fluoro-2,4-dinitrobenzene [0.15\% in $\mathrm{AOO}]$ ); or crude MCHM at concentrations of $1 \%, 5 \%, 25 \%, 50 \%$, or $75 \%$ in AOO (Table 2).

The mice were treated for 3 consecutive days by direct epicutaneous application of $25 \mu \mathrm{L}$ of the test or control article to the dorsum of each ear. Feed and water were available ad libitum. The animals were housed up to five mice from the same treatment group per cage. Animals were weighed on days 1 and 6. Mice were observed twice daily for local irritation at the application site and for signs of systemic toxicity. Details of the study design and animal maintenance are summarized in Table 3. Information on feed composition and contaminants is provided in Appendix B. 
MCHM Hypersensitivity, NTP IMM 01

Table 2. Study Design for the Repeat Study of Crude 4-Methylcyclohexanemethanol

\begin{tabular}{|c|c|c|c|c|c|c|c|c|c|c|c|c|c|c|}
\hline & \multicolumn{14}{|c|}{ Group $^{\mathrm{a}, \mathrm{b}}$} \\
\hline & 1 & 2 & 3 & 4 & 5 & 6 & 7 & 8 & 9 & 10 & 11 & 12 & 13 & 14 \\
\hline Treatment & AOO & $1 \%$ & $5 \%$ & $25 \%$ & $50 \%$ & $75 \%$ & DNFB & AOO & $1 \%$ & $5 \%$ & $25 \%$ & $50 \%$ & $75 \%$ & DNFB \\
\hline \multicolumn{15}{|l|}{ Endpoint } \\
\hline Body Weight & $\mathrm{x}$ & $\mathrm{x}$ & $\mathrm{x}$ & $\mathrm{x}$ & $\mathrm{x}$ & $\mathrm{x}$ & $\mathrm{x}$ & $\mathrm{x}$ & $\mathrm{x}$ & $\mathrm{x}$ & $\mathrm{x}$ & $\mathrm{x}$ & $\mathrm{x}$ & $\mathrm{x}$ \\
\hline Clinical Observations & $\mathrm{x}$ & $\mathrm{x}$ & $\mathrm{x}$ & $\mathrm{x}$ & $\mathrm{x}$ & $\mathrm{x}$ & $\mathrm{x}$ & $\mathrm{x}$ & $\mathrm{x}$ & $\mathrm{x}$ & $\mathrm{x}$ & $\mathrm{x}$ & $\mathrm{x}$ & $\mathrm{x}$ \\
\hline Ear Thickness & $\mathrm{x}$ & $\mathrm{x}$ & $\mathrm{x}$ & $\mathrm{x}$ & $\mathrm{x}$ & $\mathrm{x}$ & $\mathrm{x}$ & $\mathrm{x}$ & $\mathrm{x}$ & $\mathrm{x}$ & $\mathrm{x}$ & $\mathrm{x}$ & $\mathrm{x}$ & $\mathrm{x}$ \\
\hline Lymph Node Cell Proliferation & $\mathrm{x}$ & $\mathrm{x}$ & $\mathrm{x}$ & $\mathrm{x}$ & $\mathrm{x}$ & $\mathrm{x}$ & $\mathrm{x}$ & - & - & - & - & - & - & - \\
\hline Ear Punch Biopsy Weight & - & - & - & - & - & - & - & $\mathrm{x}$ & $\mathrm{x}$ & $\mathrm{x}$ & $\mathrm{x}$ & $\mathrm{x}$ & $\mathrm{x}$ & $\mathrm{x}$ \\
\hline Ear Histopathology & - & - & - & - & - & - & - & $\mathrm{x}$ & $\mathrm{x}$ & $\mathrm{x}$ & $\mathrm{x}$ & $\mathrm{x}$ & $\mathrm{x}$ & $\mathrm{x}$ \\
\hline
\end{tabular}

$\mathrm{X}$ indicates groups for which the endpoint listed was assessed.

AOO = acetone olive oil; DNFB = 1-fluoro-2,4-dinitrobenzene.

${ }^{a}$ Groups 1 through 7 received ${ }^{125}$ I-UdrR on day 6 for evaluation of lymph node cell proliferation. Ear punch biopsy weights were obtained only for groups 8 through 14 following euthanasia on day 6.

${ }^{b} \mathrm{n}=8$ for groups $1-7 ; \mathrm{n}=5$ for groups $8-14$.

\section{Assessment of Irritancy}

Dermal irritancy potential was assessed by measuring changes in ear swelling following application of MCHM, crude MCHM, or vehicle controls. For all mice, ear thickness measurements for both ears were taken prior to dosing on day 1, after dosing on day 3, and again on day 6. Ear thickness measurements were performed using a calibrated gage (Dyer model 304196; S/N 4183012). The thickness gage and the gage block were calibrated against NISTtraceable thickness standards by an independent certification laboratory that is ISO/IEC 17025accredited. The precision of the calibrated gage allowed for ear thickness to be measured to $0.1 \mathrm{~mm}$. Mice were euthanized by carbon dioxide asphyxiation on day 6. A $6 \mathrm{~mm}$ punch biopsy was obtained from each ear of mice in the initial MCHM and crude MCHM groups in the repeat study of crude MCHM (groups 8 through 14) following terminal euthanasia. The biopsies were weighed; however, technical limitations prevented the measurement of usable data.

\section{Assessment of Hypersensitivity}

Dermal hypersensitivity was evaluated using the LLNA, which provides an indication for the skin sensitization potential of a chemical. ${ }^{32-34}$ In the assay, skin sensitization potential was measured as a function of lymphocyte proliferation within the auricular lymph nodes following dermal application of MCHM, crude MCHM, or vehicle controls to both ears.

On day 6, after ear thickness measurements and 5 hours before terminal euthanasia, mice in the initial study of MCHM and crude MCHM groups 1 through 7 were administered $2 \mu \mathrm{Ci}$

${ }^{125} \mathrm{I}$-iododeoxyuridine $\left({ }^{125} \mathrm{I}-\mathrm{UdR}\right)(0.25 \mathrm{~mL}$ of a stock solution of $8 \mu \mathrm{Ci} / \mathrm{mL})$ by intravenous injection into the lateral tail vein using a tuberculin syringe. The auricular lymph nodes were collected after terminal euthanasia into a $15 \mathrm{~mL}$ conical tube containing Hanks' balanced salt solution with HEPES (HBSS/H). The lymph nodes collected from an individual animal were pooled in a single tube. The lymph nodes were placed between the frosted ends of two glass microscope slides and macerated to produce a cell suspension. The cell suspensions were placed into centrifuge tubes containing $\mathrm{HBSS} / \mathrm{H}$ and processed through centrifugations and washes. 
Trichloroacetic acid (TCA, 5\%) was added to the tubes containing the final centrifugation pellet. The tubes were vortexed and then wrapped in lead foil and refrigerated overnight (16 to 24 hours). Subsequently, the tubes were removed from refrigeration, vortexed, and centrifuged. The resulting pellets were resuspended with 5\% TCA and added to a gamma counter tube (1 gamma counter tube per mouse). Each tube was counted on the gamma counter for 5 minutes and counts per minute (CPM) were recorded. A 1:500 dilution of the $8 \mu \mathrm{Ci} / \mathrm{mL}^{125} \mathrm{I}-\mathrm{UdR}$ stock solution was prepared and counted. Four background/blank tubes, each containing $2 \mathrm{~mL}$ of 5\% TCA were also counted. CPM values were converted to disintegrations per minute (DPM) by dividing by the gamma counter efficiency and multiplying the results by 100 . Individual DPM values were corrected by subtracting the mean DPM for the blanks. The stimulation index (SI) was calculated by dividing the group mean DPM by the mean vehicle control DPM. SI is the accepted standard for quantification of skin sensitization potential, and an SI of 3 (a threefold increase in lymphocyte proliferation) has previously been determined to be a consistent distinguishing factor between sensitizers and nonsensitizers. ${ }^{35}$ The EC3 value, or effective concentration for an SI of 3, has further been successfully used to directly determine the skin sensitization potential of chemicals. ${ }^{34}$ The EC3 values were calculated via a linear regression model; all of the study data were used for the linear interpolation.

Table 3. Experimental Design and Materials and Methods in the Dermal Hypersensitivity and Irritancy Studies of 4-Methylcyclohexanemethanol and Crude 4-Methylcyclohexanemethanol

\begin{tabular}{l}
\hline \multicolumn{1}{c}{ Study Design } \\
\hline Study Laboratory \\
Burleson Research Technologies, Inc. (Morrisville, NC) \\
Strain and Species \\
BALB/c mice \\
Animal Source \\
Taconic Biosciences, Inc. (Germantown, NY) \\
Time Held Before Studies \\
MCHM and crude 4-methylcyclohexanemethanol: 8 days \\
Crude MCHM (repeat study): 17 days \\
Average Age When Studies Began \\
8 weeks \\
Date of First Dose \\
MCHM and crude 4-methylcyclohexanemethanol: December 10, 2014 \\
Crude MCHM (repeat study): March 20, 2015 \\
Duration of Dosing \\
Once daily for 3 days \\
Date of Last Dose \\
MCHM and crude 4-methylcyclohexanemethanol: December 12, 2014 \\
Crude MCHM (repeat study): March 22, 2015 \\
Terminal Euthanasia \\
MCHM and crude 4-methylcyclohexanemethanol: December 15, 2014 \\
Crude MCHM (repeat study): March 25, 2015 \\
\hline
\end{tabular}




\section{Study Design}

\section{Average Age at Terminal Euthanasia}

9 weeks

\section{Size of Study Groups}

MCHM and crude 4-methylcyclohexanemethanol: 5

Crude MCHM (repeat study): 8 (groups 1 through 7) or 5 (groups 8 through 14)

\section{Method of Distribution}

Animals were distributed randomly into groups of approximately equal initial mean body weights.

\section{Animals per Cage}

5

\section{Method of Animal Identification}

Tail tattoo

\section{Diet}

Irradiated NTP-2000 open formula pelleted diet (Zeigler Brothers, Inc., Gardners, PA), available ad libitum

\section{Water}

Tap water (Morrisville municipal supply) (Techniplast caging system, Techniplast, West Chester, PA), available ad libitum

Cages

Techniplast Sealsafe, individually ventilated caging system (Techniplast)

\section{Bedding}

Sani-Chips ${ }^{\circledR}$ (P.J. Murphy Forest Products Corp., Montville, NJ), changed twice weekly

\section{Animal Room Environment}

Temperature: $72^{\circ} \mathrm{F} \pm 3^{\circ} \mathrm{F}$

Relative humidity: $50 \% \pm 15 \%$

Room fluorescent light: 12 hours/day

Room air changes: 10/hour

\section{Concentrations}

MCHM and crude MCHM: $0 \%$, 2\%, 20\%, or 100/50\% formulations of MCHM; $1 \%, 2 \%, 5 \%, 20 \%, 40 \%$, or 100/80\% formulations of crude MCHM; 0.15\% 1-fluoro-2,4-dinitrobenzene or 5\% isoeugenol

Crude MCHM (repeat study): 1\%, 5\%, 25\%, 50\%, or 75\% crude MCHM; or 0.15\% 1-fluoro-2,4-dinitrobenzene Acetone:olive oil vehicle (AOO, 4:1 ratio) was used for all studies

\section{Type and Frequency of Observation}

Observed twice daily for toxicity and skin irritation at the application site; animals were weighed on days 1 and 6 .

\section{Method of Euthanasia}

Carbon dioxide asphyxiation

\section{Ear Thickness Measurements}

Ear thickness measurements were taken for both ears of all mice on days 1, 3, and 6. On day 6, $6 \mathrm{~mm}$ punch biopsies were taken from each ear of MCHM and crude MCHM groups and crude MCHM (repeat study) groups 8 through 14 and weighed.

\section{Local Lymph Node Assay}

On day 6, 5 hours before terminal euthanasia, ${ }^{125} \mathrm{I}-\mathrm{UdR}(2 \mu \mathrm{Ci})$ was administered by intravenous injection into the lateral tail vein of MCHM and crude MCHM groups and crude MCHM (repeat study) groups 1 through 7. After terminal kill, auricular lymph nodes were collected and disintegrations per minute and stimulation indices were determined. 


\section{Statistical Methods}

All p values are two-sided and considered statistically significant if less than 0.05.

\section{Analysis of Continuous Variables}

For dosed groups compared to the vehicle control groups, two approaches were employed to assess the significance of pairwise comparisons in the analysis of continuous variables. Body weight data, which historically have approximately normal distributions, were analyzed with the parametric multiple comparison procedures of Dunnett ${ }^{36}$ and Williams. ${ }^{37 ;} 38$ Ear thickness, lymph node counts, and stimulation indices, which have typically skewed distributions, were analyzed using the nonparametric multiple comparison methods of Shirley ${ }^{39}$ (as modified by Williams ${ }^{40}$ ) and Dunn. ${ }^{41}$ Jonckheere's test $^{42}$ was used to assess the significance of the dose-related trends and to determine whether a trend-sensitive test (Williams' or Shirley’s test) was more appropriate for pairwise comparisons than would be a test that does not assume a monotonic dose-related trend (Dunnett's or Dunn's test). Prior to statistical analysis, extreme values identified by the outlier test of Dixon and Massey ${ }^{43}$ were examined by NTP personnel, and implausible values were eliminated from the analysis.

\section{Quality Assurance Methods}

The dermal hypersensitivity and irritancy studies were conducted in compliance with Food and Drug Administration Good Laboratory Practice Regulations. ${ }^{44}$ In addition, as records from the studies were submitted to the NTP Archives, they were audited retrospectively by an independent quality assessment contractor. Separate audits covered both completeness and accuracy of the data and a draft of this NTP Immunotoxicity Study Report. Audit procedures and findings are presented in the audit report and are on file at NIEHS. The audit findings were reviewed and assessed by NTP staff, and all comments were resolved or otherwise addressed during the preparation of this Immunotoxicity Study Report. 


\section{Results}

\section{Data Availability}

The National Toxicology Program (NTP) evaluated all study data. Data relevant for evaluating toxicological findings are presented here. All study data are available in the NTP Chemical Effects in Biological Systems (CEBS) database: https://doi.org/10.22427/NTP-DATA-IMM-01. ${ }^{45}$

\section{4-Methylcyclohexanemethanol}

4-Methylcyclohexanemethanol (MHCM) was initially tested at concentrations of 2\%, 20\%, and $100 \%$. All mice administered $2 \%$ or $20 \%$ survived to the end of the study with no clinical observations of toxicity (Table 4, Table 5, and Table 6). Mice in the $100 \%$ group demonstrated signs of morbidity on day 1 , including eye squinting, hypoactivity, hunched posture, and isolation from cage mates, resulting in two mice being euthanized moribund (Table 6). Consequently, the $100 \%$ dose was lowered to $50 \%$ on days 2 and 3 (this group is referred to hereafter as the 100/50\% group). Clinical observations noted in surviving 100/50\% mice included eye squinting and hypoactivity, albeit to a lesser extent than was observed prior to lowering the $100 \%$ dose. All clinical signs were observed during the afternoon observation period after treatment, but none was observed during morning observation the subsequent day. Group mean body weights were not significantly affected by treatment (Table 5).

Table 4. Disposition of Female Mice in the Dermal Hypersensitivity and Irritancy Study of 4-Methylcyclohexanemethanol

\begin{tabular}{lcccccc}
\hline & $\begin{array}{c}\text { Vehicle } \\
\text { Control }\end{array}$ & $\mathbf{2 \%}$ & $\mathbf{2 0 \%}$ & $\mathbf{1 0 0 / 5 0 \%}$ & $\begin{array}{c}\mathbf{0 . 1 5 \%} \\
\text { DNFB }\end{array}$ & $\begin{array}{c}\mathbf{5 \%} \\
\text { ISO }^{\mathbf{a}}\end{array}$ \\
\hline Animals Initially in Study & 5 & 5 & 5 & 5 & 5 & 5 \\
Euthanized Moribund & 0 & 0 & 0 & 2 & 0 & 0 \\
Terminal Removal & 5 & 5 & 5 & 3 & 5 & 5 \\
\hline
\end{tabular}

DNFB = 1-fluoro-2,4-dinitrobenzene; ISO = isoeugenol.

aPositive control.

Table 5. Survival and Mean Body Weights of Female Mice in the Dermal Hypersensitivity and Irritancy Study of 4-Methylcyclohexanemethanol ${ }^{\mathrm{a}}$

\begin{tabular}{lcccc}
\hline \multicolumn{1}{c}{ Concentration } & Survival $^{\mathbf{b}}$ & $\begin{array}{c}\text { Initial Body Weight } \\
\text { (g) }\end{array}$ & $\begin{array}{c}\text { Final Body Weight } \\
\text { (g) }\end{array}$ & $\begin{array}{c}\text { Absolute Weight } \\
\text { Gain or Loss }\end{array}$ \\
\hline Vehicle Control & $5 / 5$ & $17.2 \pm 0.6$ & $17.9 \pm 0.6$ & $0.7 \pm 0.2$ \\
$2 \%$ & $5 / 5$ & $17.3 \pm 0.6$ & $18.0 \pm 0.7$ & $0.7 \pm 0.2$ \\
$20 \%$ & $5 / 5$ & $17.9 \pm 0.6$ & $18.1 \pm 0.5$ & $0.2 \pm 0.2$ \\
$100 / 50 \%$ & $3 / 5^{\mathrm{d}}$ & $17.3 \pm 0.6$ & $18.4 \pm 0.5$ & $0.6 \pm 0.2$ \\
$0.15 \%$ DNFB & $5 / 5$ & $17.4 \pm 0.6$ & $18.3 \pm 0.7$ & $0.9 \pm 0.3$ \\
$5 \%$ ISO & $5 / 5$ & $17.0 \pm 0.4$ & $17.5 \pm 0.3$ & $0.5 \pm 0.2$ \\
\hline
\end{tabular}

DNFB = 1-fluoro-2,4-dinitrobenzene; ISO = isoeugenol.

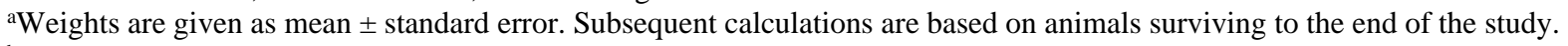

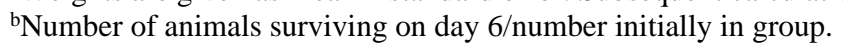

'Positive control.

${ }^{\mathrm{d}}$ Two moribund animals were removed on study day 1 . 
Table 6. Clinical Observations for Female Mice in the Dermal Hypersensitivity and Irritancy Study of 4-Methylcyclohexanemethanol

\begin{tabular}{lcccccc}
\hline & $\begin{array}{c}\text { Vehicle } \\
\text { Control }\end{array}$ & $\mathbf{2 \%}$ & $\mathbf{2 0 \%}$ & $\mathbf{1 0 0 / 5 0 \%}$ & $\begin{array}{c}\mathbf{0 . 1 5 \%} \\
\mathbf{D N F B}^{\mathbf{b}}\end{array}$ & $\begin{array}{c}\mathbf{5 \%}^{\mathbf{1}} \\
\mathbf{I S O}^{\mathbf{c}}\end{array}$ \\
\hline $\mathbf{n}$ & 5 & 5 & 5 & 5 & 5 & 5 \\
\hline Animal Behavior, Isolation $^{\mathrm{a}}$ & 0 & 0 & 0 & $5(1)$ & $5(1)$ & 0 \\
Erythema, Ear, Bilateral, Mild & 0 & 0 & 0 & 0 & $5(4)$ & 0 \\
Erythema, Ear, Bilateral, Moderate & 0 & 0 & 0 & 0 & $5(3)$ & 0 \\
Eye Shut, Bilateral & 0 & 0 & 0 & $5(1)$ & $5(1)$ & 0 \\
Hunched & 0 & 0 & 0 & $2(1)$ & 0 & 0 \\
Hypoactivity & 0 & 0 & 0 & $5(1)$ & $5(3)$ & 0 \\
\hline
\end{tabular}

DNFB = 1-fluoro-2,4-dinitrobenzene; ISO = isoeugenol.

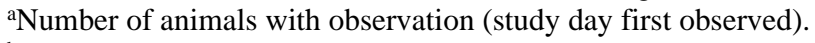

bPositive control.

'Positive control (did not perform as expected).

The irritancy properties of MCHM were assessed by evaluating changes in ear swelling, which were determined by measuring treatment-related changes in ear thickness, relative to vehicle control animals. Treatment resulted in concentration-dependent increases in mean ear thickness in the $20 \%$ and $100 / 50 \%$ groups on day 3 (4.44\% and $6.47 \%$, respectively) and day 6 (3.54\% and $5.30 \%$, respectively), relative to the vehicle control (Table 7).

Table 7. Summary of Ear Thickness Measurement Data for Female Mice in the Dermal Hypersensitivity and Irritancy Study of 4-Methylcyclohexanemethanol ${ }^{\mathrm{a}}$

\begin{tabular}{lcccccc}
\hline Concentration & $\begin{array}{c}\text { Day 1 } \\
\left(\mathbf{m m} \times \mathbf{~ 1 0}^{-\mathbf{2}}\right)\end{array}$ & $\begin{array}{c}\text { Day 3 } \\
\left(\mathbf{m m} \times \mathbf{~ 1 0}^{-\mathbf{2}} \mathbf{)}\right.\end{array}$ & $\begin{array}{c}\text { Day 6 } \\
\left(\mathbf{m m} \times \mathbf{1 0}^{-\mathbf{2}}\right)\end{array}$ & $\begin{array}{c}\text { Day 3 } \\
\mathbf{( \% )}\end{array}$ & $\begin{array}{c}\text { Day 6 } \\
\mathbf{( \% )}\end{array}$ & $\begin{array}{c}\text { Ear Weight } \\
(\mathbf{m g})\end{array}$ \\
\hline Vehicle Control & $15.58 \pm 0.17(5)$ & $15.66 \pm 0.14^{\mathbf{\Lambda}}(5)$ & $15.56 \pm 0.12^{\mathbf{\Lambda}}(5)$ & $-0.04 \pm 0.96^{\mathbf{\Lambda}}(5)$ & $0.02 \pm 0.78^{\mathbf{\Lambda}}(5)$ & $7.78 \pm 0.42(5)$ \\
$2 \%$ & $15.52 \pm 0.08(5)$ & $15.98 \pm 0.02(5)$ & $15.62 \pm 0.07(5)$ & $2.04 \pm 0.16(5)$ & $0.34 \pm 0.39(5)$ & $8.94 \pm 0.38(5)$ \\
$20 \%$ & $15.60 \pm 0.10(5)$ & $16.34 \pm 0.12^{* *}(5)$ & $16.10 \pm 0.10^{* *}(5)$ & $4.44 \pm 0.78^{* *}(5)$ & $3.54 \pm 0.64 * *(5)$ & $8.62 \pm 0.11(5)$ \\
$100 / 50 \%$ & $15.56 \pm 0.06(5)$ & $16.67 \pm 0.33^{* *}(3)$ & $16.40 \pm 0.06^{* *}(3)$ & $6.47 \pm 2.13^{* *}(3)$ & $5.30 \pm 0.46^{* *}(3)$ & $8.57 \pm 0.64(3)$ \\
$0.15 \% \mathrm{DNFB}^{\mathrm{b}}$ & $15.34 \pm 0.04(5)$ & $16.94 \pm 0.13^{* *}(5)$ & $16.98 \pm 0.09^{* *}(5)$ & $8.12 \pm 0.78^{* *}(5)$ & $8.98 \pm 0.60^{* *}(5)$ & $11.60 \pm 0.79^{* *}(5)$ \\
$5 \% \mathrm{ISO}^{\mathrm{b}}$ & $15.40 \pm 0.10(5)$ & $16.92 \pm 0.05^{* *}(5)$ & $16.60 \pm 0.19^{*}(5)$ & $7.96 \pm 0.39^{* *}(5)$ & $6.74 \pm 1.20^{*}(5)$ & $8.10 \pm 1.02(5)$ \\
\hline
\end{tabular}

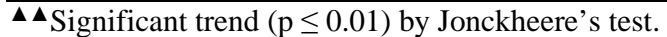

*Significantly different $(\mathrm{p} \leq 0.05)$ from the vehicle control group by Shirley's or Dunn's test.

$* * \mathrm{p} \leq 0.01$.

DNFB = 1-fluoro-2,4-dinitrobenzene; ISO = isoeugenol.

${ }^{a}$ Ear thickness data are presented as mean \pm standard error (n); percentages are calculated as ear swelling (difference from vehicle control) using the equation: [mean measurement for both ears for each animal (day 3 or 6 ) - vehicle control mean ear thickness (day 3 or 6)]/[vehicle control mean ear thickness (day 3 or 6 ) $\times 100]$.

bPositive control.

The local lymph node assay (LLNA) was used to evaluate the ability of MCHM to induce dermal sensitization. The LLNA uses incorporation of ${ }^{125}$ I-iododeoxyuridine $\left({ }^{125} \mathrm{I}-\mathrm{UdR}\right.$ ) as a measure of DNA synthesis and lymphocyte proliferation. On day 6, 3 days after final dosing, mice were injected intravenously with ${ }^{125} \mathrm{I}-\mathrm{UdR}$ and rested for 5 hours to allow for incorporation of the labeled material into proliferating cells in the draining lymph nodes. Treatment with MCHM did not significantly modulate mean group disintegrations per minute (DPM) compared to that of the 
vehicle control group or the stimulation index (SI; treated group mean DPM/vehicle control group mean DPM) values (Table 8 and Figure 2). No EC3 value was calculated for MCHM as all SI values were below 3 .

Table 8. Summary of ${ }^{125}$ I-UdR Incorporation and Stimulation Index Data for Female Mice in the Dermal Hypersensitivity and Irritancy Study of 4-Methylcyclohexanemethanol ${ }^{\mathrm{a}}$

\begin{tabular}{lccc}
\hline \multicolumn{1}{c}{ Concentration } & n & Lymph Node Counts (DPM) & Stimulation Index \\
\hline Vehicle Control & 5 & $20.76 \pm 4.67$ & $1.00 \pm 0.22$ \\
$2 \%$ & 5 & $2.33 \pm 0.97^{* *}$ & $0.11 \pm 0.05^{* *}$ \\
$20 \%$ & 5 & $5.86 \pm 1.33$ & $0.28 \pm 0.06$ \\
$100 / 50 \%$ & 3 & $18.39 \pm 6.10$ & $0.88 \pm 0.29$ \\
$0.15 \% \mathrm{DNFB}^{\mathrm{b}}$ & 5 & $208.37 \pm 5.25^{* *}$ & $10.02 \pm 1.19^{* *}$ \\
$5 \% \mathrm{ISO}^{\mathrm{b}}$ & 5 & $34.07 \pm 5.25$ & $1.64 \pm 0.25$ \\
\hline
\end{tabular}

**Significantly different $(\mathrm{p} \leq 0.01)$ from the vehicle control group by Shirley’s or Dunn’s test.

$\mathrm{DPM}=$ disintegrations per minute; stimulation index = ratio of treated group mean DPM/vehicle control group mean DPM;

DNFB = 1-fluoro-2,4-dinitrobenzene; ISO = isoeugenol.

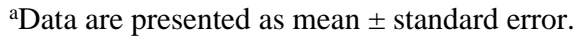

bPositive control.

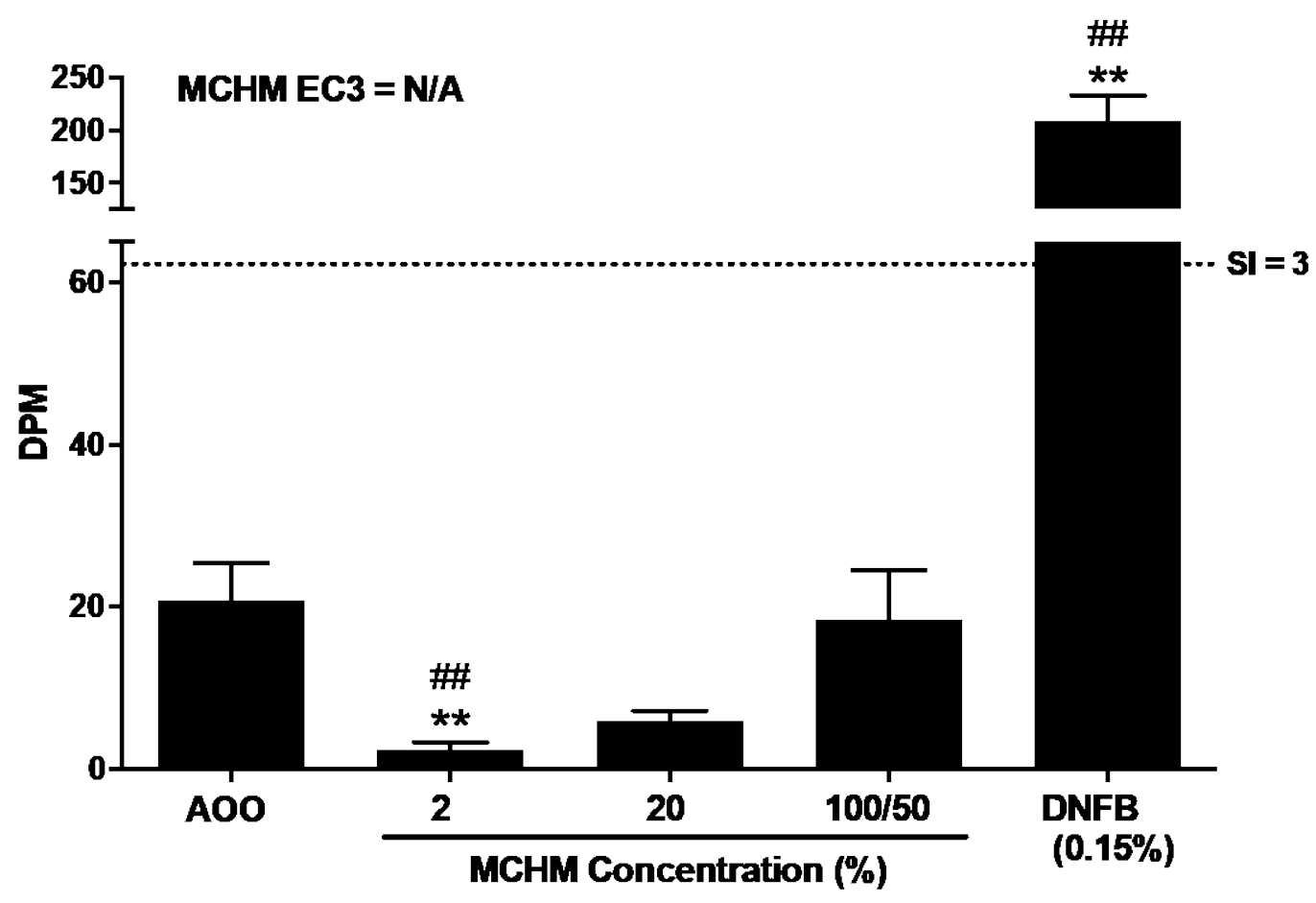

Figure 2. ${ }^{125}$ I-UdR Incorporation and Stimulation Index Data in the Dermal Hypersensitivity and Irritancy Study of 4-Methylcyclohexanemethanol

$\mathrm{AOO}=$ acetone/olive oil vehicle control; DNFB = 1-fluoro-2,4-dinitrobenzene positive control; DPM = disintegrations per minute; $\mathrm{MCHM}=4$-methylcyclohexanemethanol; $\mathrm{SI}=$ stimulation index; EC3 = concentration of test article that results in an $\mathrm{SI}=3$; N/A = not applicable; ** = significantly different $(\mathrm{p} \leq 0.01)$ from the vehicle control group by Shirley’s or Dunn's test; $\# \#$ = significantly different $(\mathrm{p} \leq 0.01)$ SI value from the vehicle control group by Shirley’s or Dunn’s test. 
Two positive controls were utilized in the study of MCHM: 1-fluoro-2,4-dinitrobenzene (0.15\%), a strong sensitizer, and isoeugenol (5\%), a weak sensitizer. 1-Fluoro-2,4-dinitrobenzene performed as expected; however, isoeugenol did not elicit the anticipated sensitizing response.

\section{Crude 4-Methylcyclohexanemethanol}

Crude MCHM was initially administered at concentrations of 1\%, 2\%, 5\%, 20\%, 40\%, and $100 \%$. All mice survived to the end of the study (Table 9 and Table 10). Clinical signs of toxicity, including eye squinting, hypoactivity, and isolation from cage mates, were observed on day 1 in mice in the $100 \%$ group (Table 11). Consequently, the concentration was lowered to $80 \%$ (this group is referred to hereafter as the $100 / 80 \%$ group) for exposure days 2 and 3 . Clinical signs of toxicity in the 100/80\% group included eye squinting (days 1 through 3 ), hypoactivity (days 1 and 2), and isolation from cage mates (days 1 and 2). All clinical signs of toxicity were observed during the afternoon observation period after treatment, but not during morning observation the subsequent day. No clinical signs of toxicity were observed in the groups administered $40 \%$ or less. Group mean body weights were not significantly affected by treatment (Table 10).

Table 9. Disposition of Female Mice in the Dermal Hypersensitivity and Irritancy Study of Crude 4-Methylcyclohexanemethanol

\begin{tabular}{lccccccccc}
\hline & $\begin{array}{c}\text { Vehicle } \\
\text { Control }\end{array}$ & $\mathbf{1 \%}$ & $\mathbf{2 \%}$ & $\mathbf{5 \%}$ & $\mathbf{2 0 \%}$ & $\mathbf{4 0 \%}$ & $\mathbf{1 0 0 / 8 0 \%}$ & $\begin{array}{c}\mathbf{0 . 1 5 \%} \\
\text { DNFB }^{\mathbf{a}}\end{array}$ & $\begin{array}{c}\mathbf{5 \%} \\
\text { ISO }^{\mathbf{a}}\end{array}$ \\
\hline Animals Initially in Study & 5 & 5 & 5 & 5 & 5 & 5 & 5 & 5 & 5 \\
Terminal Removal & 5 & 5 & 5 & 5 & 5 & 5 & 5 & 5 & 5 \\
\hline
\end{tabular}

DNFB = 1-fluoro-2,4-dinitrobenzene; ISO = isoeugenol.

aPositive control.

Table 10. Survival and Mean Body Weights of Female Mice in the Dermal Hypersensitivity and Irritancy Study of Crude 4-Methylcyclohexanemethanol ${ }^{\mathrm{a}}$

\begin{tabular}{lcccc}
\hline \multicolumn{1}{c}{ Concentration } & Survival $^{\mathbf{b}}$ & Initial Body Weight (g) $^{\text {Final Body Weight (g) }}$ & $\begin{array}{c}\text { Absolute Weight Gain } \\
\text { or Loss }\end{array}$ \\
\hline Vehicle Control & $5 / 5$ & $17.2 \pm 0.6$ & $17.9 \pm 0.6$ & $0.7 \pm 0.2$ \\
$1 \%$ & $5 / 5$ & $17.1 \pm 0.7$ & $18.3 \pm 0.7$ & $1.2 \pm 0.2$ \\
$2 \%$ & $5 / 5$ & $17.7 \pm 0.8$ & $18.3 \pm 0.9$ & $0.6 \pm 0.2$ \\
$5 \%$ & $5 / 5$ & $17.4 \pm 0.5$ & $18.3 \pm 0.5$ & $0.9 \pm 0.1$ \\
$20 \%$ & $5 / 5$ & $17.2 \pm 0.6$ & $18.2 \pm 0.5$ & $1.0 \pm 0.2$ \\
$40 \%$ & $5 / 5$ & $18.2 \pm 0.8$ & $19.0 \pm 0.8$ & $0.9 \pm 0.2$ \\
$100 / 80 \%$ & $5 / 5$ & $17.8 \pm 0.7$ & $17.6 \pm 0.7$ & $-0.2 \pm 0.1^{* *}$ \\
$0.15 \% \mathrm{DNFB}^{\mathrm{c}}$ & $5 / 5$ & $17.4 \pm 0.6$ & $18.3 \pm 0.7$ & $0.9 \pm 0.3$ \\
$5 \% \mathrm{ISO}^{\mathrm{c}}$ & $5 / 5$ & $17.0 \pm 0.4$ & $17.5 \pm 0.3$ & $0.5 \pm 0.2$ \\
\hline
\end{tabular}

**Significantly different $(\mathrm{p} \leq 0.01)$ from the vehicle control group by Shirley's or Dunn's test.

DNFB = 1-fluoro-2,4-dinitrobenzene; ISO = isoeugenol.

${ }^{a}$ Weights are given as mean \pm standard error.

${ }^{b}$ Number of animals surviving on day 6/number initially in group.

'Positive control. 
Table 11. Clinical Observations for Female Mice in the Dermal Hypersensitivity and Irritancy Study of Crude 4-Methylcyclohexanemethanol

\begin{tabular}{lccccccccc}
\hline & $\begin{array}{c}\text { Vehicle } \\
\text { Control }\end{array}$ & $\mathbf{1 \%}$ & $\mathbf{2 \%}$ & $\mathbf{5 \%}$ & $\mathbf{2 0 \%}$ & $\mathbf{4 0 \%}$ & $\mathbf{1 0 0 / 8 0 \%}$ & $\begin{array}{c}\mathbf{0 . 1 5 \%} \\
\mathbf{D N F B}^{\mathbf{b}}\end{array}$ & $\begin{array}{c}\mathbf{5 \%} \\
\mathbf{I S O}^{\mathbf{c}}\end{array}$ \\
\hline $\mathbf{n}$ & 5 & 5 & 5 & 5 & 5 & 5 & 5 & 5 & 5 \\
\hline Animal Behavior, Isolation $^{\mathrm{a}}$ & 0 & 0 & 0 & 0 & 0 & 0 & $5(1)$ & $5(1)$ & 0 \\
Erythema, Ear, Bilateral, Mild & 0 & 0 & 0 & 0 & 0 & 0 & 0 & $5(4)$ & 0 \\
Erythema, Ear, Bilateral, Moderate & 0 & 0 & 0 & 0 & 0 & 0 & 0 & $5(3)$ & 0 \\
Eye Shut, Bilateral & 0 & 0 & 0 & 0 & 0 & 0 & $5(1)$ & $5(1)$ & 0 \\
Hypoactivity & 0 & 0 & 0 & 0 & 0 & 0 & $5(1)$ & $5(3)$ & 0 \\
\hline
\end{tabular}

DNFB = 1-fluoro-2,4-dinitrobenzene; ISO = isoeugenol.

${ }^{a}$ Number of animals with observation (study day first observed).

bositive control.

'Positive control (did not perform as expected).

Compared to that of the vehicle control group, mean ear thickness was significantly increased on day 6 (3.86\%) in the $20 \%$ group (Table 12 ) only. There was a significant concentration-related trend for increased ear swelling on day 3.

Table 12. Summary of Ear Thickness Measurement Data for Female Mice in the Dermal Hypersensitivity and Irritancy Study of Crude 4-Methylcyclohexanemethanol ${ }^{\mathrm{a}}$

\begin{tabular}{|c|c|c|c|c|c|c|}
\hline Concentration & $\begin{array}{c}\text { Day } 1 \\
\left(\mathrm{~mm} \times 10^{-2}\right)\end{array}$ & $\begin{array}{c}\text { Day } 3 \\
\left(\mathrm{~mm} \times \mathbf{1 0}^{-2}\right)\end{array}$ & $\begin{array}{c}\text { Day } 6 \\
\left(\mathrm{~mm} \times 10^{-2}\right)\end{array}$ & $\begin{array}{c}\text { Day } 3 \\
(\%)\end{array}$ & $\begin{array}{c}\text { Day } 6 \\
(\%)\end{array}$ & $\begin{array}{c}\text { Ear Weight } \\
\text { (mg) }\end{array}$ \\
\hline Vehicle Control & $15.58 \pm 0.17(5)$ & $15.66 \pm 0.14^{\boldsymbol{\Delta} \Delta}(5)$ & $15.56 \pm 0.1^{\wedge \boldsymbol{\Lambda}}(5)$ & $-0.04 \pm 0.96^{\boldsymbol{\Lambda}} \mathbf{\Delta}(5)$ & $0.02 \pm 0.78^{\Delta \wedge}$ (5) & $7.78 \pm 0.42(5)$ \\
\hline $1 \%$ & $15.78 \pm 0.08$ (5) & $15.54 \pm 0.07(5)$ & $15.72 \pm 0.10(5)$ & $-0.84 \pm 0.39$ (5) & $0.98 \pm 0.60(5)$ & $8.10 \pm 0.52(5)$ \\
\hline $2 \%$ & $15.52 \pm 0.08(5)$ & $15.50 \pm 0.00(5)$ & $15.50 \pm 0.00(5)$ & $-1.00 \pm 0.00(5)$ & $-0.30 \pm 0.00(5)$ & $8.42 \pm 0.46(5)$ \\
\hline $5 \%$ & $15.82 \pm 0.09(5)$ & $15.98 \pm 0.09(5)$ & $15.74 \pm 0.09(5)$ & $1.88 \pm 0.60(5)$ & $1.14 \pm 0.53(5)$ & $8.40 \pm 1.14(5)$ \\
\hline $20 \%$ & $15.22 \pm 0.10(5)$ & $16.56 \pm 0.17(5)$ & $16.16 \pm 0.10^{* *}(5)$ & $5.72 \pm 1.06(5)$ & $3.86 \pm 0.64 * *(5)$ & $8.98 \pm 0.43(5)$ \\
\hline $40 \%$ & $15.46 \pm 0.16(5)$ & $15.88 \pm 0.05(5)$ & $15.56 \pm 0.06(5)$ & $1.24 \pm 0.39(5)$ & $0.02 \pm 0.32$ (5) & $8.32 \pm 0.12(5)$ \\
\hline $100 / 80 \%$ & $15.42 \pm 0.13(5)$ & $16.14 \pm 0.19$ & $15.72 \pm 0.10(5)$ & $3.00 \pm 1.24(5)$ & $0.98 \pm 0.60$ (5) & $8.66 \pm 1.10(5)$ \\
\hline $0.15 \% \mathrm{DNFB}^{\mathrm{b}}$ & $15.34 \pm 0.04(5)$ & $16.94 \pm 0.13^{* *}(5)$ & $16.98 \pm 0.09 * *$ & $8.12 \pm 0.78^{* *}(5)$ & $8.98 \pm 0.60 * *(5)$ & $11.60 \pm 0.79 * *(5)$ \\
\hline $5 \% \mathrm{ISO}^{\mathrm{b}}$ & $15.40 \pm 0.10(5)$ & $16.92 \pm 0.05^{* *}(5)$ & $16.60 \pm 0.19 *(5)$ & $7.96 \pm 0.39 * *(5)$ & $6.74 \pm 1.20 *(5)$ & $8.10 \pm 1.02(5)$ \\
\hline
\end{tabular}

$\overline{\triangle \triangle}$ Significant trend $(\mathrm{p} \leq 0.01)$ by Jonckheere's test.

*Significantly different $(\mathrm{p} \leq 0.05)$ from the vehicle control group by Shirley’s or Dunn’s test.

$* * \mathrm{p} \leq 0.01$.

DNFB = 1-fluoro-2,4-dinitrobenzene; ISO = isoeugenol.

${ }^{a}$ Ear thickness data are presented as mean \pm standard error (n); percentages are calculated as ear swelling (difference from vehicle control) using the equation: [mean measurement for both ears for each animal (day 3 or 6 ) - vehicle control mean ear thickness (day 3 or 6)]/[vehicle mean ear thickness (day 3 or 6$) \times 100]$.

bPositive control.

In the $5 \%$ or greater groups, incorporation of ${ }^{125} \mathrm{I}-\mathrm{UdR}$ (expressed as mean DPM) into lymphocytes from the draining lymph nodes was significantly increased relative to vehicle controls, and this proliferative response followed a significant concentration-related trend. Mean DPM values ranged from 47.53 to 100.41 DPM in the $5 \%$ or greater groups (Table 13 and Figure 3). Mice treated with $5 \%$ or greater had significantly increased mean SI values, with SI values of more than 3.0 occurring at $40 \%$ (3.09) and 100/80\% (4.83). The concentration that would result in an SI of 3.0 (EC3), was calculated to be $34.6 \%$ (Figure 3). 
Table 13. Summary of ${ }^{125}$ I-UdR Incorporation and Stimulation Index for Female Mice in the Dermal Hypersensitivity and Irritancy Study of Crude 4-Methylcyclohexanemethanol ${ }^{\mathrm{a}}$

\begin{tabular}{lccc}
\hline \multicolumn{1}{c}{ Concentration } & $\mathbf{n}$ & Lymph Node Counts (DPM) & Stimulation Index \\
\hline Vehicle Control & 5 & $20.76 \pm 4.67^{\mathbf{\Lambda}}$ & $1.00 \pm 0.22^{\mathbf{\Lambda}}$ \\
$1 \%$ & 5 & $38.16 \pm 13.29$ & $1.83 \pm 0.64$ \\
$2 \%$ & 5 & $35.96 \pm 3.05$ & $1.73 \pm 0.15$ \\
$5 \%$ & 5 & $47.53 \pm 5.68^{*}$ & $2.29 \pm 0.27^{*}$ \\
$20 \%$ & 5 & $61.35 \pm 6.82^{* *}$ & $2.95 \pm 0.33^{* *}$ \\
$40 \%$ & 5 & $64.32 \pm 12.07^{* *}$ & $3.09 \pm 0.58^{* *}$ \\
$100 / 80 \%$ & 5 & $100.41 \pm 16.89^{* *}$ & $4.83 \pm 0.81^{* *}$ \\
$0.15 \%$ DNFB $^{\mathrm{b}}$ & 5 & $208.37 \pm 5.25^{* *}$ & $10.02 \pm 1.19^{* *}$ \\
$5 \%$ ISO $^{\mathrm{b}}$ & 5 & $34.07 \pm 5.25$ & $1.64 \pm 0.25$ \\
\hline
\end{tabular}

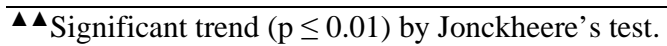

*Significantly different $(\mathrm{p} \leq 0.05)$ from the vehicle control group by Shirley’s or Dunn's test.

$* * \mathrm{p} \leq 0.01$.

$\mathrm{DPM}=$ disintegrations per minute; stimulation index = ratio of treated group mean DPM/vehicle control group mean DPM;

DNFB = 1-fluoro-2,4-dinitrobenzene; ISO = isoeugenol.

${ }^{\text {aD }}$ ata are presented as mean \pm standard error.

bositive control.

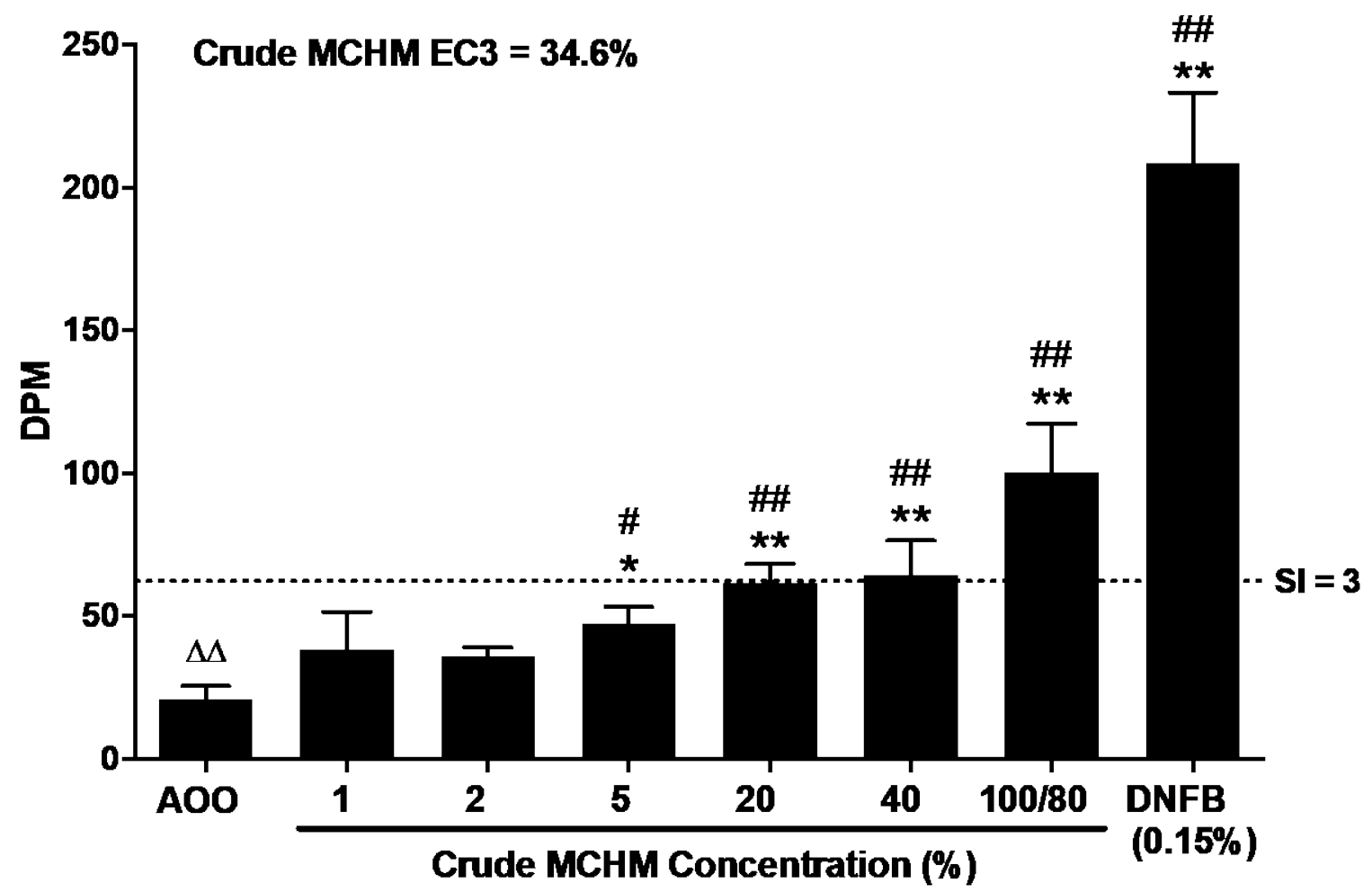

Figure 3. ${ }^{125}$ I-UdR Incorporation and Stimulation Index Data in the Dermal Hypersensitivity and Irritancy Study of Crude 4-Methylcyclohexanemethanol

$\mathrm{AOO}=$ acetone/olive oil vehicle control; DNFB = 1-fluoro-2,4-dinitrobenzene positive control; DPM = disintegrations per minute; MCHM = 4-methylcyclohexanemethanol; SI = stimulation index; EC3 = concentration of test article that results in an SI 3; $\Delta \Delta=$ significant trend $(\mathrm{p} \leq 0.01)$ for DPM by Jonckheere's test; * = significantly different $(\mathrm{p} \leq 0.05)$ from the vehicle control group by Shirley's or Dunn's test; ** $=(\mathrm{p} \leq 0.01)$; \# = significantly different $(\mathrm{p} \leq 0.05)$ SI value from the vehicle control group by Shirley's or Dunn's test; \#\# = $(\mathrm{p} \leq 0.01)$. 
The positive controls utilized for the study of crude MCHM, 1-fluoro-2,4-dinitrobenzene (0.15\%), and isoeugenol (5\%) were shared controls with the study of MCHM. 1-Fluoro-2,4dinitrobenzene performed as expected; however, isoeugenol did not elicit the anticipated sensitizing response.

\section{Crude 4-Methylcyclohexanemethanol (Repeat Study)}

A repeat study of crude MCHM was conducted to confirm the results observed in the initial study and more clearly establish levels at which the test article induced sensitization in the absence of clinical toxicity. Crude MCHM was administered at concentrations of 1\%, 5\%, 25\%, $50 \%$, and $75 \%$. All mice survived to the end of the study (Table 14 and Table 15). Clinical signs of toxicity were observed on days 1 through 3 in the 75\% group and included eye squinting (in 8 of 13 mice) and isolation from cage mates (all 13 mice); isolation from cage mates was also observed on day 1 in all 13 mice in the 50\% group (Table 16). All clinical signs of toxicity were observed during the afternoon after treatment, and none was observed during morning observation the subsequent day. No clinical signs of toxicity were observed in the $1 \%$, $5 \%$, or $25 \%$ groups. Group mean body weights were not significantly affected by treatment (Table 15).

Table 14. Disposition of Female Mice in the Dermal Hypersensitivity and Irritancy Study of Crude 4-Methylcyclohexanemethanol (Repeat Study)

\begin{tabular}{lccccccc}
\hline & $\begin{array}{c}\text { Vehicle } \\
\text { Control }\end{array}$ & $\mathbf{1 \%}$ & $\mathbf{5 \%}$ & $\mathbf{2 5 \%}$ & $\mathbf{5 0 \%}$ & $\mathbf{7 5 \%}$ & $\begin{array}{c}\mathbf{0 . 1 5 \%} \\
\mathbf{D N F B}^{\mathbf{a}}\end{array}$ \\
\hline Animals Initially in Study & 13 & 13 & 13 & 13 & 13 & 13 & 13 \\
Terminal Removal & 13 & 13 & 13 & 13 & 13 & 13 & 13 \\
\hline
\end{tabular}

DNFB = 1-fluoro-2,4-dinitrobenzene.

aPositive control.

Table 15. Survival and Mean Body Weights of Female Mice in the Dermal Hypersensitivity and Irritancy Study of Crude 4-Methylcyclohexanemethanol (Repeat Study) ${ }^{\mathrm{a}}$

\begin{tabular}{lcccc}
\hline \multicolumn{1}{c}{ Concentration } & Survival $^{\mathbf{b}}$ & $\begin{array}{c}\text { Initial Body Weight } \\
\text { (g) }\end{array}$ & $\begin{array}{c}\text { Final Body Weight } \\
\text { (g) }\end{array}$ & $\begin{array}{c}\text { Absolute Weight } \\
\text { Gain or Loss }\end{array}$ \\
\hline Vehicle Control & $13 / 13$ & $16.9 \pm 0.3$ & $17.2 \pm 0.2$ & $0.2 \pm 0 . \mathbf{\Lambda}^{\mathbf{4}}$ \\
$1 \%$ & $13 / 13$ & $17.2 \pm 0.4$ & $17.3 \pm 0.3$ & $0.1 \pm 0.1$ \\
$5 \%$ & $13 / 13$ & $17.3 \pm 0.3$ & $17.8 \pm 0.3$ & $0.5 \pm 0.1$ \\
$25 \%$ & $13 / 13$ & $17.2 \pm 0.3$ & $17.5 \pm 0.3$ & $0.3 \pm 0.1$ \\
$50 \%$ & $13 / 13$ & $17.3 \pm 2.0$ & $17.7 \pm 0.3$ & $0.4 \pm 0.1$ \\
$75 \%$ & $13 / 13$ & $17.1 \pm 1.0$ & $17.6 \pm 0.3$ & $0.5 \pm 0.1$ \\
$0.15 \%$ DNFB $^{\mathrm{c}}$ & $13 / 13$ & $17.4 \pm 0.3$ & $17.7 \pm 0.3$ & $0.3 \pm 0.1$ \\
\hline
\end{tabular}

$\mathbf{\Delta \triangle}$ Significant trend $(\mathrm{p} \leq 0.01)$ by Jonckheere's test.

aWeights are given as mean \pm standard error.

bumber of animals surviving on day 6/number initially in group.

'Positive control; DNFB = 1-fluoro-2,4-dinitrobenzene. 
Table 16. Clinical Observations for Female Mice in the Dermal Hypersensitivity and Irritancy Study of Crude 4-Methylcyclohexanemethanol (Repeat Study)

\begin{tabular}{|c|c|c|c|c|c|c|c|}
\hline & $\begin{array}{l}\text { Vehicle } \\
\text { Control }\end{array}$ & $1 \%$ & $5 \%$ & $25 \%$ & $50 \%$ & $75 \%$ & $\begin{array}{c}\text { 0.15\% } \\
\text { DNFB }^{b}\end{array}$ \\
\hline $\mathbf{n}$ & 13 & 13 & 13 & 13 & 13 & 13 & 13 \\
\hline Animal Behavior, Isolation ${ }^{\mathrm{a}}$ & 0 & 0 & 0 & 0 & $13(1)$ & $13(1)$ & $13(1)$ \\
\hline Erythema, Ear, Bilateral, Mild & 0 & 0 & 0 & 0 & 0 & 0 & $13(5)$ \\
\hline Eye Shut, Bilateral & 0 & 0 & 0 & 0 & 0 & $8(1)$ & $4(1)$ \\
\hline \multicolumn{8}{|c|}{$\begin{array}{l}\text { DNFB = 1-fluoro-2,4-dinitrobenzene. } \\
\text { aNumber of animals with observation (study day first observed). } \\
\text { bPositive control. }\end{array}$} \\
\hline \multicolumn{8}{|c|}{$\begin{array}{l}\text { Ear thickness in the } 75 \% \text { group was significantly increased relative to that of the vehicle control } \\
\text { group on days } 3(1.63 \%) \text { and } 6(2.39 \%) \text { (Table } 17) \text {. Ear swelling was also increased in the } \\
100 / 80 \% \text { group in the initial study of crude MCHM, however, not to a significant extent } \\
\text { (Table } 12) \text {. No changes in ear thickness were observed in the remaining dosed groups (Table } 17)\end{array}$} \\
\hline
\end{tabular}


Table 17. Summary of Ear Thickness Measurement Data for Female Mice in the Dermal Hypersensitivity and Irritancy Study of Crude 4-Methylcyclohexanemethanol (Repeat Study) ${ }^{a}$

\begin{tabular}{|c|c|c|c|c|c|c|}
\hline Concentration & Day $1\left(\mathrm{~mm} \times 10^{-2}\right)$ & Day $3\left(\mathrm{~mm} \times 10^{-2}\right)$ & Day $6\left(\mathrm{~mm} \times 10^{-2}\right)$ & Day $3(\%)$ & Day 6 (\%) & Ear Weight (mg) \\
\hline Vehicle Control & $18.01 \pm 0.03^{\Delta \wedge}$ (13) & $17.92 \pm 0.04^{\boldsymbol{\Delta} \Delta}$ (13) & $17.56 \pm 0.04^{\Delta} \mathbf{\Delta}(13)$ & $0.02 \pm 0.24^{\Delta \wedge}(13)$ & $0.02 \pm 0.23^{\Delta \wedge}$ (13) & $8.62 \pm 0.10(5)$ \\
\hline $1 \%$ & $17.66 \pm 0.07 * *$ & $17.88 \pm 0.06(13)$ & $17.50 \pm 0.01(13)$ & $-0.20 \pm 0.31(13)$ & $-0.31 \pm 0.09(13)$ & $8.08 \pm 0.42(5)$ \\
\hline $5 \%$ & $17.52 \pm 0.06^{* *}(13)$ & $17.82 \pm 0.06(13)$ & $17.60 \pm 0.05(13)$ & $-0.52 \pm 0.36(13)$ & $0.24 \pm 0.26(13)$ & $8.9 \pm 0.58(5)$ \\
\hline $25 \%$ & $17.55 \pm 0.06^{* *}(13)$ & $17.89 \pm 0.05(13)$ & $17.58 \pm 0.04(13)$ & $-0.15 \pm 0.30(13)$ & $0.13 \pm 0.23(13)$ & $9.28 \pm 0.35(5)$ \\
\hline $50 \%$ & $17.47 \pm 0.05^{* *}(13)$ & $17.96 \pm 0.06(13)$ & $17.65 \pm 0.08(13)$ & $0.28 \pm 0.03(13)$ & $0.52 \pm 0.47(13)$ & $9.60 \pm 0.63(5)$ \\
\hline $75 \%$ & $17.40 \pm 0.04 * *(13)$ & $18.21 \pm 0.06^{* *}(13)$ & $17.99 \pm 0.06^{* *}(13)$ & $1.63 \pm 0.30 * *(13)$ & $2.39 \pm 0.33^{* *}(13)$ & $8.96 \pm 0.52(5)$ \\
\hline $0.15 \% \mathrm{DNFB}^{\mathrm{b}}$ & $17.35 \pm 0.06^{* *}(13)$ & $18.00 \pm 0.02(13)$ & $18.77 \pm 0.14^{* *}(13)$ & $0.50 \pm 0.14(13)$ & $6.77 \pm 0.79 * *(13)$ & $11.88 \pm 0.66^{* *}(5)$ \\
\hline
\end{tabular}

$\triangle \mathbf{\triangle}$ Significant trend $(\mathrm{p} \leq 0.01)$ by Jonckheere’s test.

**Significantly different $(\mathrm{p} \leq 0.01)$ from the vehicle control group by Shirley's or Dunn's test.

DNFB = 1-fluoro-2,4-dinitrobenzene.

${ }^{a}$ Ear thickness data are presented as mean \pm standard error (n); percentages are calculated as ear swelling (difference from vehicle control) using the equation: [mean measurement for both ears for each animal (day 3 or 6 ) - vehicle control mean ear thickness (day 3 or 6)]/[vehicle control mean ear thickness (day 3 or 6$) \times 100]$.

bPositive control. 
Generally, concentration-related increases in DPM values occurred, and the increases were significant at 50\% (68.29 DPM) and 75\% (128.43 DPM) (Table 18 and Figure 4). Increased DPM values correlated with concentration-related increases in SI values that were also significant in the 50\% (2.24) and 75\% (4.22) groups. The increase in DPM in the 50\% group occurred in the absence of irritation, suggesting that crude MCHM is a sensitizer. The positive control, DNFB (0.15\%), performed as expected. The concentration that would result in an SI of 3.0 (EC3) was calculated to be $60.0 \%$ (Figure 4 ).

Table 18. Summary of ${ }^{125}$ I-Udr Incorporation and Stimulation Index Data for Female Mice in the Dermal Hypersensitivity and Irritancy Study of Crude 4-Methylcyclohexanemethanol (Repeat Study) $^{\mathrm{a}}$

\begin{tabular}{llcc}
\hline \multicolumn{1}{c}{ Concentration } & $\mathbf{n}$ & Lymph Node Counts (DPM) & Stimulation Index \\
\hline Vehicle Control & 8 & $30.46 \pm 7.28^{\mathbf{\Lambda}}$ & $1.00 \pm 0.24^{\mathbf{\Lambda}}$ \\
$1 \%$ & 8 & $33.42 \pm 8.63$ & $1.10 \pm 0.28$ \\
$5 \%$ & 8 & $22.25 \pm 2.98$ & $0.73 \pm 0.10$ \\
$25 \%$ & 8 & $44.14 \pm 8.23$ & $1.45 \pm 0.27$ \\
$50 \%$ & 8 & $68.29 \pm 14.10^{*}$ & $2.24 \pm 0.46^{*}$ \\
$75 \%$ & 8 & $128.43 \pm 16.45^{* *}$ & $4.22 \pm 0.54^{* *}$ \\
$0.15 \%$ DNFB $^{\mathrm{b}}$ & 8 & $2,315.52 \pm 380.62^{* *}$ & $76.02 \pm 12.50^{* *}$ \\
\hline
\end{tabular}

$\triangle \triangle$ Significant trend $(\mathrm{p} \leq 0.01)$ by Jonckheere’s test.

*Significantly different ( $\mathrm{p} \leq 0.05$ ) from the vehicle control group by Shirley's or Dunn's test.

$* * \mathrm{p} \leq 0.01$.

DNFB = 1-fluoro-2,4-dinitrobenzene.

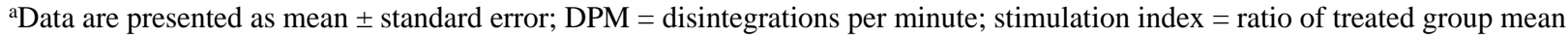
DPM/vehicle control group mean DPM.

bositive control. 


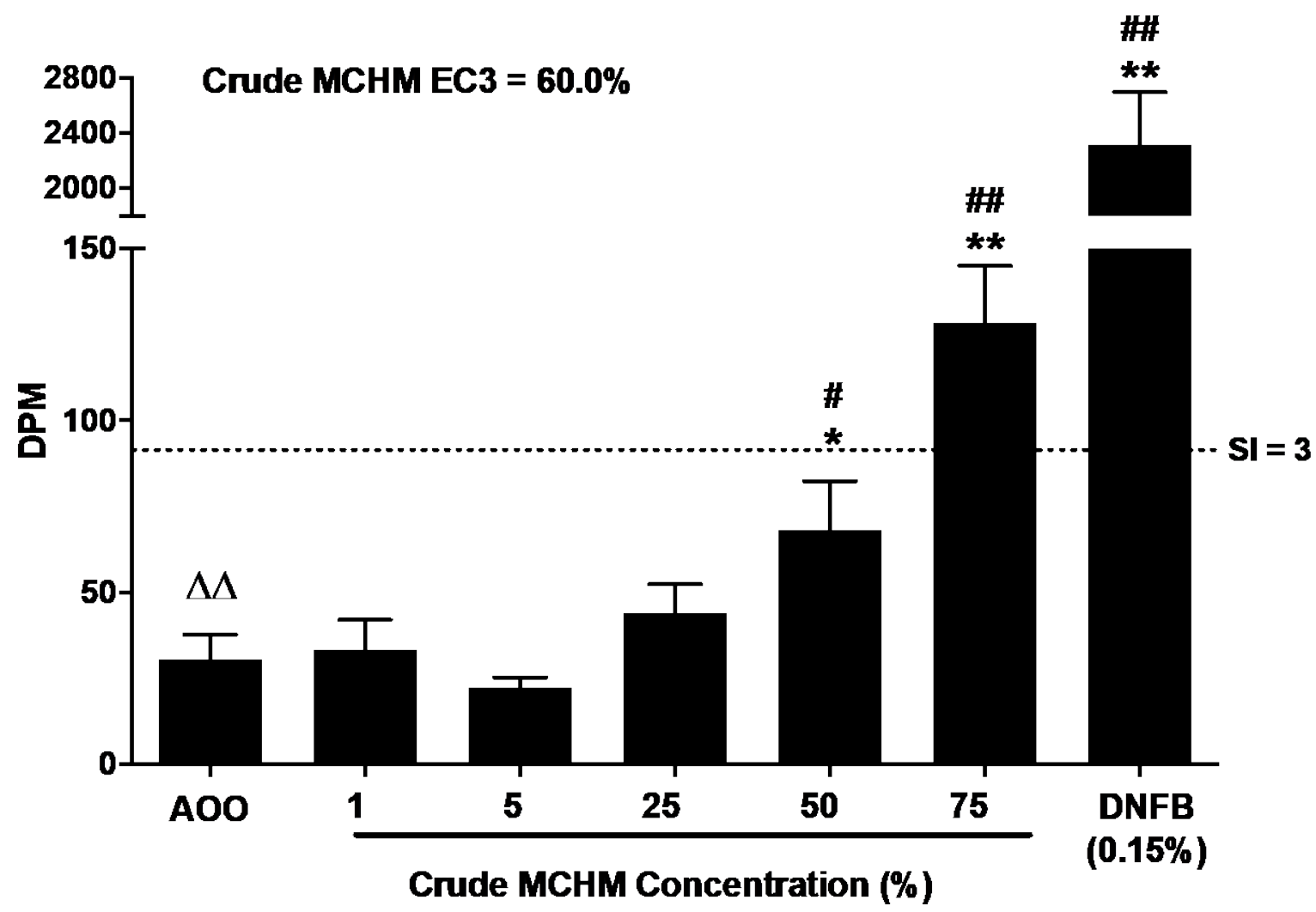

Figure 4. ${ }^{125}$ I-UdR Incorporation and Stimulation Index Data in the Dermal Hypersensitivity and Irritancy Study of Crude 4-Methylcyclohexanemethanol (Repeat Study)

AOO = acetone/olive oil vehicle control; DNFB = 1-fluoro-2,4-dinitrobenzene positive control; DPM = disintegrations per minute; MCHM = 4-methylcyclohexanemethanol; SI = stimulation index; EC3 = concentration of test article that results in an $\mathrm{SI}=3 ; \Delta \Delta=$ significant trend $(\mathrm{p} \leq 0.01)$ for DPM by Jonckheere's test; * = significantly different $(\mathrm{p} \leq 0.05)$ from the vehicle control group by Shirley's or Dunn's test; $* *=(\mathrm{p} \leq 0.01)$; \# = significantly different $(\mathrm{p} \leq 0.05)$ SI value from the vehicle control group by Shirley's or Dunn's test; \#\# = $(\mathrm{p} \leq 0.01)$. 


\section{Discussion}

The primary concern for human exposure to 4-methylcyclohexanemethanol (MCHM) is via occupational routes, primarily during handling or use of the chemical. However, on January 9, 2014, approximately 10,000 gallons of a chemical mixture containing predominantly MCHM was spilled into the Elk River, upstream of a municipal water source serving approximately 300,000 people in Charleston, West Virginia. ${ }^{10}$ Immediately following the spill, there were numerous reports of mild rashes and reddened skin due to dermal exposure to the contaminated water. ${ }^{24}$ Following nominations by the Centers for Disease Control and Prevention and the Agency for Toxic Substances and Disease Registry, the National Toxicology Program (NTP) conducted dermal hypersensitivity and irritancy studies of both MCHM and crude MCHM in female BALB/c mice.

In the initial study, MCHM (2\%, 20\%, and 100\%) and crude MCHM (1\%, 2\%, 5\%, 20\%, 40\%, and $100 \%$ ) formulations were applied to the ears of female BALB/c mice for 3 consecutive days via direct epicutaneous application. Two mice administered 100\% MCHM were euthanized moribund on day 1 of the study due to signs of morbidity, and the dose was subsequently lowered to $50 \%$. Also, due to clinical signs of toxicity in mice administered $100 \% \mathrm{MCHM}$, this dose was lowered to $80 \%$. A repeat study of crude MCHM was performed to confirm the observed dermal hypersensitivity response and more clearly establish levels at which the test article induced sensitization in the absence of clinical toxicity. Formulations of 1\%, 5\%, 25\%, $50 \%$, and 75\% crude MCHM were utilized in the repeat study.

MCHM induced dermal irritation at concentrations greater than 20\%. Administration of 20\% and $100 / 50 \%$ MCHM induced significant concentration-dependent increases in mean ear thickness on day 3 (4.44\% and 6.47\%, respectively) and day 6 (3.54\% and 5.30\%, respectively). For crude MCHM, there was minimal evidence of irritation and the results were inconsistent between studies. In the initial study a statistically significant increase in irritation was observed on day 6 in the $20 \%$ group only (3.86\%) and not at doses of 40 or $100 / 80 \%$. In the repeat study significant changes in ear thickness occurred only at $75 \%$, with no evidence of a concentration-dependent response. The results from these studies indicate that MCHM should be considered a dermal irritant on the basis of the Globally Harmonized System of Classification and Labelling of Chemicals. ${ }^{46}$ These results are consistent with those from studies previously conducted by Eastman Kodak Company, which demonstrated that topical administration of MCHM and crude MCHM caused strong dermal irritation in guinea pigs (MCHM), albino rabbits (crude MCHM), and rats (crude MCHM). ${ }^{16 ; 25 ; 27 ; 18 ; 26}$ The results of the studies described in this Immunotoxicity Report suggest that MCHM is likely a more potent irritant than crude MCHM. These results also suggest that MCHM itself, and not the other chemicals found in crude MCHM, was responsible for the dermal irritation reported following the Elk River spill.

The local lymph node assay (LLNA) is the standard assay for evaluating the potential of a compound to act as a skin sensitizer. ${ }^{32-34}$ Skin sensitization potential is assessed as a measurement of lymph node cell proliferation in response to application of the compound in question, and a compound is classified as a skin sensitizer if one or more concentrations causes a threefold or greater increase in lymph node cell proliferation relative to vehicle control (stimulation index $[\mathrm{SI}] \geq 3$ ); the effective concentration of a compound that induces an SI equal to 3 is known as the EC3. In these studies, crude MCHM was determined to be a sensitizer, with 
an EC3 in the concentration range of 35\% to 60\%. This is in contrast to sensitization results using the guinea pig footpad test and previously reported by Eastman Kodak Company ${ }^{27}$; however, this is likely due to the difference in testing methodologies.

MCHM was not deemed to be a skin sensitizer in these studies. These results suggest that although MCHM is a dermal irritant, other chemical components of crude MCHM are likely responsible for the observed stimulation in the LLNA. This is supported by results from structure-activity relationship analyses performed by NTP that indicated some of the minor components of crude MCHM were potential sensitizers. ${ }^{47}$ Inconsistencies were observed in the studies of crude MCHM. In the initial study, administration of 20\% crude MCHM significantly increased ear swelling, whereas administration of 50\% crude MCHM did not. The lack of a concentration-dependent trend suggests that the effects observed at 20\% MCHM might not have been treatment related. Similarly, in the repeat study of crude MCHM, treatment with 75\% crude MCHM significantly increased ear swelling but treatment with other concentrations did not. It has been reported that dermal irritants could also induce lymph node cell proliferation, possibly resulting in false positives in the LLNA ${ }^{48}$; 32 ; 33 ; however, the irritancy responses were not considered to be strong enough to cause additional proliferation in the draining lymph nodes, and, therefore, support the identification of crude MCHM as a skin sensitizer.

A decrease in the SI was observed following treatment with MCHM (2\%, 20\%, and 100/50\%) relative to vehicle control; this decrease was significant in the 2\% MCHM group and lessened with increasing MCHM concentration. The SI value for the vehicle control animals (1.00 \pm 0.22$)$ was similar to that of the vehicle controls for the repeat study of crude MCHM (1.00 \pm 0.24$)$, indicating that the vehicle was likely not the reason for the observed decrease in SI. The reason for the low SI values in mice treated with MCHM is unclear; however, it could be due to the weak sensitizing ability of MCHM as only crude MCHM was determined to be a skin sensitizer in these studies.

Two positive controls were used in this study, 1-fluoro-2,4-dinitrobenzene and isoeugenol. 1-Fluoro-2,4-dinitrobenzene and isoeugenol are standard positive controls for dermal hypersensitivity and irritancy studies, with 1-fluoro-2,4-dinitrobenzene acting as a strong sensitizer and isoeugenol acting as a weak sensitizer. In these studies, 1-fluoro-2,4dinitrobenzene performed as expected; however, isoeugenol did not elicit the anticipated sensitizing response. SI and EC3 values for the different categories of sensitizers (nonsensitizing, weak, moderate, strong, and extreme) have a wide range ${ }^{49}$ and SI values for isoeugenol, in particular, are historically variable. Despite the unexpected weak response of isoeugenol, the SI values for 1-fluoro-2,4-dinitrobenzene (10.02 and 76.02) and isoeugenol (1.64) fell within the ranges of historical values for both the NTP's and the study laboratory's designations of potent and weak sensitizers. In addition, as both the crude MCHM and 1-fluoro-2,4-dinitrobenzene LLNA results were repeated, the lack of response from isoeugenol was considered an isolated result.

The results of these studies indicate that the estimated lowest-observed-effect levels for MCHM (20\% based on irritancy) and crude MCHM (5\% based on dermal sensitization) were significantly higher than those levels found in the area's residential tap water immediately following the Elk River spill (up to $3.35 \mathrm{ppm}$ ), which, in turn, were higher than that of the Centers for Disease Control and Prevention's short-term drinking water screening level of 1 ppm. ${ }^{12}$ Despite the low levels of MCHM detected in the area's tap water following the spill, 
reports of dermal irritation were increased in the population using the contaminated water. The dosing pattern utilized in the studies reported here was a single, daily administration, whereas the pattern of human exposure following the spill was potentially more extensive due to daily showering, bathing, and hand washing habits.

Under the conditions of these dermal hypersensitivity and irritancy studies, MCHM induced dermal irritation in female mice, as indicated by increases in ear swelling at concentrations of $20 \%$ and $100 / 50 \%$. Crude MCHM was identified as a skin sensitizer, with an EC3 value in the concentration range of $35 \%$ to $60 \%$. Dermal exposure to crude MCHM produced minimal irritant effects, indicated by increases in ear swelling at concentrations of $20 \%$ and $75 \%$, which were inconsistent across repeat studies. 


\section{References}

1. Eastman Chemical Company. Safety data sheet: Crude MCHM, version 3.0. Kingsport, TN: Eastman Chemical Company; 2015.

2. Lide DR, Milne GWA. Handbook of data on organic compounds. Vol. I. No. 2228. 3rd ed. Boca Raton, FL: CRC Press, Inc. 1994.

3. United States Environmental Protection Agency (USEPA). Estimation Programs Interface Suite $^{\mathrm{TM}}$ for Microsoft Windows $\mathbb{C}$, Ver. 4.1. Washington, DC: United States Environmental Protection Agency; 2014. https://www.epa.gov/tsca-screening-tools/epi-suitetm-estimationprogram-interface

4. Foreman WT, Rose DL, Chambers DB, Crain AS, Murtagh LK, Thakellapalli H, Wang KK. Determination of (4-methylcyclohexyl) methanol isomers by heated purge-and-trap GC/MS in water samples from the 2014 Elk River, West Virginia, chemical spill. Chemosphere. 2015; 131:217-224. http://dx.doi.org/10.1016/j.chemosphere.2014.11.006

5. Gallagher DL, Phetxumphou K, Smiley E, Dietrich AM. Tale of two isomers: Complexities of human odor perception for cis-and trans-4-methylcyclohexane methanol from the chemical spill in West Virginia. Environ Sci Technol. 2015; 49(3):1319-1327.

http://dx.doi.org/10.1021/es5049418

6. National Library of Medicine (NLM). ChemIDplus: 4-methoxymethylcyclohexylmethanol. Bethesda, MD: U.S. Department of Health and Human Services, National Institutes of Health, National Library of Medicine, Toxicology Data Network; 2016.

https://chem.nlm.nih.gov/chemidplus/rn/98955-27-2 [Accessed: September 21, 2016]

7. National Library of Medicine (NLM). ChemIDplus: Methyl 4 methylcyclo-hexanecarboxylate. Bethesda, MD: U.S. Department of Health and Human Services, National Institutes of Health, National Library of Medicine, Toxicology Data Network; 2016. https://chem.nlm.nih.gov/chemidplus/rn/51181-40-9 [Accessed: September 21, 2016]

8. Eastman Chemical Company. Technical data sheet: Eastman ${ }^{\mathrm{TM}}$ DMCD. Kingsport, TN: Eastman Chemical Company; 2008.

9. Eastman Chemical Company. Technical data sheet: Eastman ${ }^{\mathrm{TM}}$ CHDM-D, CAS No. 105-088.1,4-cyclohexanedimethanol. Kingsport, TN: Eastman Chemical Company; 2008.

10. West Virginia Office of the Governor. After action review: Emergency response to January 9, 2014, Freedom Industries chemical leak. Charleston, WV: State of West Virginia, Office of the Governor, Homeland Security and Emergency Management \& West Virginia National Guard; 2015. http://governor.wv.gov/Documents/After\%20Action\%20Review.PDF [Accessed: September 21, 2016]

11. West Virginia Poison Center (WVPC). Factsheet: Freedom Industries, Elk River chemical spill, February 10, 2014. Washington, DC: West Virginia Poison Center \& Georgetown University, Mid-Atlantic Center for Children’s Health and the Environment; 2014. 
http://www.wvlegislature.gov/legisdocs/2014/committee/interim/water/Documents/Bureau\%20f or\%20Public\%20Health\%20Packet.pdf [Accessed: September 21, 2016]

12. Centers for Disease Control Prevention (CDC). Summary report of short-term screening level calculation and analysis of available animal studies for MCHM. Atlanta, GA: U.S. Department of Health and Human Services, Public Health Service, Centers for Disease Control and Prevention; 2014. http://emergency.cdc.gov/chemical/MCHM/westvirginia2014/mchm.asp [Accessed: September 21, 2016]

13. Whelton AJ, McMillan L, Connell M, Kelley KM, Gill JP, White KD, Gupta R, Dey R, Novy C. Residential tap water contamination following the Freedom Industries chemical spill: Perceptions, water quality, and health impacts. Environ Sci Technol. 2015; 49(2):813-823. http://dx.doi.org/10.1021/es5040969

14. Toxicology Excellence for Risk Assessment (TERA). Report of expert panel review of screening levels for exposure to chemicals from the January 2014 Elk River spill. Charleston, WV: Toxicology Excellence for Risk Assessment \& West Virginia Division of Homeland Security and Emergency Management, West Virginia Testing Assessment Project (WV TAP); 2014.

15. DiVincenzo GD, Ziegler DA. Metabolic fate of 1, 4-cyclo [14C] hexanedimethanol in rats. Toxicol Appl Pharmacol. 1980; 52(1):10-15. http://dx.doi.org/10.1016/0041-008X(80)90241-0

16. Eastman Kodak Company. Acute toxicity of 4-methylcyclohexane methanol. Rochester, NY: Eastman Kodak Company, Health and Environment Laboratory, Toxicological Sciences Laboratory; 1990. TX-90-5; HAEL No. 89 0081; Accession No. 907670. http://www.eastman.com/Literature_Center/Misc/Pure_Distilled_MCHMAcute_Toxicity_Battery_Containing_5_Study_Reports.pdf

17. Eastman Kodak Company. Four-week oral toxicity study of 4-methylcyclohexane methanol in the rat. Rochester, NY: Eastman Kodak Company, Health and Environment Laboratory, Toxicological Sciences Laboratory; 1990. TX-89-296; HAEL No. 89-0081; Accession. No. 907670. http://www.eastman.com/Literature_Center/Misc/Pure_Distilled_MCHM-28Day_Oral_Feeding_Study.pdf

18. Eastman Kodak Company. Crude MCHM: Acute dermal toxicity study in the rat (final report). Rochester, NY: Eastman Kodak Company, Health and Environment Laboratory, Toxicological Sciences Laboratory; 1998. TX-97-308; HAEL No. 97-0216; EAN 972790; PM No. 19717-00. http://www.eastman.com/Literature_Center/Misc/Crude_MCHMAcute_Dermal_Toxicity_Study.pdf

19. Eastman Kodak Company. Crude MCHM: Acute oral toxicity study in the rat - first study (final report). Rochester, NY: Eastman Kodak Company, Health and Environment Laboratory, Toxicological Sciences Laboratory; 1998. TX-97-306; HAEL No. 97-0216; EAN 972790; PM No. 18717-00. http://www.eastman.com/Literature_Center/Misc/Crude_MCHM-

First_Acute_Oral_Study.pdf

20. Eastman Kodak Company. Crude MCHM: Acute oral toxicity study in the rat - second study (final report). Rochester, NY: Eastman Kodak Company, Health and Environment Laboratory, Toxicological Sciences Laboratory; 1999. TX-99-188; HAEL No. 97-0216; EAN 972790; PM 
No. 18717-00. http://www.eastman.com/Literature_Center/Misc/Crude_MCHMSecond_Acute_Oral_Study.pdf

21. United States Environmental Protection Agency (USEPA). High Production Volume Information System (HPVIS) for 1,4-cyclohexanedicarboxylic acid, dimethyl ester (CAS No. 9460-0). Washington, DC: United States Environmental Protection Agency; 2016. http://ofmpub.epa.gov/oppthpv/quicksearch.display?pChem=101465 [Accessed: September 21, 2016]

22. Eastman Chemical Company. Safety data sheet: Eastman ${ }^{\mathrm{TM}}$ DMCD, version 2.1. Kingsport, TN: Eastman Chemical Company; 2016.

23. United States Environmental Protection Agency (USEPA). Screening-level hazard characterization for high production volume chemicals: 1,4-cyclohexanedimethanol (CAS No. 105-08-8) 9th CI Name; 1,4 cyclohexanemethanol. Washington, DC: United States Environmental Protection Agency, Office of Pollution Prevention and Toxics, High Production Volume Chemicals Branch, Risk Assessment Division; 2007.

24. Schade CP, Wright N, Gupta R, Latif DA, Jha A, Robinson J. Self-reported household impacts of large-scale chemical contamination of the public water supply, Charleston, West Virginia, USA. PLoS One. 2015; 10(5):e0126744.

http://dx.doi.org/10.1371/journal.pone.0126744

25. Eastman Kodak Company. Crude MCHM: Acute dermal irritation study in the rabbit (final report). Rochester, NY: Eastman Kodak Company, Health and Environment Laboratory, Toxicological Sciences Laboratory; 1997. TX-97-256; HAEL No. 97-0216; EAN 972790; PM No. 18717-00. http://www.eastman.com/Literature_Center/Misc/Crude_MCHMSkin_Irritation_Study.pdf

26. Eastman Kodak Company. Crude MCHM: A two-week dermal toxicity study in the rat (final report). Rochester, NY: Eastman Kodak Company, Health and Environment Laboratory, Toxicological Sciences Laboratory; 1999. TX-98-129; HAEL No. 7-0216; EAN 972790; PM No. 18717-00. http://www.eastman.com/Literature_Center/Misc/Crude_MCHM-14Day_Dermal_Study.pdf

27. Eastman Kodak Company. Crude MCHM: Skin sensitization study (footpad method) in the guinea pig (final report). Rochester, NY: Eastman Kodak Company, Health and Environment Laboratory, Toxicological Sciences Laboratory; 1997. TX-97-271; HAEL No. 97-0216; EAN 972790; PM No. 18717-00. http://www.eastman.com/Literature_Center/Misc/Crude_MCHM$\underline{\text { Skin_Sensitization.pdf }}$

28. National Toxicology Program (NTP). NTP update: West Virginia chemical spill: High throughput screening assays. Research Triangle Park, NC: U.S. Department of Health and Human Services, Public Health Service, National Toxicology Program; 2014. http://ntp.niehs.nih.gov/ntp/research/areas/wvspill/hts_wvupdate_508.pdf [Accessed: September $21,2016]$

29. Hou F, Xing C, Li B, Cheng J, Chen W, Zhang M. Application of BALB/C mouse in the local lymph node assay:BrdU-ELISA for the prediction of the skin sensitizing potential of chemicals. $\mathrm{J}$ Pharmacol Toxicol Methods. 2015; 72:53-58. http://dx.doi.org/10.1016/j.vascn.2015.01.001 
30. Lee YS, Yi JS, Seo SJ, Kim JH, Jung MS, Seo IK, Ahn I, Ko K, Kim TS, Lim KM et al. Comparison of BALB/c and CBA/J mice for the local lymph node assay using bromodeoxyuridine with flow cytometry (LLNA: BrdU-FCM). Regul Toxicol Pharm. 2017; 83:13-22. http://dx.doi.org/10.1016/j.yrtph.2016.10.021

31. Woolhiser MR, Munson AE, Meade BJ. Comparison of mouse strains using the local lymph node assay. Toxicology. 2000; 146(2-3):221-227. http://dx.doi.org/10.1016/s0300483x(00)00152-9

32. Gerberick GF, Robinson MK, Ryan CA, Dearman RJ, Kimber I, Basketter DA, Wright Z, Marks JG. Contact allergenic potency: Correlation of human and local lymph node assay data. Am J Contact Dermat. 2001; 12(3):156-161.

33. International Coordinating Committee on the Validation of Alternative Methods (ICCVAM). Recommended performance standards: Murine local lymph node assay. Research Triangle Park, NC: National Institutes of Health, National Institute of Environmental Health Sciences; 2009. NIH Publication No. 09-7357.

34. International Coordinating Committee on the Validation of Alternative Methods (ICCVAM). ICCVAM test method evaluation report: Usefulness and limitations of the murine local lymph node assay for potency categorization of chemicals causing allergic contact dermatitis in humans. Research Triangle Park, NC: National Institutes of Health, National Institute of Environmental Health Sciences; 2011. NIH Publication No. 11-7709.

35. Kimber I, Basketter DA, Berthold K, Butler M, Garrigue JL, Lea L, Newsome C, Roggeband R, Steiling W, Stropp G. Skin sensitization testing in potency and risk assessment. Toxicol Sci. 2001; 59(2):198-208. http://dx.doi.org/10.1093/toxsci/59.2.198

36. Dunnett CW. A multiple comparison procedure for comparing several treatments with a control. J Am Stat Assoc. 1955; 50(272):1096-1121. http://dx.doi.org/10.1080/01621459.1955.10501294

37. Williams DA. A test for differences between treatment means when several dose levels are compared with a zero dose control. Biometrics. 1971; 27:103-117.

http://dx.doi.org/10.2307/2528930

38. Williams DA. The comparison of several dose levels with a zero dose control. Biometrics. 1972; 28:519-531. http://dx.doi.org/10.2307/2556164

39. Shirley E. A non-parametric equivalent of Williams' test for contrasting increasing dose levels of a treatment. Biometrics. 1977; 33:386-389. http://dx.doi.org/10.2307/2529789

40. Williams DA. A note on Shirley's nonparametric test for comparing several dose levels with a zero-dose control. Biometrics. 1986; 42:183-186. http://dx.doi.org/10.2307/2531254

41. Dunn OJ. Multiple comparisons using rank sums. Technometrics. 1964; 6(3):241-252. http://dx.doi.org/10.1080/00401706.1964.10490181

42. Jonckheere AR. A distribution-free k-sample test against ordered alternatives. Biometrika. 1954; 41(1/2):133-145. http://dx.doi.org/10.2307/2333011 
43. Dixon WJ, Massey FJ, Jr. Introduction to statistical analysis. 2nd ed. New York: McGrawHill Book Company, Inc.; 1957. p. 276-278, 412.

44. Code of Federal Regulations (CFR). 21:Part 58.

45. National Toxicology Program (NTP). IMM-01: Data. Research Triangle Park, NC; 2020. https://doi.org/10.22427/NTP-DATA-IMM-01

46. Occupational Safety and Health Administration (OSHA). Globally harmonized system of classification and labelling of chemicals. 2015.

https://www.osha.gov/dsg/hazcom/ghsguideoct05.pdf

47. National Toxicology Program (NTP). West Virginia chemical spill, structure-activity relationship analysis, supporting data files. Research Triangle Park, NC: U.S. Department of Health and Human Services, Public Health Service, National Toxicology Program; 2016. https:/tools.niehs.nih.gov//cebs3/wvspill

48. Dearman RJ, Basketter DA, Kimber I. Local lymph node assay: Use in hazard and risk assessment. J Appl Toxicol. 1999; 19(5):299-306. http://dx.doi.org/10.1002/(SICI)10991263(199909/10)19:5<299::AID-JAT591>3.0.CO;2-C

49. Hoffmann S. LLNA variability: An essential ingredient for a comprehensive assessment of non-animal skin sensitization test methods and strategies. ALTEX. 2015; 32(4):379-383.

50. Advanced Chemistry Development Inc. SciFinder ${ }^{\circledR}$ Spectrum ID 34885035-HNMR. Predicted NMR data calculated using Advanced Chemistry Development, Inc., software V11.01. Toronto, Ontario, Canada; 1994.

51. American Chemical Society (ACS). SciFinder® Spectrum ID BR089294. 2014.

52. American Chemical Society (ACS). SciFinder® Spectrum ID NC_05067. 2014.

53. National Institute of Standards and Technology (NIST). Mass spectral library. Gaithersburg, MD: National Institute of Standards and Technology; 2008. Version d.0F; trans: ID 18215, cis: ID 18228.

54. Allen CFH, Ball WL, Young DM. Dihydro-p-tolualdehyde. Can J Res. 1933; 9(2):169-174. http://dx.doi.org/10.1139/cjr33-078

55. Advanced Chemistry Development Inc. ACD/ChemSketch v. 10.01, ACD/SpecManager v. 10.02. ACD/C+H NMR Predictors and DB v. 10.02, and ACD/PhysChem Database v. 10.01. Toronto, Ontario, Canada: ACD/Labs.

56. National Institute of Advanced Industrial Science and Technology (NIAIST). SDBS No. 16005, CDS-02-723. 2016. http://sdbs.db.aist.go.jp/sdbs/ [Accessed: February 9, 2016]

57. National Institute of Advanced Industrial Science and Technology (NIAIST). SDBS No. 16005, HSP-42-796. 2016. http://sdbs.db.aist.go.jp/sdbs [Accessed: February 9, 2016]

58. National Institute of Advanced Industrial Science and Technology (NIAIST). SDBS No. 16005, IR-NIDA-00569. 2016. http://sdbs.db.aist.go.jp/sdbs/ [Accessed: February 9, 2016] 
59. National Institute of Standards and Technology (NIST). Wiley Registry: Mass spectral library. Gaithersburg, MD: National Institute of Standards and Technology; 2005. Version G1035B/Rev. D.06.00, Entry Nos. 339581, 339455, 338455.

60. Sigma-Aldrich library. 2014. http://www.sigmaaldrich.com/spectra/fnmr/FNMR010098.pdf

61. National Institute of Advanced Industrial Science and Technology (NIAIST). SDBS No. 10307, IR-NIDA-64369. 2010. http://sdbs.db.aist.go.jp/sdbs/ [Accessed: May 25, 2010] 


\section{Appendix A. Chemical Characterization and Dose Formulation Studies}

\section{Table of Contents}

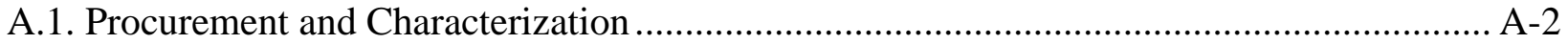

A.2. Preparation and Analysis of Dose Formulations..................................................... A-4

\section{Tables}

Table A-1. Gas Chromatography Systems Used in the Dermal Hypersensitivity and Irritancy Studies of 4-Methylcyclohexanemethanol

Table A-2. Preparation and Storage of Dose Formulations in the Dermal Hypersensitivity and Irritancy Studies of 4-Methylcyclohexanemethanol

Table A-3. Results of Analyses of Dose Formulations Administered to Female Mice on Day 3 in the Dermal Hypersensitivity and Irritancy Study of 4Methylcyclohexanemethanol and Crude 4-Methylcyclohexanemethanol (Initial Study)

Table A-4. Results of Analyses of Dose Formulations Administered to Female Mice in the Dermal Hypersensitivity and Irritancy Study of Crude 4-Methylcyclohexanemethanol (Repeat Study)....

\section{Figures}

Figure A-1. Fourier Transform Infrared Absorption Spectrum of 4Methylcyclohexanemethanol A-8

Figure A-2. Fourier Transform Proton Nuclear Magnetic Resonance Spectrum of 4-Methylcyclohexanemethanol A-8 


\section{A.1. Procurement and Characterization}

\section{A.1.1. 4-Methylcyclohexanemethanol}

4-Methylcyclohexanemethanol (MCHM) was obtained from TCI America (Portland, OR) in one lot (KDY3F). Crude MCHM was obtained from Eastman Chemical Company (Kingsport, TN) in one lot (TP14044373). Identity, purity, and stability analyses were conducted by the analytical chemistry laboratory at MRIGlobal (Kansas City, MO). Reports on analyses performed in support of the MCHM studies are on file at the National Institute of Environmental Health Sciences.

Lot KDY3F of the pure chemical, a clear, colorless liquid, was identified as MCHM using Fourier transform infrared (FTIR) spectroscopy, Fourier transform (FT) proton and carbon-13 nuclear magnetic resonance (NMR) spectroscopy, and gas chromatography (GC) with mass spectrometry (MS) detection. In addition, the boiling point, density, and octanol:water partition coefficient were determined. All spectra were consistent with isomers of the proposed structure and literature spectra of MCHM. ${ }^{50-53}$ Representative FTIR and FT proton NMR spectra are presented in Figure A-1 and Figure A-2, respectively. Two components tentatively identified as cis- and trans- isomers of MCHM were observed for the test article using GC/MS. The boiling point of the test chemical was $199.4^{\circ} \mathrm{C}$ (consistent with a literature reference value of $202^{\circ} \mathrm{C}$ ), ${ }^{54}$ the relative density was $0.9203 \mathrm{~g} / \mathrm{mL}$, and the octanol:water partition coefficient, $\log \mathrm{P}$, was 2.55 .

Karl Fischer titration was used to determine the water content of lot KDY3F. Elemental analyses for carbon, hydrogen, and nitrogen were conducted by Galbraith Laboratories, Inc. (Knoxville, $\mathrm{TN}$ ). The purity profile was determined using GC with flame ionization detection (FID) and two columns with differing polarities.

For lot KDY3F, Karl Fischer titration indicated $0.21 \%$ water. Elemental analyses for carbon, hydrogen, and nitrogen were consistent with the theoretical values for MCHM. GC/FID analysis by system A (Table A-1) detected two major peaks with a combined area of $99.97 \%$ of the total peak area and no impurities with areas greater than or equal to $0.05 \%$ of the total peak area. The relative areas of the two major peaks indicated that MCHM consisted of $67.99 \%$ cis- and $31.98 \%$ trans-isomers. GC/FID by system B detected two major peaks with a combined relative area of 99.83\% (with relative areas of $67.80 \%$ ([cis] and 32.03\% [trans] isomers), and two minor impurities totaling $0.13 \%$ of the total peak area. The overall purity of lot KDY3F was determined to be greater than or equal to $99.8 \%$.

A chemical identity and purity screen of lot TP14044373 of the crude test chemical, a clear liquid, was performed using GC/MS. The test article was found to be a $90.35 \%$ mix of the cis(33.45\%) and trans- (56.90\%) isomers of MCHM on the basis of the relative areas of the two major peaks. Six impurity components with a relative percent total area greater than or equal to $0.05 \%$ were observed, with a combined area of $9.66 \%$. Three of these impurity components (each with an individual relative percent area greater than 1\%) were tentatively identified as cyclohexanemethanol (1.82\%), and a mix of the cis- and trans-isomers of 1,4-cyclohexanedimethanol (7.15\%). Three minor impurities (each with an individual relative percent area between $0.05 \%$ and $1.0 \%$ ) were tentatively identified as methyl 4-methylcyclohexanecarboxylate (0.50\%), cis-octahydroisobenzofuran (0.13\%), and 2-ethyl-1- 
hexanol (0.06\%). The purity of lot TP14044373, relative to MCHM isomers, was estimated to be greater than $90 \%$.

Stability studies of lot KDY3F were conducted using GC/FID by system A. These studies indicated that MCHM was stable as a bulk chemical for at least 14 days when stored in amber glass vials under an inert headspace at temperatures up to $60^{\circ} \mathrm{C}$. To ensure stability, both bulk chemicals were stored at room temperature in amber glass bottles, and MCHM was stored under an inert headspace.

\section{A.1.2. Isoeugenol}

Isoeugenol was obtained from Sigma-Aldrich, Inc. (St. Louis, MO), in one lot (05622BEV) that was used as a positive control in the initial dermal hypersensitivity and irritancy study. Identity, purity, and stability analyses were conducted by the analytical chemistry laboratory at Research Triangle Institute (RTI) (Research Triangle Park, NC).

The identity of lot 05622BEV, received as a clear liquid, was determined using FTIR and proton and carbon-13 NMR spectroscopy and GC/MS spectrometry. All spectra were consistent with the structure of isoeugenol and literature spectra, where available. ${ }^{55-59}$ An accurate molecular mass was measured using ultra-high-performance liquid chromatography (UHPLC)/time-offlight (TOF) MS; results were within $1.2 \mathrm{ppm}$ of the theoretical mass (165.0910 Da) for isoeugenol.

Karl Fischer titration was used to determine the water content of lot 05622BEV. Elemental analyses for carbon, hydrogen, and oxygen were conducted by Galbraith Laboratories, Inc. The purity was determined using GC/FID and UHPLC with photodiode array (PDA) detection. The Acquity ${ }^{\circledR}$ UHPLC/PDA system consisted of a UHP liquid chromatograph, a PDA detector (254 nm), and an ethylene bridged hybrid C18 column (2.1 mm $\times 50 \mathrm{~mm}, 1.7 \mu \mathrm{m}$ particle size), all from Waters Corporation (Milford, MA). The mobile phases consisted of A) 10:90:0.1 acetonitrile:deionized water:acetic acid and B) 90:10:0.1 acetonitrile:deionized water:acetic acid, programmed with a gradient starting at $100 \%$ A for 1 minute, then to $50 \%$ B in 7 minutes, then to $100 \% \mathrm{~B}$ in 1 minute, then reversed to $100 \% \mathrm{~A}$ in 1 minute, and held for 2 minutes; the flow rate was $0.6 \mathrm{~mL} / \mathrm{minute}$.

For lot 05622BEV, Karl Fischer titration indicated 0.23\% water. Elemental analyses for carbon, hydrogen, and oxygen were in agreement with the theoretical values for isoeugenol. GC/FID analysis by system $\mathrm{C}$ indicated two major isomer peaks (totaling $98.7 \%$ of the total peak area) and two impurities ( $0.7 \%$ and $0.4 \%$ of the total peak area). UHPLC/PDA analysis indicated two major isomer peaks (totaling $99.1 \%$ of the total peak area) and two impurities $(0.6 \%$ and $0.1 \%$ of the total peak area). The overall purity of lot $05622 \mathrm{BEV}$ was determined to be greater than or equal to $98.7 \%$.

Stability studies of lot $05622 \mathrm{BEV}$ conducted using GC/FID by system C indicated that isoeugenol was stable as a bulk chemical for at least 14 days when stored in amber glass vials sealed with Teflon-lined caps at temperatures up to $60^{\circ} \mathrm{C}$. To ensure stability, the bulk chemical was stored at room temperature under nitrogen. 


\section{A.1.3. 1-Fluoro-2,4-dinitrobenzene}

1-Fluoro-2,4-dinitrobenzene was obtained from Sigma-Aldrich, Inc., in one lot (BCBN2339V) that was used as a positive control in the initial and repeat hypersensitivity and irritancy studies. Identity, purity, and stability analyses were conducted by the analytical chemistry laboratory at RTI.

The identity of lot BCBN2339V, a clear liquid, was determined using FTIR and proton, carbon13, and fluorine-19 NMR spectroscopy and GC/MS spectrometry. All spectra were consistent with the structure of 1-fluoro-2,4-dinitrobenzene and literature spectra, where available. ${ }^{60 ; 55 ; 61 ; 59}$ An accurate molecular mass was measured using UHPLC/TOF MS; results were within $2.2 \mathrm{ppm}$ of the theoretical mass for 1-fluoro-2,4-dinitrobenzene.

The water content of lot BCBN2339V was determined using Karl Fischer titration. Elemental analyses for carbon, hydrogen, nitrogen, oxygen, and fluorine were conducted by Galbraith Laboratories, Inc. The purity was determined using GC/FID and UHPLC with PDA detection. The Acquity ${ }^{\circledR}$ UHPLC/PDA system consisted of a UHP liquid chromatograph, a PDA detector ( $240 \mathrm{~nm}$ ), and an ethylene bridged hybrid C18 column $(2.1 \mathrm{~mm} \times 50 \mathrm{~mm}, 1.7 \mu \mathrm{m}$ particle size), all from Waters Corporation. The mobile phases consisted of A) water and B) acetonitrile, programmed with a gradient starting at $10 \% \mathrm{~B}$ for 1 minute, then to $30 \% \mathrm{~B}$ in 7 minutes, then to $100 \% \mathrm{~B}$ in 0.5 minutes, held for 0.5 minutes, then reversed to $10 \% \mathrm{~B}$ in 0.5 minutes, and held for 2.5 minutes; the flow rate was $0.6 \mathrm{~mL} /$ minute.

For lot BCBN2339V, the water content was less than the limit of quantitation of $0.1 \%$. Elemental analyses for carbon, hydrogen, nitrogen, and oxygen were in agreement with the theoretical values for 1-fluoro-2,4-dinitrobenzene; fluorine was not accurately quantitated due to interference with oxygen. GC/FID using system C indicated one major peak (99.6\% of the total peak area), and two impurity peaks ( $0.2 \%$ each of the total peak area). UHPLC/PDA analysis indicated one major peak (99.4\% of the total peak area) and three impurity peaks $(0.1 \%, 0.2 \%$, and $0.3 \%$ of the total peak area). The overall purity of lot BCBN2339V was determined to be greater than or equal to $99.4 \%$.

Stability studies of lot BCBN2339V conducted using GC/FID by system C indicated that 1fluoro-2,4-dinitrobenzene was stable as a bulk chemical for at least 14 days when stored in amber glass vials sealed with Teflon-lined caps at temperatures up to $60^{\circ} \mathrm{C}$. To ensure stability, the bulk chemical was stored at room temperature under nitrogen.

\section{A.2. Preparation and Analysis of Dose Formulations}

\section{A.2.1. Formulation Materials}

Acetone and olive oil were obtained from multiple suppliers in multiple lots and these materials were combined with a 4:1 ratio to prepare the vehicle for the initial and repeat studies. For the repeat study, J.T. Baker Acetone (lot K30J01; Thermofisher Scientific, Waltham, MA) was analyzed using GC/FID by system D indicating a purity of $99.9 \%$, acceptable for use in the study. Olive oil (lot 0240-0545; Welch, Holme, and Clark Co., Newark, NJ) was analyzed to determine peroxide levels using potentiometric titration (platinum combination redox electrode) using a Mettler Toledo pH meter (Mettler Toledo, Columbus, $\mathrm{OH}$ ) and AOAC method 965.33 (AOAC, 1990). Peroxide levels were within the acceptable limit of $5 \mathrm{mEq} / \mathrm{kg}$. 
Dose formulations of the test articles and positive controls were prepared daily by mixing the appropriate amounts of each chemical with acetone:olive oil (4:1) to achieve the required concentrations (Table A-2). The dose formulations were stored in amber glass vials sealed with Teflon-lined caps at room temperature or refrigerated temperatures (1-fluoro-2,4-dinitrobenzene formulations in the repeat study only) for up to 14 days.

Stability studies of the 1\% dose formulation of crude MCHM and the $0.15 \%$ dose formulation of 1-fluoro-2,4-dinitrobenzene were performed by RTI using GC/FID by systems E and C, respectively (Table A-1). Stability was confirmed for at least 14 days for these dose formulations stored in amber glass vials with minimal headspace sealed with Teflon-lined lids at room temperature and for 3 hours under simulated animal room conditions.

Analyses of the dose formulations for the initial and repeat studies were conducted by RTI using GC/FID by system E (for MCHM and crude MCHM) and system C (for the positive controls isoeugenol and 1-fluoro-2,4-dinitrobenzene). During the initial hypersensitivity and irritancy study, the dose formulations were analyzed once; two of three MCHM dose formulations were within 15\% of the target concentrations and five of six crude MCHM dose formulations were within $15 \%$ of the target concentrations (Table A-3). Single dose formulations of the positive controls isoeugenol and 1-fluoro-2,4-dinitrobenzene were each found to be within $15 \%$ of the target concentrations. During the repeat dermal hypersensitivity and irritancy study, the dose formulations were analyzed once, and animal room samples of these dose formulations were also analyzed (Table A-4). All five crude MCHM dose formulations were within 15\% of the target concentrations; all five animal room samples were also within $15 \%$ of the target concentrations. A single dose formulation of 1-fluoro-2,4-dinitrobenzene and its associated animal room sample were both found to be within $15 \%$ of the target concentrations.

Table A-1. Gas Chromatography Systems Used in the Dermal Hypersensitivity and Irritancy Studies of 4-Methylcyclohexanemethanol ${ }^{\mathrm{a}}$

\begin{tabular}{|c|c|c|c|}
\hline Detection System & Column & Carrier Gas & $\begin{array}{c}\text { Oven Temperature } \\
\text { Program }\end{array}$ \\
\hline \multicolumn{4}{|l|}{ System A } \\
\hline Flame Ionization & $\begin{array}{l}\text { Zebron }^{\mathrm{TM}} \text { ZB-624, } \\
30 \mathrm{~m} \times 0.53 \mathrm{~mm}, 3.0 \mu \mathrm{m} \\
\text { film (Phenomenex, Inc., } \\
\text { Torrance, CA) }\end{array}$ & Helium at $5 \mathrm{~mL} / \mathrm{minute}$ & $\begin{array}{l}50^{\circ} \mathrm{C} \text { for } 2 \text { minutes, then } \\
10^{\circ} \mathrm{C} / \text { minute to } 240^{\circ} \mathrm{C} \text {, held } \\
\text { for } 4 \text { (purity studies) or } \\
9 \text { (stability studies) minutes }\end{array}$ \\
\hline \multicolumn{4}{|l|}{ System B } \\
\hline Flame Ionization & $\begin{array}{l}\mathrm{DB}-1,30 \mathrm{~m} \times 0.53 \mathrm{~mm}, \\
1.5 \mu \mathrm{m} \text { film (Agilent J\&W, } \\
\text { Folsom, CA) }\end{array}$ & Helium at $5 \mathrm{~mL} / \mathrm{minute}$ & $\begin{array}{l}50^{\circ} \mathrm{C} \text { for } 2 \text { minutes, then } \\
10^{\circ} \mathrm{C} / \text { minute to } 240^{\circ} \mathrm{C} \text {, held } \\
\text { for } 4 \text { minutes }\end{array}$ \\
\hline \multicolumn{4}{|l|}{ System C } \\
\hline Flame Ionization & $\begin{array}{l}\text { HP-5, } 30 \mathrm{~m} \times 0.32 \mathrm{~mm} \text {, } \\
0.25 \mu \mathrm{m} \text { film (Agilent } \\
\text { Technologies, Inc., } \\
\text { Santa Clara, CA) }\end{array}$ & Helium at $1.5 \mathrm{~mL} /$ minute & $\begin{array}{l}50^{\circ} \mathrm{C} \text { for } 2 \text { minutes, then } \\
10^{\circ} \mathrm{C} / \text { minute to } 280^{\circ} \mathrm{C} \text {, held } \\
\text { for } 5 \text { minutes }\end{array}$ \\
\hline
\end{tabular}




\begin{tabular}{|c|c|c|c|}
\hline Detection System & Column & Carrier Gas & $\begin{array}{c}\text { Oven Temperature } \\
\text { Program }\end{array}$ \\
\hline \multicolumn{4}{|l|}{ System D } \\
\hline Flame Ionization & $\begin{array}{l}\text { DB WAX, } \\
30 \mathrm{~m} \times 0.53 \mathrm{~mm}, 1.5 \mu \mathrm{m} \\
\text { film (Agilent) }\end{array}$ & Helium at $10 \mathrm{~mL} /$ minute & $\begin{array}{l}40^{\circ} \mathrm{C} \text { for } 5 \text { minutes, then } \\
10^{\circ} \mathrm{C} / \text { minute to } 220^{\circ} \mathrm{C} \text {, held } \\
\text { for } 5 \text { minutes }\end{array}$ \\
\hline \multicolumn{4}{|l|}{ System E } \\
\hline Flame Ionization & $\begin{array}{l}\text { DB-5, } 30 \mathrm{~m} \times 0.53 \mathrm{~mm} \text {, } \\
1.5 \mu \mathrm{m} \text { film }(\mathrm{J} \& W \\
\text { Scientific, Folsom, CA) }\end{array}$ & Helium at $6 \mathrm{~mL} /$ minute & $\begin{array}{l}50^{\circ} \mathrm{C} \text { to } 200^{\circ} \mathrm{C} \text { at } \\
10^{\circ} \mathrm{C} / \text { minute, held for } \\
5 \text { minutes }\end{array}$ \\
\hline
\end{tabular}

aThe gas chromatographs were manufactured by Agilent Technologies, Inc. (Santa Clara, CA).

Table A-2. Preparation and Storage of Dose Formulations in the Dermal Hypersensitivity and Irritancy Studies of 4-Methylcyclohexanemethanol

\section{4-Methylcyclohexanemethanol and Crude 4-Methylcyclohexanemethanol (Initial Study)}

\section{Preparation}

The vehicle was prepared by adding the appropriate amounts of acetone and olive oil into a clear mixing bottle to obtain a $4: 1$ ratio. The mixing bottle was then capped and shaken for approximately 30 seconds. Dose formulations were prepared by transferring the appropriate amounts of neat or crude 4-methylcyclohexanemethanol, isoeugenol, or 1-fluoro2,4-dinitrobenzene into volumetric flasks and bringing the flasks to final volume with the vehicle. The flasks were capped, and the contents were mixed by inversion. The dose formulations were prepared daily during the study.

\section{Chemical Lot Numbers}

KDY3F (4-Methylcyclohexanemethanol)

TP14044373 (Crude 4-methylcyclohexanemethanol)

05622BEV (Isoeugenol; positive control)

BCBN2339V (1-Fluoro-2,4-dinitrobenzene; positive control)

\section{Maximum Storage Time}

N/A

\section{Storage Conditions}

The dose formulations were stored in amber glass vials sealed with Teflon-lined lids at room temperature.

\section{Study Laboratory}

Burleson Research Technologies, Inc. (Morrisville, NC) Burleson Research Technologies, Inc. (Morrisville, NC) N/A = not applicable.

Crude 4-Methylcyclohexanemethanol (Repeat Study)
The vehicle was prepared by adding the appropriate amounts of acetone and olive oil into an amber mixing bottle to obtain a $4: 1$ ratio. The mixing bottle was then capped and mixed by inversion. Dose formulations were prepared by transferring the appropriate amounts of neat crude 4-methylcyclohexanemethanol or 1-fluoro-2,4dinitrobenzene into volumetric flasks and bringing the flasks to final volume with the vehicle. The flasks were capped, and the contents were mixed by inversion. The dose formulations were prepared daily during the study.

TP14044373 (Crude 4-methylcyclohexanemethanol) BCBN2339V (1-Fluoro-2,4-dinitrobenzene; positive control)

$-$

14 days

The dose formulations were stored in amber glass vials sealed with Teflon-lined lids at room temperature (crude 4-methylcyclohexanemethanol) or at refrigerated temperatures (1-fluoro-2,4-dinitrobenzene). 
Table A-3. Results of Analyses of Dose Formulations Administered to Female Mice on Day 3 in the Dermal Hypersensitivity and Irritancy Study of 4-Methylcyclohexanemethanol and Crude 4-Methylcyclohexanemethanol (Initial Study)

\begin{tabular}{|c|c|c|c|c|}
\hline Date Prepared & Date Analyzed & $\begin{array}{c}\text { Target } \\
\text { Concentration (\%) }\end{array}$ & $\begin{array}{c}\text { Determined } \\
\text { Concentration }^{\mathrm{a}}(\%)\end{array}$ & $\begin{array}{c}\text { Difference from } \\
\text { Target (\%) }\end{array}$ \\
\hline \multicolumn{5}{|c|}{ 4-Methylcyclohexanemethanol } \\
\hline \multirow[t]{3}{*}{ December 12, 2014} & December 12-16, 2014 & 2 & 1.54 & $-23^{\mathrm{b}}$ \\
\hline & & 20 & 21.0 & +5 \\
\hline & & 50 & 44.8 & -10 \\
\hline \multicolumn{5}{|c|}{ Crude 4-Methylcyclohexanemethanol } \\
\hline \multirow[t]{6}{*}{ December 12, 2014} & December 12-16, 2014 & 1 & 0.896 & -10 \\
\hline & & 2 & 2.01 & +1 \\
\hline & & 5 & 3.84 & $-23^{\mathrm{b}}$ \\
\hline & & 20 & 19.2 & -4 \\
\hline & & 40 & 37.1 & -7 \\
\hline & & 80 & 82.0 & +3 \\
\hline \multicolumn{5}{|c|}{ Isoeugenol (Positive Control) } \\
\hline December 12, 2014 & December 12-16, 2014 & 5 & 5.30 & +6 \\
\hline \multicolumn{5}{|c|}{ 1-Fluoro-2,4-dinitrobenzene (Positive Control) } \\
\hline December 12, 2014 & December 12-16, 2014 & 0.150 & 0.172 & +15 \\
\hline
\end{tabular}

Results of triplicate analyses.

${ }^{\mathrm{b}}$ Formulation was outside the acceptable range of $\pm 15 \%$ of target concentration. Formulations were prepared at the study laboratory and sent for chemical analysis after the study had already been initiated.

Table A-4. Results of Analyses of Dose Formulations Administered to Female Mice in the Dermal Hypersensitivity and Irritancy Study of Crude 4-Methylcyclohexanemethanol (Repeat Study)

\begin{tabular}{|c|c|c|c|c|}
\hline Date Prepared & Date Analyzed & $\begin{array}{c}\text { Target } \\
\text { Concentration (\%) }\end{array}$ & $\begin{array}{c}\text { Determined } \\
\text { Concentration }^{\mathrm{a}}(\%)\end{array}$ & $\begin{array}{c}\text { Difference from } \\
\text { Target (\%) } \\
\end{array}$ \\
\hline \multicolumn{5}{|c|}{ Crude 4-Methylcyclohexanemethanol } \\
\hline \multirow[t]{10}{*}{ March 9-10, 2015} & March 10, 2015 & 1 & 0.985 & -2 \\
\hline & & 5 & 5.05 & +1 \\
\hline & & 25 & 24.4 & -2 \\
\hline & & 50 & 47.6 & -5 \\
\hline & & 75 & 72.5 & -3 \\
\hline & March 23, 2015 & 1 & 1.03 & +3 \\
\hline & & 5 & 5.12 & +2 \\
\hline & & 25 & 24.6 & -2 \\
\hline & & 50 & 46.6 & -7 \\
\hline & & 75 & 72.4 & -3 \\
\hline \multicolumn{5}{|c|}{ 1-Fluoro-2,4-dinitrobenzene (Positive Control) } \\
\hline \multirow[t]{2}{*}{ March 9, 2015} & March 9, 2015 & 0.150 & 0.150 & 0 \\
\hline & March 23, 2015 & 0.150 & 0.156 & +4 \\
\hline
\end{tabular}

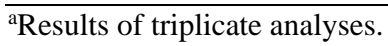

${ }^{\mathrm{b}}$ Animal room samples. 


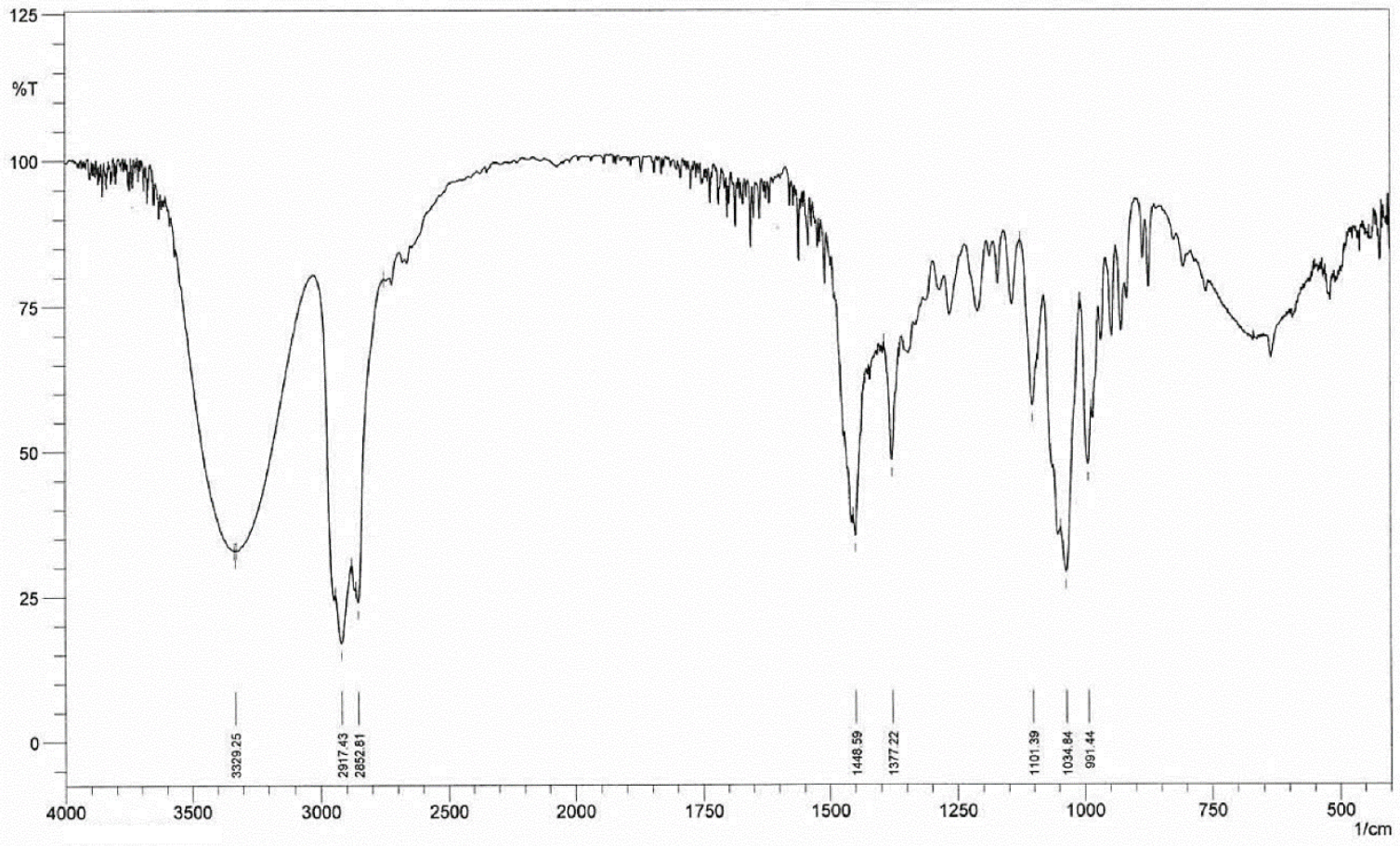

Figure A-1. Fourier Transform Infrared Absorption Spectrum of 4-Methylcyclohexanemethanol

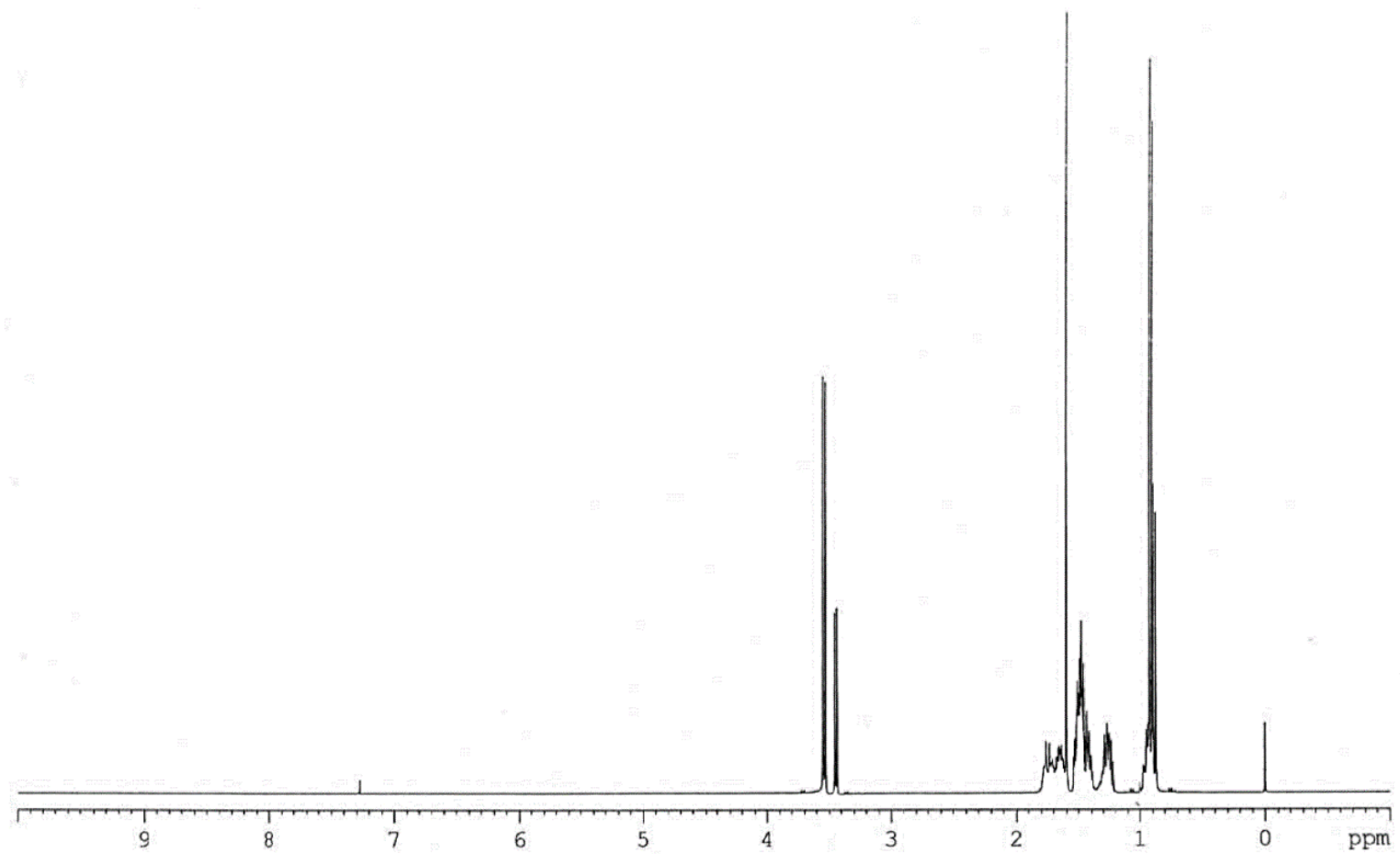

Figure A-2. Fourier Transform Proton Nuclear Magnetic Resonance Spectrum of 4-Methylcyclohexanemethanol 


\section{Appendix B. Ingredients, Nutrient Composition, and Contaminant Levels in NTP-2000 Rat and Mouse Ration}

\section{Tables}

Table B-1. Ingredients of NTP-2000 Rat and Mouse Ration ....

B-2

Table B-2. Vitamins and Minerals in NTP-2000 Rat and Mouse Ration .....................................

Table B-3. Nutrient Composition of NTP-2000 Rat and Mouse Ration .....................................3

Table B-4. Contaminant Levels in NTP-2000 Rat and Mouse Ration 
Table B-1. Ingredients of NTP-2000 Rat and Mouse Ration

\begin{tabular}{|c|c|c|}
\hline Ingredients & & Percentage by Weight \\
\hline Ground Hard Winter Wheat & & 22.26 \\
\hline Ground \#2 Yellow Shelled Corn & & 22.18 \\
\hline Wheat Middlings & & 15.0 \\
\hline Oat Hulls & & 8.5 \\
\hline Alfalfa Meal (Dehydrated, 17\% Protein) & & 7.5 \\
\hline Purified Cellulose & & 5.5 \\
\hline Soybean Meal (49\% Protein) & & 5.0 \\
\hline Fish meal (60\% Protein) & & 4.0 \\
\hline Corn Oil (without Preservatives) & & 3.0 \\
\hline Soy Oil (without Preservatives) & & 3.0 \\
\hline Dried Brewer’s Yeast & & 1.0 \\
\hline Calcium Carbonate (USP) & & 0.9 \\
\hline Vitamin Premix ${ }^{\mathrm{a}}$ & & 0.5 \\
\hline Mineral Premix ${ }^{b}$ & & 0.5 \\
\hline Calcium Phosphate, Dibasic (USP) & & 0.4 \\
\hline Sodium Chloride & & 0.3 \\
\hline Choline Chloride (70\% Choline) & & 0.26 \\
\hline Methionine & & 0.2 \\
\hline \multicolumn{3}{|l|}{$\begin{array}{l}\text { USP = United States Pharmacopeia. } \\
\text { aWheat middlings as carrier. } \\
\text { bCalcium carbonate as carrier. }\end{array}$} \\
\hline & Amount & Source \\
\hline \multicolumn{3}{|l|}{ Vitamins } \\
\hline A & 4,000 IU & Stabilized vitamin A palmitate or acetate \\
\hline $\mathrm{D}$ & $1,000 \mathrm{IU}$ & D-activated animal sterol \\
\hline $\mathrm{K}$ & $1.0 \mathrm{mg}$ & Menadione sodium bisulfite complex \\
\hline$\alpha$-Tocopheryl Acetate & $100 \mathrm{IU}$ & - \\
\hline Niacin & $23 \mathrm{mg}$ & - \\
\hline Folic Acid & $1.1 \mathrm{mg}$ & $\alpha$-Calcium pantothenate \\
\hline d-Pantothenic Acid & $10 \mathrm{mg}$ & - \\
\hline Riboflavin & 3.3 mg & Thiamine mononitrate \\
\hline Thiamine & $4 \mathrm{mg}$ & - \\
\hline $\mathrm{B}_{12}$ & $52 \mu \mathrm{g}$ & - \\
\hline Pyridoxine & $6.3 \mathrm{mg}$ & Pyridoxine hydrochloride \\
\hline Biotin & $0.2 \mathrm{mg}$ & $\alpha$-Biotin \\
\hline
\end{tabular}




\begin{tabular}{lcl}
\hline & Amount & \multicolumn{1}{c}{ Source } \\
\hline Minerals & & \\
Magnesium & $514 \mathrm{mg}$ & Magnesium oxide \\
Iron & $35 \mathrm{mg}$ & Iron sulfate \\
Zinc & $12 \mathrm{mg}$ & Zinc oxide \\
Manganese & $10 \mathrm{mg}$ & Manganese oxide \\
Copper & $2.0 \mathrm{mg}$ & Copper sulfate \\
Iodine & $0.2 \mathrm{mg}$ & Calcium iodate \\
Chromium & $0.2 \mathrm{mg}$ & Chromium acetate \\
\hline
\end{tabular}

aer kg of finished product.

Table B-3. Nutrient Composition of NTP-2000 Rat and Mouse Ration

\begin{tabular}{lccc}
\hline \multicolumn{1}{c}{ Nutrient } & Mean \pm Standard Deviation & Range & Number of Samples \\
\hline Protein (\% by Weight) & $14.9 \pm 0.26$ & $14.6-15.1$ & 3 \\
Crude Fat (\% by Weight) & $8.2 \pm 0.17$ & $8.1-8.4$ & 3 \\
Crude Fiber (\% by Weight) & $9.4 \pm 0.14$ & $9.2-9.5$ & 3 \\
Ash (\% by Weight) & $6.6 \pm 2.72$ & $4.9-9.7$ & 3 \\
\hline Amino Acids (\% of Total Diet) & & & 26 \\
Arginine & $0.794 \pm 0.070$ & $0.670-0.970$ & 26 \\
Cystine & $0.220 \pm 0.022$ & $0.150-0.250$ & 26 \\
Glycine & $0.700 \pm 0.038$ & $0.620-0.800$ & 26 \\
Histidine & $0.344 \pm 0.074$ & $0.270-0.680$ & 26 \\
Isoleucine & $0.546 \pm 0.041$ & $0.430-0.660$ & 26 \\
Leucine & $1.092 \pm 0.063$ & $0.960-1.240$ & 26 \\
Lysine & $0.700 \pm 0.110$ & $0.310-0.860$ & 26 \\
Methionine & $0.408 \pm 0.043$ & $0.260-0.490$ & 26 \\
Phenylalanine & $0.621 \pm 0.048$ & $0.470-0.720$ & 26 \\
Threonine & $0.508 \pm 0.040$ & $0.430-0.610$ & 26 \\
Tryptophan & $0.153 \pm 0.027$ & $0.110-0.200$ & 26 \\
Tyrosine & $0.413 \pm 0.063$ & $0.280-0.540$ & \\
Valine & $0.663 \pm 0.040$ & $0.550-0.730$ & \\
Essential Fatty Acids (\% of Total Diet) & $3.49-4.55$ & \\
Linoleic & $3.95 \pm 0.242$ & $0.21-0.35$ & \\
Linolenic & $0.31 \pm 0.030$ & $27.0-124.0$ & 26 \\
Vitamins & & & \\
Vitamin A (IU/kg) & $1,000^{\mathrm{a}}$ & & \\
Vitamin D (IU/kg) & & & 26 \\
$\alpha$-Tocopherol (ppm) & & & 26 \\
\hline & & & 26 \\
\hline
\end{tabular}


MCHM Hypersensitivity, NTP IMM 01

\begin{tabular}{|c|c|c|c|}
\hline Nutrient & Mean \pm Standard Deviation & Range & Number of Samples \\
\hline Thiamine (ppm) ${ }^{\mathrm{b}}$ & $8.2 \pm 0.69$ & $7.4-8.6$ & 3 \\
\hline Riboflavin (ppm) & $8.1 \pm 2.91$ & $4.20-17.50$ & 26 \\
\hline Niacin (ppm) & $78.9 \pm 8.52$ & $66.4-98.2$ & 26 \\
\hline Pantothenic Acid (ppm) & $26.7 \pm 11.63$ & $17.4-81.0$ & 26 \\
\hline Pyridoxine (ppm) $)^{\mathrm{b}}$ & $9.7 \pm 2.09$ & $6.44-14.3$ & 26 \\
\hline Folic Acid (ppm) & $1.59 \pm 0.45$ & $1.15-3.27$ & 26 \\
\hline Biotin (ppm) & $0.32 \pm 0.10$ & $0.20-0.704$ & 26 \\
\hline Vitamin $\mathrm{B}_{12}(\mathrm{ppb})$ & $51.8 \pm 36.6$ & $18.3-174.0$ & 26 \\
\hline Choline (ppm) ${ }^{\mathrm{b}}$ & $2,665 \pm 631$ & $1,160-3,790$ & 26 \\
\hline \multicolumn{4}{|l|}{ Minerals } \\
\hline Calcium (\%) & $0.918 \pm 0.026$ & $0.894-0.946$ & 3 \\
\hline Phosphorus (\%) & $0.553 \pm 0.029$ & $0.535-0.586$ & 3 \\
\hline Potassium (\%) & $0.669 \pm 0.030$ & $0.626-0.733$ & 26 \\
\hline Chloride (\%) & $0.386 \pm 0.037$ & $0.300-0.474$ & 26 \\
\hline Sodium (\%) & $0.193 \pm 0.024$ & $0.160-0.283$ & 26 \\
\hline Magnesium (\%) & $0.216 \pm 0.057$ & $0.185-0.490$ & 26 \\
\hline Sulfur (\%) & $0.170 \pm 0.029$ & $0.116-0.209$ & 14 \\
\hline Iron (ppm) & $190.5 \pm 38.0$ & $135-311$ & 26 \\
\hline Manganese (ppm) & $50.7 \pm 9.72$ & $21.0-73.1$ & 26 \\
\hline Zinc (ppm) & $58.2 \pm 26.89$ & $43.3-184.0$ & 26 \\
\hline Copper (ppm) & $7.44 \pm 2.60$ & $3.21-16.3$ & 26 \\
\hline Iodine (ppm) & $0.514 \pm 0.195$ & $0.158-0.972$ & 26 \\
\hline Chromium (ppm) & $0.674 \pm 0.265$ & $0.330-1.380$ & 25 \\
\hline Cobalt (ppm) & $0.235 \pm 0.157$ & $0.094-0.864$ & 24 \\
\hline
\end{tabular}

aFrom formulation.

${ }^{\mathrm{b}}$ As hydrochloride (thiamine and pyridoxine) or chloride (choline). 
MCHM Hypersensitivity, NTP IMM 01

Table B-4. Contaminant Levels in NTP-2000 Rat and Mouse Ration ${ }^{\mathrm{a}}$

\begin{tabular}{|c|c|c|c|}
\hline & Mean \pm Standard Deviation ${ }^{b}$ & Range & Number of Samples \\
\hline \multicolumn{4}{|l|}{ Contaminants } \\
\hline Arsenic (ppm) & $0.22 \pm 0.011$ & $0.21-0.23$ & 3 \\
\hline Cadmium (ppm) & $0.05 \pm 0.004$ & $0.046-0.053$ & 3 \\
\hline Lead (ppm) & $0.12 \pm 0.027$ & $0.09-0.14$ & 3 \\
\hline Mercury (ppm) & $<0.02$ & - & 3 \\
\hline Selenium (ppm) & $0.2 \pm 0.033$ & $0.17-0.23$ & 3 \\
\hline Aflatoxins (ppb) & $<5.00$ & - & 3 \\
\hline Nitrate Nitrogen $(\mathrm{ppm})^{\mathrm{c}}$ & $11.51 \pm 2.18$ & $10.0-14.0$ & 3 \\
\hline Nitrite Nitrogen $(\mathrm{ppm})^{\mathrm{c}}$ & 0.61 & - & 3 \\
\hline $\mathrm{BHA}(\mathrm{ppm})^{\mathrm{d}}$ & $1.41 \pm 0.72$ & $1.0-2.24$ & 3 \\
\hline BHT (ppm) ${ }^{\mathrm{d}}$ & $<1.0$ & - & 3 \\
\hline Aerobic Plate Count (CFU/g) & $<10$ & - & 3 \\
\hline Coliform (MPN/g) & $3.0 \pm 0.0$ & $3.0-3.0$ & 3 \\
\hline Escherichia coli (MPN/g) & $<10$ & - & 3 \\
\hline Salmonella (MPN/g) & Negative & - & 3 \\
\hline Total Nitrosoamines (ppb) ${ }^{\mathrm{e}}$ & $14.2 \pm 0.07$ & $14.1-14.2$ & 3 \\
\hline$N$-Nitrosodimethylamine (ppb) & $6.5 \pm 2.05$ & $5.0-7.9$ & 3 \\
\hline$N$-Nitrosopyrrolidine (ppb) ${ }^{\mathrm{e}}$ & $7.7 \pm 2.12$ & $6.2-9.2$ & 3 \\
\hline \multicolumn{4}{|l|}{ Pesticides (ppm) } \\
\hline$\alpha-\mathrm{BHC}$ & $<0.01$ & - & 3 \\
\hline$\beta-\mathrm{BHC}$ & $<0.02$ & - & 3 \\
\hline$\gamma$-BHC & $<0.01$ & - & 3 \\
\hline$\delta$-BHC & $<0.01$ & - & 3 \\
\hline Heptachlor & $<0.01$ & - & 3 \\
\hline Aldrin & $<0.01$ & - & 3 \\
\hline Heptachlor Epoxide & $<0.01$ & - & 3 \\
\hline DDE & $<0.01$ & - & 3 \\
\hline DDD & $<0.01$ & - & 3 \\
\hline DDT & $<0.01$ & - & 3 \\
\hline HCB & $<0.01$ & - & 3 \\
\hline Mirex & $<0.01$ & - & 3 \\
\hline Methoxychlor & $<0.05$ & - & 3 \\
\hline Dieldrin & $<0.01$ & - & 3 \\
\hline Endrin & $<0.01$ & - & 3 \\
\hline Telodrin & $<0.01$ & - & 3 \\
\hline
\end{tabular}


MCHM Hypersensitivity, NTP IMM 01

\begin{tabular}{|c|c|c|c|}
\hline & Mean \pm Standard Deviation & Range & Number of Samples \\
\hline Chlordane & $<0.05$ & - & 3 \\
\hline Toxaphene & $<0.10$ & - & 3 \\
\hline Estimated PCBs & $<0.20$ & - & 3 \\
\hline Ronnel & $<0.01$ & - & 3 \\
\hline Ethion & $<0.02$ & - & 3 \\
\hline Trithion & $<0.05$ & - & 3 \\
\hline Diazinon & $<0.10$ & - & 3 \\
\hline Methyl Chlorpyrifos & $0.060 \pm 0.044$ & $0.020-0.107$ & 3 \\
\hline Methyl Parathion & $<0.02$ & - & 3 \\
\hline Ethyl Parathion & $<0.02$ & - & 3 \\
\hline Malathion & $0.017 \pm 0.017$ & $0.021-0.247$ & 3 \\
\hline Endosulfan I & $<0.01$ & - & 3 \\
\hline Endosulfan II & $<0.01$ & - & 3 \\
\hline Endosulfan Sulfate & $<0.03$ & - & 3 \\
\hline
\end{tabular}

$\overline{\mathrm{CFU}}$ = colony-forming units; $\mathrm{MPN}$ = most probable number; $\mathrm{BHC}=$ hexachlorocyclohexane or benzene hexachloride.

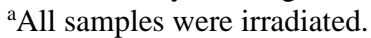

${ }^{\mathrm{b}}$ For values less than the limit of detection, the detection limit is given as the mean.

'Sources of contamination: alfalfa, grains, and fish meal.

dSources of contamination: soy oil and fish meal.

eAll values were corrected for percent recovery. 


\section{Appendix C. Sentinel Animal Program \\ Table of Contents}

C.1. Methods

C.2. Results

C-3

\section{Table}

Table C-1. Laboratory Methods and Agents Tested for in the Sentinel Animal Program ..........C-2 


\section{C.1. Methods}

Rodents used in the National Toxicology Program are produced in optimally clean facilities to eliminate potential pathogens that could affect study results. The Sentinel Animal Program is part of the periodic monitoring of animal health that occurs during the toxicological evaluation of test compounds. Under this program, the disease state of the rodents is monitored via sera or feces from extra (sentinel) or dosed animals in the study rooms. The sentinel animals and the study animals are subject to identical environmental conditions. Furthermore, the sentinel animals come from the same production source and weanling groups as the animals used for the studies of test compounds.

In the dermal hypersensitivity and irritancy studies of MCHM and crude MCHM, blood samples were collected, allowed to clot and the serum was separated. All samples were processed appropriately with serology testing performed by IDEXX BioResearch (formerly Research Animal Diagnostic Laboratory, University of Missouri), Columbia, MO for determination of the presence of pathogens. The laboratory methods and agents for which testing was performed are tabulated below; the times at which samples were collected during the studies are also listed.

Blood was collected from five female mice per time point.

Table C-1. Laboratory Methods and Agents Tested for in the Sentinel Animal Program

\begin{tabular}{ll}
\hline \multicolumn{1}{c}{ Method and Test } & \multicolumn{1}{c}{ Time of Collection } \\
\hline Mice & \\
Three-day Study (2014) & \\
Multiplex Fluorescent Immunoassay (MFI) & 1 week postarrival \\
Ectromelia virus & 1 week postarrival \\
EDIM & 1 week postarrival \\
Lymphocytic choriomeningitis virus (LCMV) & 1 week postarrival \\
Mycoplasma pulmonis & 1 week postarrival \\
Mouse hepatitis virus (MHV) & 1 week postarrival \\
Mouse norovirus (MNV) & 1 week postarrival \\
Mouse parvovirus (MPV) & 1 week postarrival \\
Minute virus of mice (MVM) & 1 week postarrival \\
Pneumonia virus of mice (PVM) & 1 week postarrival \\
Reovirus 3 (REO3) & 1 week postarrival \\
Theiler's murine encephalomyelitis virus (TMEV) & 1 week postarrival \\
Sendai &
\end{tabular}

\section{Three-day Study (2015)}

Multiplex Fluorescent Immunoassay (MFI)

Ectromelia virus

1 week postarrival

EDIM

1 week postarrival 
MCHM Hypersensitivity, NTP IMM 01

\begin{tabular}{|c|c|}
\hline Method and Test & Time of Collection \\
\hline LCMV & 1 week postarrival \\
\hline M. pulmonis & 1 week postarrival \\
\hline MHV & 1 week postarrival \\
\hline MNV & 1 week postarrival \\
\hline MPV & 1 week postarrival \\
\hline MVM & 1 week postarrival \\
\hline PVM & 1 week postarrival \\
\hline REO3 & 1 week postarrival \\
\hline TMEV & 1 week postarrival \\
\hline Sendai & 1 week postarrival \\
\hline
\end{tabular}

\section{C.2. Results}

All test results were negative. 


\section{Appendix D. Supplemental Data}

Tables with supplemental data can be found here: https://doi.org/10.22427/NTP-DATA-IMM-01.

\section{D.1. MCHM Pure - I14001}

I01 - Animal Removal Summary (32 KB)

I04 - Mean Body Weight Summary (51 KB)

I04G - Mean Body Weight Gain (45 KB)

I05 - Clinical Observations Summary (58 KB)

M01 - Irritancy Assay Summary (39 KB)

M02 - Hypersensitivity Assay Summary (32 KB)

\section{D.2. MCHM Pure - I14001 Individual Animal Data}

Individual Animal Body Weight Data (5 MB)

Individual Animal Clinical Observation Data (24 KB)

Individual Animal Hypersensitivity Data (11 KB)

Individual Animal Irritancy (15 KB)

Individual Animal Removal Reasons (10 KB)

\section{D.3. MCHM Crude - I14013}

I01 - Animal Removal Summary (31 KB)

I04 - Mean Body Weight Summary (65 KB)

I04G - Mean Body Weight Gain (53 KB)

I05 - Clinical Observations Summary (71 KB)

M01 - Irritancy Assay Summary (44 KB)

M02 - Hypersensitivity Assay Summary (35 KB)

\section{D.4. MCHM Crude - I14013 Individual Animal Data}

Individual Animal Body Weight Data (5 MB)

Individual Animal Clinical Observation Data (32 KB)

Individual Animal Hypersensitivity Data (13 KB) 
Individual Animal Irritancy (15 KB)

Individual Animal Removal Reasons (11 KB)

D.5. MCHM Crude - I14013B

I01 - Animal Removal Summary (29 KB)

I04 - Mean Body Weight Summary (54 KB)

I04G - Mean Body Weight Gain (47 KB)

I05 - Clinical Observations Summary (50 KB)

M01 - Irritancy Assay Summary (40 KB)

M02 - Hypersensitivity Assay Summary (32 KB)

\section{D.6. MCHM Crude - I14013B Individual Animal Data}

Individual Animal Body Weight Data (19 KB)

Individual Animal Clinical Observation Data (55 KB)

Individual Animal Death Details (13 KB)

Individual Animal Hypersensitivity (13 KB)

Individual Animal Irritancy (21 KB)

Individual Animal Removal Reasons (100 KB) 


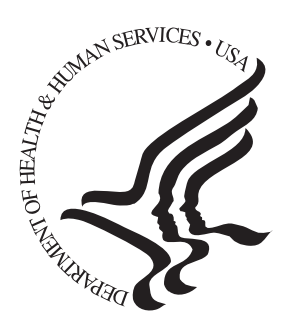

National Toxicology Program

NTP Central Data Management, MD EC-03

National Institute of Environmental Health Sciences

P.O. Box 12233

Research Triangle Park, NC 27709

http://ntp.niehs.nih.gov 